\title{
Transformation of a Pre-Algebra Developmental Mathematics Course that Led to the Redesign of the Developmental Mathematics Program at a Rural Community College
}

Mary Beth Angeline

Follow this and additional works at: https://researchrepository.wvu.edu/etd

\section{Recommended Citation}

Angeline, Mary Beth, "Transformation of a Pre-Algebra Developmental Mathematics Course that Led to the Redesign of the Developmental Mathematics Program at a Rural Community College" (2015).

Graduate Theses, Dissertations, and Problem Reports. 5110.

https://researchrepository.wvu.edu/etd/5110

This Dissertation is protected by copyright and/or related rights. It has been brought to you by the The Research Repository @ WVU with permission from the rights-holder(s). You are free to use this Dissertation in any way that is permitted by the copyright and related rights legislation that applies to your use. For other uses you must obtain permission from the rights-holder(s) directly, unless additional rights are indicated by a Creative Commons license in the record and/ or on the work itself. This Dissertation has been accepted for inclusion in WVU Graduate Theses, Dissertations, and Problem Reports collection by an authorized administrator of The Research Repository @ WVU.

For more information, please contact researchrepository@mail.wvu.edu. 
Transformation of a Pre-Algebra Developmental Mathematics Course that Led to the Redesign of the Developmental Mathematics Program at a Rural Community College by

\author{
Mary Beth Angeline \\ Dissertation submitted to the Faculty of the \\ Doctor of Education \\ in \\ Higher Education Administration \\ Committee Members: \\ Dr. Reagan Curtis \\ Dr. Neal Shambaugh \\ Dr. Patricia Obenauf \\ Dr. Marjorie Darrah \\ Dr. Jessica Deshler
}

College of Education and Human Services at West Virginia University

in partial fulfillment of the requirements for the degree of

Keywords: developmental, remediation, redesign, mathematics, design and development research 
Transformation of a Pre-Algebra Developmental Mathematics Course that Led to the Redesign of the Developmental Mathematics Program at a Rural Community College by

Mary Beth Angeline

\begin{abstract}
This dissertation documents the redesign of a developmental mathematics program at a rural community college and compares the course pass rates between the redesigned courses and the traditional lecture-based courses. A design and developmental methodology was used to chronicle changes to outcomes, learning environment, instructor role, and curricular practices over four course offerings that occurred over three semesters. Effectiveness of these changes was used to continually make corrections to the course structure, and make a case to expand the redesign of the course to the entire developmental mathematics program.
\end{abstract}




\section{Table of Content}

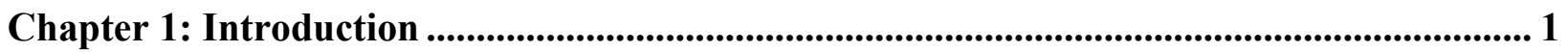

Program Status of Student Success...................................................................................................... 3

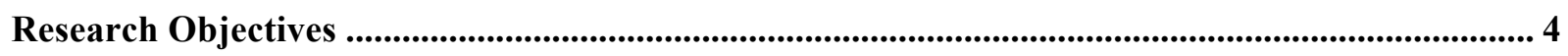

Description of the Chapters ........................................................................................................................ 5

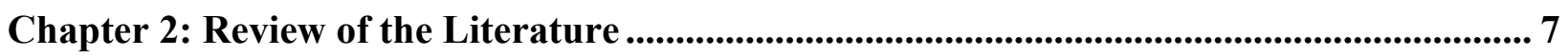

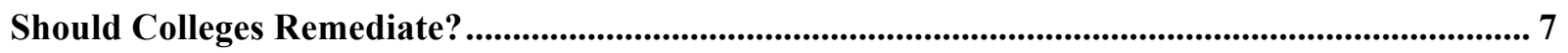

Common Developmental Mathematics Practices ......................................................................... 11

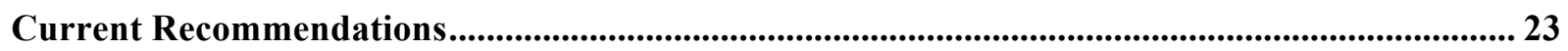

Program Review ........................................................................................................................................ 29

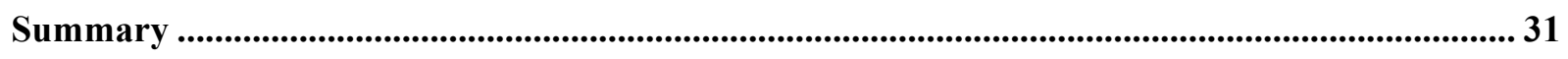

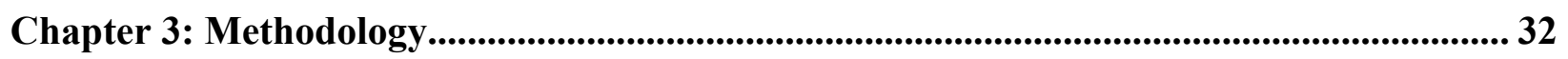

Design and Developmental Research ..................................................................................................... 32

Participants ...................................................................................................................................................... 34

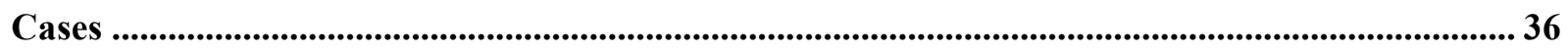

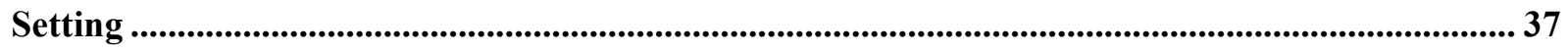

Emporium Instructional Approach ...................................................................................................... 42

Data Sources and Collection Procedures..................................................................................................... 44

Phase I- Needs assessment, Design and Development ........................................................................... 44

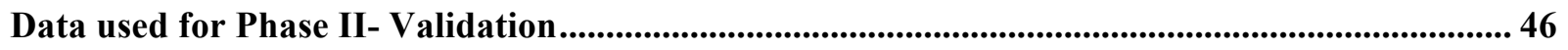

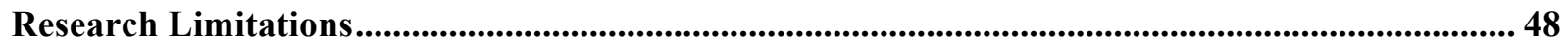

Chapter 4: Findings ......................................................................................................................... 49

The Pre-Algebra Course ...................................................................................................................................... 53

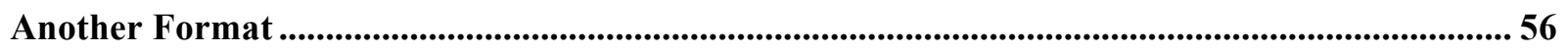


Phase I: Redesigning Developmental Mathematics.................................................................................... 62

Further Redesign Research ............................................................................................................................ 72

The Open Pathway Project ............................................................................................................................... 75

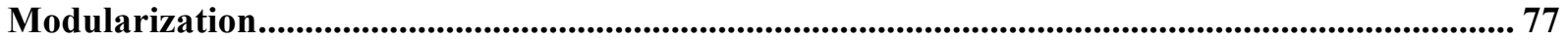

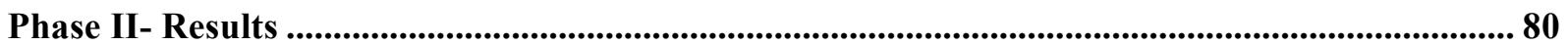

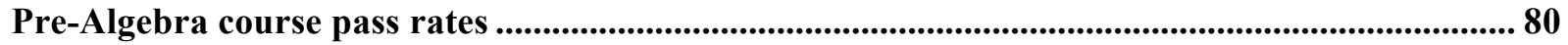

Institutional and State College-level Success ............................................................................................... 88

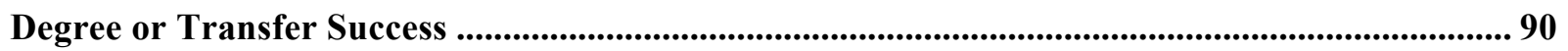

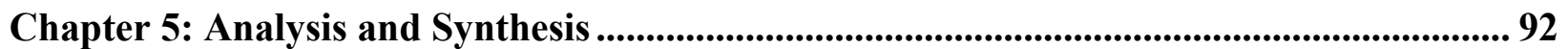

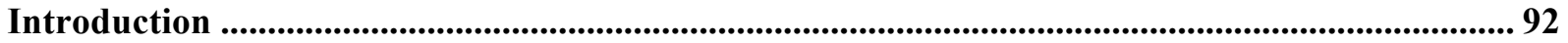

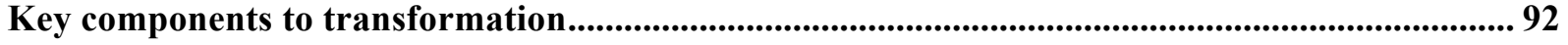

Recommendations for future implementation ....................................................................................98

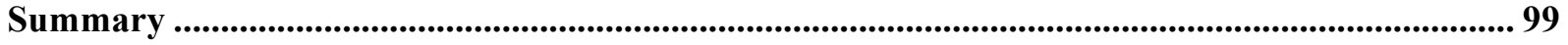

Significance of the Research for Developmental Mathematics Programs ........................................ 99

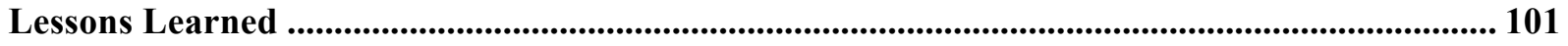

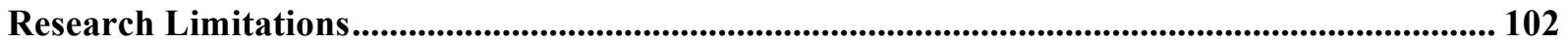

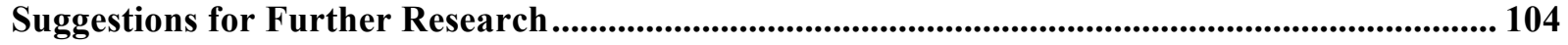

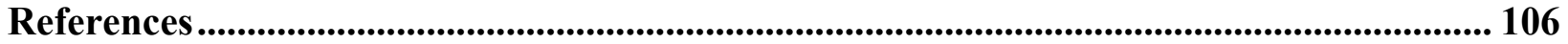




\section{List of Tables}

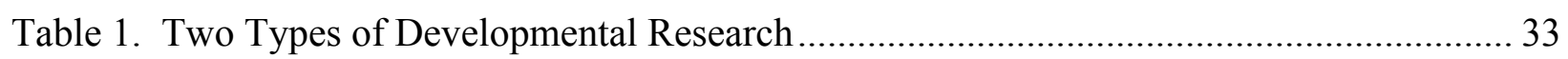

Table 2. Community College Sample Population Student Majors ............................................... 35

Table 3. Entry-level Mathematics Course Placement Requirements............................................. 36

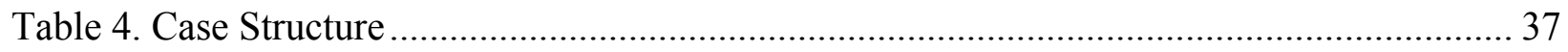

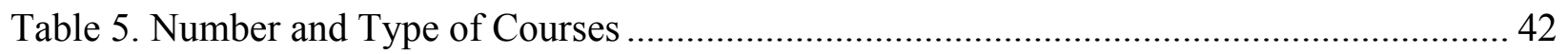

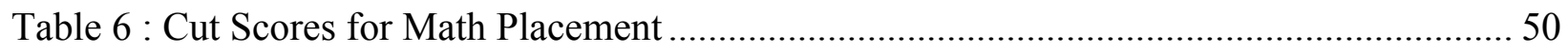

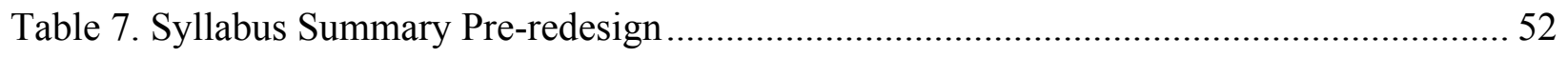

Table 8. Data Points Related to Research Questions ...................................................................... 54

Table 9. Four-year Graduation Rate for Developmental Mathematics Students .......................... 63

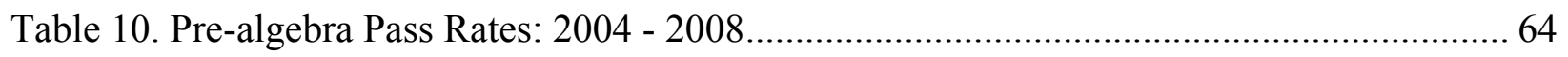

Table 11. Institutional Developmental Mathematics Pass Rates 2006 - 2010_............................. 64

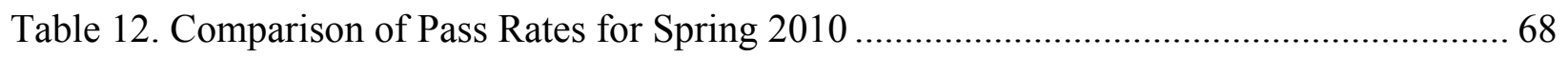

Table 13. Overall Pass Rates for Students in Redesigned Courses vs. All Courses Fall 2010..... 72

Table 14. Overall Pass Rates for Students in Redesigned Courses vs. All Courses Spring 201174

Table 15. Redesigned Pre-Algebra Course Student Pass Rates Spring 2010-Spring 2011 .......... 81

Table 16. Institutional Pre-Algebra Course Pass Rates Fall 2004-Fall 2008 Prior to Redesign .. 82

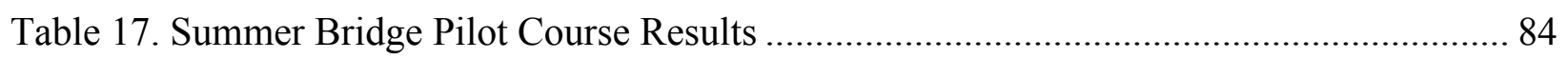

Table 18. Summary of Redesigned Course Student Pass Rates .................................................. 86

Table 19. College-level Course Success from Developmental..................................................... 87

Table 20. College-level Pass Rates for Students in Redesigned Courses.................................... 90

Table 21. Graduation or GPA to Transfer Rates for Students in Redesigned Courses ................. 91 


\section{List of Figures}

Figure 1. Institutional Developmental Mathematics Pass Rates 2004-2011............................ 2

Figure 2: Online program question example …........................................................ 58

Figure 3. Developmental Mathematics Pass Rates: College vs State...................................... 77

Figure 4. WVHEPC First-time, Full-time Freshman \% of Cohort Returning Following Fall ..... 85

Figure 5. College-level Course Success from Developmental .......................................... 88

Figure 6. Pass Rates of College-level Course Through Developmental Program..................... 89 


\section{Appendices}

Appendix A: Teaching Objectives for Basic Mathematics................................................. 112

Appendix B: Teaching Objectives for Pre-algebra ...................................................... 113

Appendix C: Teaching Objectives for Elementary Algebra ................................................. 115

Appendix D: Learning Outcomes for Intermediate Algebra ............................................ 117

Appendix E :NCAT Pre-Post Redesign Pass Rates NCAT Pre-Post Redesign Pass Rates....... 120

Appendix F: Example of Multimedia Aids ................................................................. 121

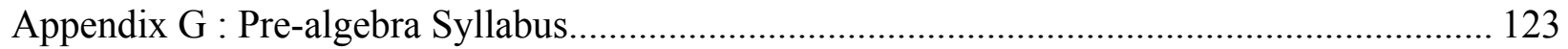

Appendix H : Rational Expressions Worksheet Used in Class........................................... 131

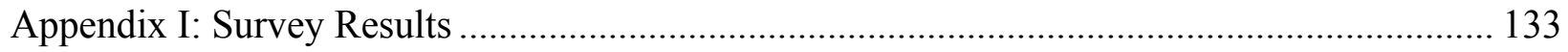

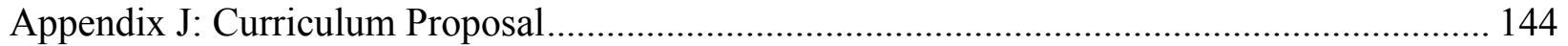

Appendix K: Data Points Related to Research Questions ................................................. 163 


\section{ACKNOWLEDGEMENTS}

Although my name is the only one that appears on the diploma, I had an army of support to realize this academic achievement. My committee chair, Dr. Reagan Curtis, adopted me late in my program. I am very grateful for his willingness to step in and his commitment to guiding me through this dissertation. Thank you to my math department colleagues, Dr. Jessica Deshler and Dr. Marjorie Darrah, and my college of education colleagues, Dr. Neal Shambaugh and Dr. Patricia Obenauf, for giving their time, feedback and advice. Thank you to Dr. Eddie Fuller for giving me the time I needed to complete my degree.

Thank you to my former colleague and friend, Nancy Parks, for helping me with edits and always being available to help me when I needed it. Her writing skills, wisdom and wit are unparalleled and appreciated. She kept me calm in the face of adversity while I conducted my research and helped me professionally and personally to deal with the innumerable challenges.

It is said that it takes an army to raise a family, but I know it takes a family to write a dissertation. My husband gave me unwavering support. Even when I doubted I could do it, he did not. It is hard to be a cheerleader for five years, but he somehow managed to continually cheer me on to finish. He and my three sons have suffered through watching me attend school for the better part of the last 20 years. As I continued on in my studies, I watched all three graduate from college with undergraduate and graduate degrees. If nothing, I have instilled in them an appreciation for education and they have made me proud. During this journey, two sons have married and three grandchildren have been born. It is my love for this family that kept me going.

My dearest mother is responsible for instilling in me the importance of education. I

dedicate this to her. She was so proud of me and unfortunately did not live to see my graduation day. Her spirit survives in me and I am eternally grateful to God for her wisdom and guidance. 
Thank you to my father for always being there for me and supporting me in whatever I did. And lastly, I would like to thank my brothers, sister-in-law and daughters-in-law. I cannot express how much this family means to me. I took this journey because they have always been proud of me, even when my work interfered with family time.

Lastly, thanks to my friends. They know who they are I cannot express how much I appreciate and value our friendships. 


\section{REDESIGN OF A DEVELOPMENTAL MATHEMATICS PROGRAM}

\section{Chapter 1: Introduction}

West Virginia has the lowest rate in the nation of adults with a bachelor's degree at 17 percent, and the state ranks 44th as to the percentage of adults with a high school diploma (Education Sector, 2009). "Education remains a strong shield against poverty. The poverty rate for West Virginians with a bachelor's degree or higher was 4.6 percent in 2010, while the poverty rate for those with only a high school diploma was 14.3 percent" (WV Center on Budget and Policy [WVCBP], 2011, p. 1). As educational level rises, so does income potential and privilege. However, increasing the educational level of citizens is a complicated task. Although opinions differ widely as to how best to increase overall levels of education, it is evident that actions must include increasing preparedness for the transition from high school to college, especially in mathematics.

Higher-level mathematics courses open the door to high paying jobs in the science, technology, engineering and mathematics (STEM) fields. With the rise of technology-based jobs, mathematics has become the gatekeeper to a higher standard of living. Higher education institutions must enable access to a new population of students that are unprepared for college rigor by sufficiently preparing students to succeed-especially in college-level mathematics courses (United States, 2014)

One of the largest obstacles to college success is that students are arriving unprepared for the rigors of the college mathematics curriculum; in particular, more than $50 \%$ and as many as $67.7 \%$ of students entering college end up placing into a developmental mathematics course and 85.6\% of African Americans do not complete their remediation and college-level course (Complete College America, 2012). Higher education institutions design developmental courses to remediate students' mathematics deficiencies and prepare them for college level mathematics 


\section{REDESIGN OF A DEVELOPMENTAL MATHEMATICS PROGRAM}

courses. These courses themselves, though, do not typically satisfy college mathematics requirements. Unfortunately, most students never complete the preparatory course work, let alone a college level mathematics course and consequently do not achieve a college degree. This research will not discuss problems with the K-12 system. As every system has flaws, these issues are beyond the control of the college leaders charged with solving the remediation issues. Although public education may need to examine teacher preparation and college readiness, that is beyond the scope of this paper.

The average developmental mathematics pass rate for all community colleges in the state where this study was conducted had fallen below 50 percent in 2011. (Higher Education Policy Commission, HEPC, 2013). For the four years prior to this study, the developmental mathematics pass rate at the community college where this study was conducted had steadily declined from a high of $59.7 \%$ in 2007 to a low of 33.4 percent in 2011 (Chart 1).

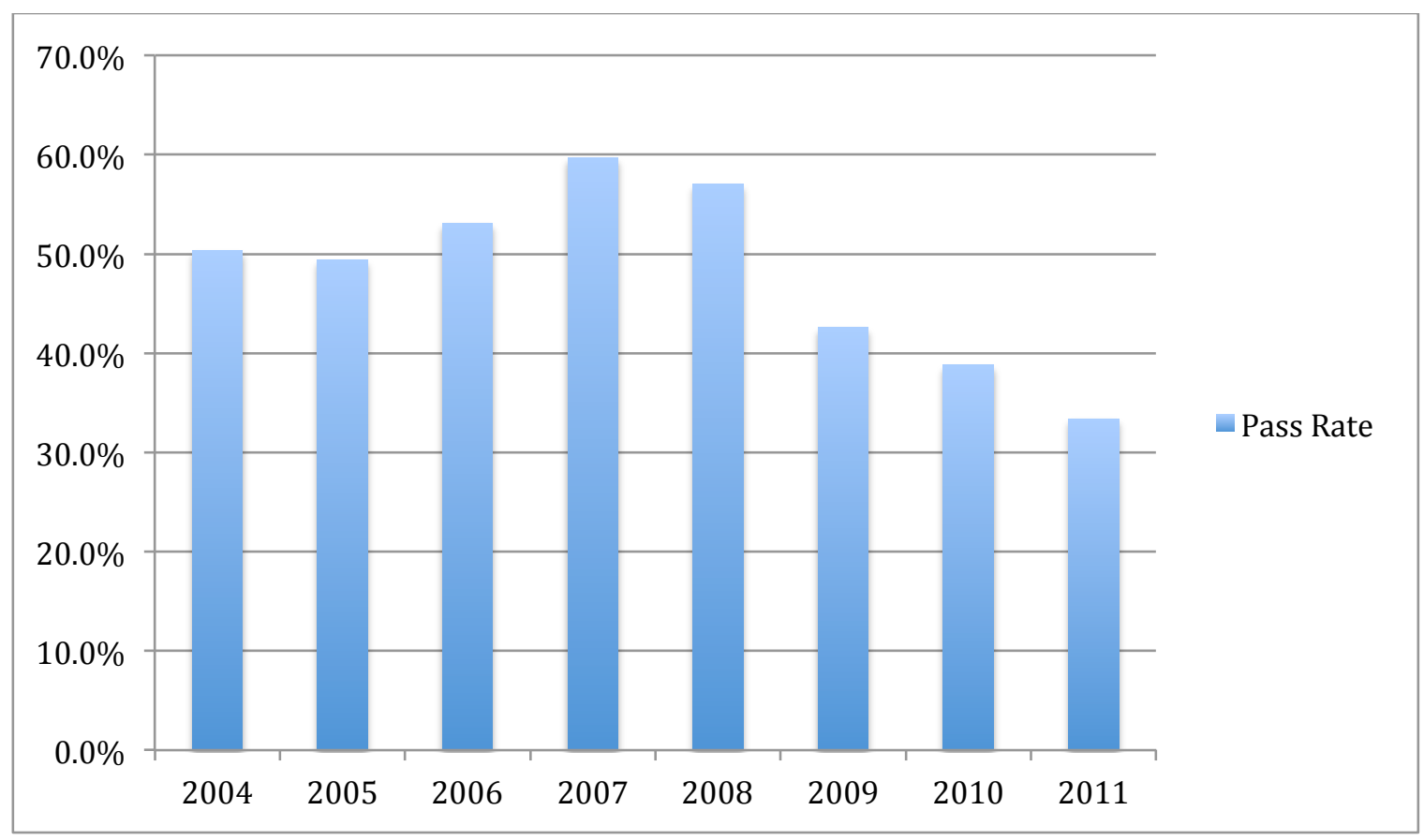

Figure 1. Institutional Developmental Mathematics Pass Rates 2004-2011.

*Includes Basic Math, Pre-Algebra, and Elementary Algebra 


\section{REDESIGN OF A DEVELOPMENTAL MATHEMATICS PROGRAM}

There had to be an immediate and drastic response to such dismal statistics. As a community college faculty member at this institution, I was asked to recommend changes to the developmental mathematics program to increase student success in both the developmental program and, subsequently, the required college-level mathematics course. There had been no significant changes made to the college's program over the last 20 years other than increasing the number of developmental skills mathematics courses and the overall number of learning outcomes. These changes led only to the college having to declare the state's lowest pass rates among all ten of its community colleges. Immediate action was not only warranted but also long overdue. This dissertation chronicles the redesign of the developmental mathematics program at a mid-size rural community college, as well as the initial impacts of that re-design.

\section{Program Status of Student Success}

It is clear from the trending developmental mathematics pass rate trend that what may once have been working at this particular college was no longer effective. The students, the courses, or both had changed. To ascertain what should be happening in a developmental mathematics program, a review of the literature was done. A common theme that surfaced was that colleges' developmental mathematics courses "replicate approaches in K-12 education that may not have served students well" (Epper \& Baker, 2009, p. 5). If the K-12 system had the answer and the curriculum and instruction were effective, the students would leave high school prepared to take a college level mathematics course and there would be no need for remediation in that content area. This is not the case, however, and it appears higher education is replicating an ineffective methodology and attempting to do it in a shorter time frame. Instead, higher education institutions must alter their methods and develop a program that meets the goal of 


\section{REDESIGN OF A DEVELOPMENTAL MATHEMATICS PROGRAM}

remediating students to enable them to move on to satisfy their college level mathematics requirements and ultimately attain a degree in a timely manner.

The National Center for Post-Secondary Research (NCPR, 2012) is funded from a grant from the Institute of Education Sciences (IES) of the U.S. Department of Education and has focused research on studies that measure the effectiveness of programs designed to help students make the transition to college and master basic skills needed to persist to degree. These studies and others commissioned by the Lumina and Gates Foundations have led to a plethora of recommendations for improving mathematics remediation at the post-secondary level (CCRC, 2014). Although many strategies have shown marginal success, there is no panacea. The recommended prescription is to incorporate multiple pedagogical strategies into a comprehensive developmental mathematics program. Each strategy requires planning, money, research, and faculty buy-in; however, the American Federation of Teachers (AFT, 2010, p. 3) reported that part-time and adjunct faculty represents $70 \%$ of the instructional workforce in community colleges. Institutional data shows the percentage of part-time faculty at this particular institution is $73 \%$. This heavy reliance on adjunct faculty make it even more difficult to address the faculty "buy-in" component necessary to initiate a transformational change significant enough to translate in to student success in terms of increasing pass rates in developmental mathematics programs and in persistence to degree attainment.

\section{Research Objectives}

A review of the literature that detailed isolated strategies for success suggests that comprehensive program changes are warranted. Due to limited resources, the many variables associated with such a transformation, and the urgency for change, a developmental and design research methodology was employed. This method permits continuous changes to the variables 


\section{REDESIGN OF A DEVELOPMENTAL MATHEMATICS PROGRAM}

that affect the results of implementing multiple strategies, yet the method responds to the urgency of making immediate necessary changes. This research was guided by the following questions:

1. How did a rural community college transform the developmental mathematics program from a three-course, lecture-based format to a one-course, outcomebased, computer-mediated design?

2. What were the effects of the resulting computer-mediated program on the student's success in the course, the program, their college-level mathematics course and graduation or transfer rate?

This dissertation presents the results of an initial program analysis; describes the decisions and changes made to the program during each implementation case; and presents the results that address the questions above.

\section{Description of the Chapters}

Chapter 2 begins with a review of the literature to determine what is and is not working in developmental mathematics programs, exploring some possible reasons for the failures. Then I review recommended components and promising strategies of developmental mathematics programs that are showing signs of improving student success. Finally, I describe the developmental research method that was used to transform the developmental mathematics program at this particular community college. In Chapter 3, I describe the research and design methodology, which includes an analysis of the design decisions made and the data sources used to make those decisions for each of the three iterations of the course offering.

Chapter 4 reports the results of how the developmental mathematics program was transformed over the course of three years, the impact on course pass rates, and concludes with a 
follow up to the student's successes with an examination of their developmental mathematics program pass rate, college-level mathematics pass rate and concludes with a report on the student's graduation rate. Chapter 5 concludes with an analysis and synthesis of the results. I will include recommendations for redesigning a developmental mathematics program, the significance of the research, the lessons learned, future research possibilities and the limitations of the study. Lastly, I will report on the current status of the program, and how this model could help similar institutions. 


\section{REDESIGN OF A DEVELOPMENTAL MATHEMATICS PROGRAM}

\section{Chapter 2: Review of the Literature}

A review of the literature will show that there are three points of consideration. First, there is a continual debate as to whether colleges should remediate students. There is no one correct answer to this question. Each college must decide if it is necessary to enforce remediation to increase student success. Next, I explore common developmental practices that pervade mathematics remediation programs and why they are ineffective. Lastly, I explore current developing trends that strongly encourage transforming the curriculum. These trends became the foundation for the transformation of the developmental mathematics program of this study and support the purpose of this research.

\section{Should Colleges Remediate?}

Over the last several years, there has been a national push to increase the mathematics proficiency level of students in the United States. According to the latest Trends in International Mathematics and Science Study (TIMSS, 2011), United States fourth and eighth graders remain 11 th and 9 th in the world in mathematics out of 26 nations studied. Millions of dollars have been dedicated to determining why and how our nation could improve our ranking. The National Mathematics Advisory Panel report (NMAP, 2008) summed it up well when they issued the following statement:

This report is about actions that must be taken to strengthen American people in this central area of learning. Success matters to the nation at large. It matters, too, to individual students and their families because it opens doors and creates opportunities. (NMAP, 2008. p. xi).

The job growth in mathematics intensive fields is 3:1 versus all other job growth (NMAP, 2008). Therefore, it is vital to the future of this country that students be prepared to enter college ready to pursue Science, Technology, Engineering and Mathematics (STEM) fields. However, 


\section{REDESIGN OF A DEVELOPMENTAL MATHEMATICS PROGRAM}

only $23 \%$ of 12 th graders in the United States are at the proficient level in mathematics as determined by (Grigg, Donahue, \& Dion, 2007). This figure supports the contention of higher education institutions that students are coming to college unprepared to handle the rigors of college level mathematics.

In the California Community College system, $85 \%$ of incoming students place into precollegiate mathematics courses (Klein \& Wright, 2009). In New York, an estimated 60-70\% of freshman test into a remedial mathematics course, and only $40-50 \%$ pass on their first attempt (Trenholm, 2006). These statistics highlight the challenge to the higher education system. Higher education institutions are consistently pressured to reduce student time to degree completion, to reduce costs to the student, to reduce rates of students receiving grades of Ds, Fs, or withdrawing from the course ("DFW" rates), and to graduate individuals who are workforce ready. Institutions must partner with public school leaders to determine why so many students are graduating from high school unprepared to begin college-level work and find a remedy for it. Until this occurs, higher education institutions will need to remediate those students who enter college unprepared to enter college-level mathematics courses.

Community colleges are open access higher education institutions with the mission to provide educational opportunities to all. Therefore, students' lack of preparation has always been an issue that needed to be addressed. However, today the problem is overwhelming the college system. Can a college take a student operating at a middle school or high school level and bring them to a college level in a very short period of time?

There is little rigorous research that supports whether remedial education is effective. One reason for the lack of reliable studies is due to the plethora of variables that constitute developmental education. Differing definitions of college-ready skills, placement tests, cut 


\section{REDESIGN OF A DEVELOPMENTAL MATHEMATICS PROGRAM}

scores and course content makes it very difficult to come to a comprehensive conclusion. However, a study by Bettinger and Long (2005) and Calcagno and Long (2008) used longitudinal state datasets and quasi-experimental methods to study the effects of developmental mathematics courses for students whose placement scores were close to college placement score minimums. Their study showed some positive results of remediation; students were passing the next college level course. Unfortunately, they also concluded that while remediation may promote early persistence to the next level, it does not necessarily increase the student's progress toward a degree. Two limitations to this study should be considered. First, students with very weak skills were not included in the study. Very weak students are ones that place more than two levels below college-ready. More research needs to be done to conclude if remediation increases the chances for the very weak student to acquire a college degree. Another drawback to the study is the co-mingling of data from many institutions. For example, the results for colleges that are successfully remediating students will not show when the results are aggregated with the colleges that are failing.

Bailey (2009) reported similar results when he reviewed a database of 256,672 of Achieving the Dream community college students. Of these students, of the ones who were deemed developmental in mathematics, only $25 \%$ went on to earn a degree in eight years as compared to $40 \%$ of the non-developmental student. He concluded that remediation is not very effective, especially because only $31 \%$ complete the recommended developmental sequence. More than $25 \%$ of all students referred to developmental mathematics courses dropped out between courses. He concluded the sequences are too long and have multiple exit points. Students cannot reap the full benefits of a program if they can opt to exit the program at any time. 


\section{REDESIGN OF A DEVELOPMENTAL MATHEMATICS PROGRAM}

In contrast, Bahr (2008) conducted a comparative analysis efficacy test of every California community college freshman student in the remedial mathematics programs in their 107 college system for eight years by comparing the long-term academic outcomes of credential attainment and transfer of students who remediated successfully into a college-level mathematics course with those who achieved college level mathematics success without remediation. His study had a sample size of 190,177 student records that spanned six years. Bahr's in-depth analysis using course descriptions and academic catalogs indicated 2,750 courses that he divided into two categories, remedial and college-level.

Bahr's results were significant and indicated that remediation has the capacity to fully resolve the economic disadvantage of mathematics skill deficiencies. Unfortunately, he also found that 75.4 percent of remedial mathematics students do not remediate successfully. This confirms the results by Bettinger, Long, and Calcagno (2005 \& 2008). Although remediation can increase success, it is difficult to retain the students until they successfully remediate.

Then why remediate? Mulvey (2008) adequately summarized the problem in her literature review by recognizing that this is an "at-risk" population but who, by their sheeer numbers, generate significant tuition dollars necessary for colleges' survival. When a college accepts a student, it is a contract saying, "The student will be offered what she/he needs to graduate.” (p. 81). Calcagno and Long, (2008) and Bailey (2009) concluded that institutions should use a rigorous research design and focus on the broad reform of institutional policies, practices, services and classroom strategies and identify characteristics of successful and innovative approaches to remediation. Therefore, without any concrete evidence to the contrary and with the continual college acceptance of students with deficiencies, mathematics remediation programs will continue. We will never achieve an educational utopia where every student who 


\section{REDESIGN OF A DEVELOPMENTAL MATHEMATICS PROGRAM}

arrives on campus is prepared to take and pass a college level mathematics class. Therefore, the colleges become responsible for providing adequate services to better increase the chances of student success.

In conclusion, the results are mixed as to the efficacy of college mathematics remediation programs. This does not suggest that remediation cannot work but that, most often, it does not. Therefore, the new question is, "Can the remediation process be modified so that a higher percentage of these students can successfully remediate and matriculate to a college credit mathematics class and persist to degree?" In short, "Can it be fixed? To help answer this, I reviewed what is currently happening in developmental mathematics programs.

\section{Common Developmental Mathematics Practices}

The review of the literature found numerous reasons many remedial mathematics programs are not working and students are exiting before completion. These include a variety of reasons including, but not limited to, the following: course sequences that are too long; students' inefficient or non-existent study skills; the social acceptance of being "bad" at mathematics; content that is too linear; placement tests that are too rigid (Boylen, 2011); a lack of research (Collins, 2010; Epper \& Baker, 2009); ineffective lectures (Klein \& Wright, 2009; Trenholm, 2006) and open door admissions (Zhu \& Polianskaia, 2007).

I will begin with describing a significant study that made several strong recommendations in 1998 as to what constituted an effective developmental mathematics program. McCabe and Philip (1998, p. 4) stated, "We have learned that comprehensive developmental education programs marked by high expectations, well-trained faculty, carefully structured courses, multiple learning options, and extensive student support systems are indispensable in institutions with open admissions." These recommendations appeared to be the script for our developmental 


\section{REDESIGN OF A DEVELOPMENTAL MATHEMATICS PROGRAM}

mathematics program. We had a comprehensive developmental program. We had high expectations. We had a well-trained faculty, carefully structured courses, multiple learning options and extensive support. However, it was not working for us. Over the last 14 years, the developmental dilemma has become a developmental crisis. The number of students who need remediation has dramatically increased as overall college enrollments have increased. Schools are spending millions of dollars to remediate, yet students and institutions are not netting any promising results.

Unfortunately, upon closer examination, this study did not have the rigor necessary to make compel widespread reform recommendations. Thirty different people evaluated ten different colleges. Colleges were deemed "successful" based on the structure of their programs, not on the success of their students. McCabe \& Philip (1998) stated, "Student success levels regularly reach 80 percent in English, reading and mathematics...”(p. 25) The data in the report, however, did not support this claim. Every college reported the percentage of students that achieved success at the next level of mathematics. These rates were all between $27 \%$ and $68 \%$.

No data was reported, though, to show the true rate of completion that included students who did not complete a developmental course. However, colleges followed the recommended program revisions in the study, and it became the blueprint for developmental mathematics for approximately ten years. The Epper and Baker (2009) report, the most recent equivalent to the McCabe and Philip report, includes an overview of colleges that are showing signs of successfully remediating developmental mathematics students. The data source for the Epper and Baker report was interviews with faculty and administrators at each college. It is impossible to determine if the conclusions are valid without the data. With these concerns in mind, I will examine how higher education institutions responded to McCabe and Philip's findings. 


\section{REDESIGN OF A DEVELOPMENTAL MATHEMATICS PROGRAM}

Carefully structured courses. With the recommendation in 1998 of carefully structured courses, multiple level courses were developed. This brought the onset of placement testing and rigid placement policies. The rationale was to enable students to succeed by not allowing them to enter a class for which they were unprepared. Unfortunately, higher education developed a system of structured courses that mirrored the public school system and its strict course sequencing. What was once one "fix-it-all" course morphed into three to four courses.

One of the most cited reasons for mathematics remediation failure is colleges approaching mathematics remediation with highly structured courses in the same manner as the K-12 system. The K-12 curriculum, as described in the Trends in International Mathematics and Science Study (TIMSS, 2011) is "a mile wide and an inch deep." In the Charles A. Dana Center (2012) report, the key factor to attrition is the long sequences of courses that mirror K-12 education. Many colleges have three to four levels for remediation including basic math, prealgebra, elementary algebra and intermediate algebra. These courses may as well be titled 7th and 8th grade math, Algebra I and Algebra II because they have identical content. Most students place into pre-algebra or beginning algebra (Epper \& Baker, 2009), yet intermediate algebra is the equivalent of high school Algebra II, which the American College Testing organization (ACT, 2008) recommends as the minimum level for college algebra readiness. Therefore, most students are two to three levels below college ready when they enter college. Students are expected to retrace the ineffective sequence of mathematics through the algebra curriculum in one to four semesters when they were unable to learn it well enough to retain it when they had four years to learn it (Mulvey, 2008). Having multiple courses gives the students many opportunities to drop out or fail (Charles A. Dana Center, 2012). The more often a students take a class, the less likely they are to pass it (Bolyan, 2011), and the likelihood of successful 


\section{REDESIGN OF A DEVELOPMENTAL MATHEMATICS PROGRAM}

remediation in mathematics declines sharply as a student's degree of deficiency and prescribed number of remedial courses increases (Bahr, 2008).

Attewell, Lavin, Domina, and Levey (2006) used transcript data from the National Educational Longitudinal Study, published by NCES in 2000 to match students who had similar high school curricular backgrounds and standardized test scores. This was one of the most rigorous studies reviewed. In this study, the researchers separated pre-existing academic skills and weaknesses from the effects of remedial education. They used the statistical technique known as "counterfactual model of causal inference" methodology tool to separate the effects of remedial coursework from those of similar background variables. This permitted them to separate out the effects of the remediation.

The researchers concluded that for entrants to four-year colleges, there was a statistically significant disadvantage for students who took three or more remedial courses: their graduation rates were between $12 \%$ and $15 \%$ lower than those of students with comparable skills and backgrounds who took fewer or no remedial courses. Multiple studies show that increasing the number of remediation courses does not increase chances for student success, making it clear that this recommendation should be revisited.

Current Curricular Practices. In addition to the K-12 sequence, the same K-12 instructional practices are used. For example, students are required to get a " $\mathrm{C}$ " to move to the next level. Unfortunately, a "C" does not equate to being able to pass the next level (Bolyan, 2011), and when students get a "D" or "F", they must repeat the entire semester. Failing a developmental mathematics class is disheartening to students and jeopardizes their persistence (Zachary, 2008). Awarding points for homework completion and not correctness and awarding bonus points for attending lectures may result in a student receiving a passing grade that leaves 


\section{REDESIGN OF A DEVELOPMENTAL MATHEMATICS PROGRAM}

the student without true comprehension, jeopardizing their success at the next level. Requiring a student to complete a remedial class in its entirety and rewarding behavior as opposed to performance are just two examples of how remedial mathematics programs follow curricular practices similar to the $\mathrm{K}-12$ system.

It has been shown that teachers at the K-12 level are concerned with correct or incorrectness of an answer and not with understanding. They are concerned about how much content is covered and not with depth of understanding (Johnson, 2000). The teachers ask lowlevel questions more than $80 \%$ of the time. The students that have the most difficulty are grouped in a lower level course. Teachers increase the seatwork time instead of instructional time. The teachers do not give an appropriate amount of wait time and do not give the students the opportunity to develop their own understanding (Johnson, 2000).

The teaching methodology remains unchanged from K-12 to higher education. At the community college that served as the focus of this particular research, students met 150 minutes a week on a Monday, Wednesday, Friday or Tuesday, Thursday schedule with homework (computer or paper-based) with follow-up quizzes and tests. Students gathered points to determine their grade. There was no exit exam or insurance that the student comprehended the concepts. The focus of the grade was on correctness and not comprehension.

With highly structured courses, students must follow a prescribed path and pace with no flexibility. Students are often locked in to semester-long courses in a prescribed sequence that can last up to two years if they enter college three levels below being college ready for their first college credit mathematics course. Getting a student from a 5th grade level to a 10th grade level in only one semester should not be labeled a failure. Even if the student is not quite where he/she needs to be (Bailey, 2009) he/she should not be forced to repeat the entire course with no 


\section{REDESIGN OF A DEVELOPMENTAL MATHEMATICS PROGRAM}

credit assigned for what progress was made. It appears that highly structured courses are not the answer to successful remediation.

Placement practices. With the onset of highly structured courses, the higher education system had to devise a method of determining where a student should begin in his mathematics curriculum. Where is the optimum starting point for a student to learn and to be successful? This was easy to determine in the public school system. Students did K-8 mathematics in sequence: algebra, geometry, and then algebra II. A strong student could continue into trigonometry, precalculus, or statistics upon the successful completion of the prescribed sequence. Higher education, however, does not prescribe a sequence as if every student enters college with the aforementioned sequence completed successfully. There are many reasons for this, including the fact that not all students are required to take college algebra for their major and even those who are may not have successfully complete the high school sequence. Therefore, the placement exam was born.

Improper placement, though, can be a major factor that can lead to student failure. Placement tests and cut scores vary widely from institution to institution. Just one point's difference can decide the number of semesters required for remediation. As previously discussed, there are up to four levels of remediation: basic mathematics, pre-algebra, beginning algebra, and intermediate algebra. A difference of fewer than four questions can add a year of remediation to a student's college career, which adds significant costs in both time and tuition. This makes the test high stakes with major financial consequences. Epper and Baker (2009) found that a large number of students place into the pre-algebra and beginning algebra courses, and a disproportionate number of these students are ethnic minority and or first generation students, the ones most often least likely to be able to afford the added financial burden. 


\section{REDESIGN OF A DEVELOPMENTAL MATHEMATICS PROGRAM}

Many factors influence a students' success on a placement test. Boylan (2011) found that the amount of time elapsed since the student's most recently completed mathematics class and the time of the placement test has significant consequences on a student's prescribed developmental curriculum. The more time that has passed has an inverse relationship to the placement level. Often, students may need only one semester of review, yet they place at a much lower level, causing them to subsequently satisfy every developmental course. Boylan also found that calculators in K-12 mathematics instruction have replaced facts memorization, which leads to decreased automaticity of general facts and the ability to perform paper/pencil calculations. Many students complain about the "lack of time" needed to complete the placement assessment, many of which do not permit the use of calculators. Therefore, the assessment is not adequately determining where the student would be most successful.

The placement process is also too restrictive (Charles A. Dana Center, 2012; Bailey, 2009) and does not account for student differences, such as persistence, as well as time since their last mathematics class. Two students who get an identical placement may have very different needs. One may have forgotten the content and needs to refresh. It is possible the other student never learned the content and needs intensive guidance. Safran and Visher (2010) found many issues with the mathematics placement process while conducting a case study of three different community colleges, Community College of Baltimore County, Houston Community College and Merced Community College. They were chosen for their diversity in size and location (p. 10). They found four significant issues with the placement process. First, students took the placement exam without realizing the importance of the test and the high-stakes nature of the test. Second, colleges relied solely on standardized test scores and did not consider high school courses completed, grades or work samples. Third, the placement exam did not provide 


\section{REDESIGN OF A DEVELOPMENTAL MATHEMATICS PROGRAM}

the instructor with any information as to what skills were deficient and how to remediate them. And lastly, there were few if any organizational structures to examine and evaluate the effectiveness of the placement process. For example, if a student were deficient in fractions, the student would place into the lowest level. However, the student could be proficient in function analysis, which is at a much higher level. The student's poor performance on lower-level skills would yield a placement score that would require the student to complete the entire developmental mathematics sequence, which was not only unnecessary, but also disheartening.

The conclusions are based on qualitative data collected during site visits to the colleges, as well as a review of relevant documents at each college. Site visits included interviews with an instructional dean, the director or dean of student services, staff who coordinate student testing, and one or two developmental education instructors (p. 10).

Sofran and Visher (2010) also concluded that minimum score requirements vary greatly for college credit course entry as well as in to the varying levels of developmental instruction among the colleges they examined. A student would qualify at one college for college algebra, but not at a neighboring college just ten miles down the road. In an attempt to stem these differences, minimum entrance scores were set by state policy, but the policy allowed the individual institutions to determine the number of developmental courses in their developmental mathematics sequence. Unfortunately, at most institutions that sequence had remained unchanged for more than ten years, and cut scores for each level of developmental were not validated with research nor adjusted to reflect state policy.

In summary, the recommendation to highly structure courses led to the convoluted development of placement tests with arbitrary cut scores, which in turn led to the intervention by state policy makers. In their attempts to make placement policies fair and consistent across all 


\section{REDESIGN OF A DEVELOPMENTAL MATHEMATICS PROGRAM}

colleges under their authority, policies were enacted without any research on which to support those decisions. One reason for the lack of this research is that community colleges do not have the faculty and financial resources to assess their practices. Community college faculty members teach five to six classes a semester, leaving them little time for research.

Faculty preparedness. Klein and Wright (2009), Trenholm (2006), Asera (2011), Zachary, (2008) and the National Mathematics Advisory Panel (2008) all attribute teacher quality as a major factor in student success. Community colleges have traditionally relied on part-time/adjunct faculty, and even more so for remedial courses. According to a report by Hart Research Associates (2010) commissioned by the American Federation of Teachers (AFT), community college part-time/adjunct faculty represent more than $70 \%$ of the instructional workforce. Although most adjunct faculty are competent, many lack the professional development that a full-time faculty member receives. This is a particular challenge for remedial classes. Adjunct faculty are less available to students, receive less professional development, and are less vested in the institution (Mulvey, 2008). Many community colleges recruit high school teachers to teach mathematics remediation. The students are high-risk with mathematics learning issues, and adjuncts are often less knowledgeable in this realm. High school teachers teaching the same content taught in high school classes but in a faster-paced delivery tend to revert to what they know when time constrained (Epper \& Baker, 2009). These methods are the same methods that contributed to the students' need for remediation.

The lack of time and the pressure to teach all of the outcomes do not create a strong learning experience for students. Faculty should be trained to help the students learn in this highpressure situation. The community colleges must constantly track students, research best 


\section{REDESIGN OF A DEVELOPMENTAL MATHEMATICS PROGRAM}

practices and update their programs. However, as previously stated, most community college faculty are part-time/adjuncts with no support for faculty development and research.

Klein and Wright (2009) conducted a self-study at their own Pasadena City College. The directors of the teaching and learning center held Faculty Inquiry Group (FIG) meetings and found that many instructors, not exclusively adjuncts, were stuck in the traditional lecture mode and were driven by a textbook. The National Mathematics Advisory Panel (2008) report stated the panel "agrees broadly that the delivery system in mathematics education, the system that translates mathematical knowledge into value and ability for the next generation is broken and must be fixed" (p. 13).

As seen from the multiple levels of developmental mathematics courses, students arrive with varying degrees of deficiencies. Technology has improved at a rapid rate and can enhance student engagement and individually address deficiencies. However, faculty are often reluctant to embrace or even use these smart software programs, and their administrators are unwilling or unable to require them to use the technology. This has contributed to the system's status quo. Many "tried it once" then dismissed it (Trenholm, 2006). Training adjunct faculty would be another hurdle due to the sheer number of adjuncts and the nature of their appointments, which often call for classroom duties only without any additional requirements or incentives for professional development, including training in the use of classroom technologies.

Zhu and Polianskaia (2007) conducted a comparison study of traditional lecture and computer-mediated instruction (CMI) in developmental mathematics at the University of Houston. Lecture was considered teacher-centered and CMI student-centered. In this study the students chose the path and the pace of instruction. He found that lecture classes had better completion rates in seven out of ten years. However, he also found that the level of difficulty and 


\section{REDESIGN OF A DEVELOPMENTAL MATHEMATICS PROGRAM}

grading tendencies varied significantly by instructor. Students in the lecture courses had higher pass rates with a $\mathrm{C}$ or better compared to $\mathrm{CMI}$ students, but the percentage of students who passed the Texas Higher Education Assessment (THEA) was an average of 1\% higher for computer-mediated classes over ten years (Zhu \& Polianskaia, 2007). This difference may be attributable to several factors including student motivation, teacher bias or both.

The majority of the students who are in developmental mathematics have previously been taught the content. The problem is they have not learned it. Re-teaching it the same way is not working. McCabe and Phillip (1998) recommended multiple learning options to enhance the development of mathematical learning, yet it appears those recommendations as a whole were ineffective at this community college.

After an exhaustive examination of over 16,000 research publications and policy reports, the National Mathematics Advisory Panel (2008) concluded that the research does not support the exclusive use of either teacher-centered or student-centered instructional practices. Striking a balance between the two instructional practices would appear to be a compromise that may benefit all. This leads to the issue of adjunct and full-time faculty preparedness to teach developmental courses in a technology-enhanced environment. Getting buy-in with support and professional development training is critical to transform the instructional and curricular practices. Next, I will discuss what learning options are commonly utilized in the teaching and learning of developmental mathematics.

Multiple learning options and support. Students should be able to acquire the content from multiple learning options. In addition to the traditional lecture, which some students prefer, there are many computer-based options. They include videos, animations, step-by-step tutorials, and online homework problems that provide immediate feedback. Non-computer based options 


\section{REDESIGN OF A DEVELOPMENTAL MATHEMATICS PROGRAM}

include learning communities, tutoring centers, supplemental instruction, and other forms of academic support services. There is evidence to suggest that most colleges offer student support systems, but are those support systems effective?

Many community college students are part time students with jobs and families, and many have responsibilities other than school that inhibit their use of the academic support services that require additional time on campus. Learning communities have shown promising results at a few community colleges. According to Hord (1997, p. 10), a learning community "is being used to mean any number of things, such as extending classroom practice into the community; bringing community personnel into the school to enhance the curriculum and learning tasks for students; or engaging students, teachers, and administrators simultaneously in learning - to suggest just a few." Learning communities typically included additional contact time with the other students in the community or extra collaboration within the class. A study was launched by the National Center for Postsecondary Research (NCPR) in 2008. After an extensive six-year study, with over 7,000 randomly assigned students in over 174 different learning communities, Visher, Weiss, Weissman, Rudd and Wathington (2012) reported that learning communities showed no impact on persistence in college and a modest half-credit estimated impact on credits earned in mathematics. Although the experiences of the students in the experimental group and control group were significantly different, the actual results do not warrant the high costs associated with implementing the strategy of learning communities.

Second, many colleges have learning centers. The resources located in learning centers range from tutoring help to computer centers to testing assistance. Many students do not utilize these resources. This is unfortunate. Perin (2004) reported that students had a $1 / 2$ to 1 -point higher grade point average when students visited the learning center more than six times. Habley and 


\section{REDESIGN OF A DEVELOPMENTAL MATHEMATICS PROGRAM}

McClanahan (2004) found that 78\% of high performing campuses (campuses that had a high retention rate) reported having a math-learning center or lab compared to $52 \%$ of campuses that were low performing. The most popular strategies to improve student achievement were tutoring, supplemental instruction, advising, success courses, and learning communities. "However, a majority of these reforms reached less than 10 percent of their intended target population" (MDRC, 2011, p. ES-3). This statistic points to the contention that community college students are not engaging in the academic resources provided to them. In summary, learning centers can be effective but only if students utilize them. Community colleges must find a method of providing these services to non-traditional students in a non-traditional way.

The only recommendation made by McCabe and Philip (1998) that was not evaluated in this literature review was the need for high expectations. There are no studies that can point to low expectations enhancing student success. It is a highly accepted ideology that higher expectations lead to greater student success. All other recommendations from the McCabe and Philip (1998) report have not been substantiated.

Next, I will examine the current recommendations. There is a plethora of studies on what is not working, yet very few on what is working. None of the studies examined meet a rigorous design methodology. However, this is not a reason to ignore the need for change and consider the recommendations.

\section{Current Recommendations}

Three themes emerged from the literature review that highlighted needed changes to developmental mathematics programs: curricular policy reform, increased use of computer-based software to enhance learning and acceleration of students through courses and programs, and program assessment. However, the need for a transformational change to all aspects of 


\section{REDESIGN OF A DEVELOPMENTAL MATHEMATICS PROGRAM}

developmental mathematics is the overarching theme in all of the studies. A discussion follows about these recommendations. Unfortunately, there is no discussion in the literature as to the implementation of these changes and all studies conclude there is very little scientific rigor supporting these recommendations and call for more research.

Curricular reform. Multiple studies have concluded that there is a high need to reform the developmental mathematics curriculum and polices that guide it. We will begin with curricular reform. Several studies have shown that the amount of concepts that are considered essential to developmental should be reduced (Boylan, 2011), Dana Center (2012), Epper \& Baker (2009). Findings showed that there is a flawed logic that longer is better when the opposite is actually true. The longer the course sequence (and consequently the number of outcomes), the students have many opportunities to drop out and do drop out. As the number of concepts is reduced, so should the number of courses. Epper and Baker (2009) recommend questioning to what depth and breadth in developmental mathematics is necessary for student success in the required college-level mathematics course. Safran and Visher (2010) found that less than half of the students referred to developmental mathematics completed the sequence within three years. Klein and Wright (2009) discovered that at their college, the developmental mathematics curriculum was calculus focused and less than $0.5 \%$ students would need those outcomes in their college-level course. They recommended that the curriculum focus on greater mastery of fewer concepts. It is critical to reduce these outcomes to decrease the time spent in developmental mathematics.

I determined that there had not been a substantial change to the developmental math curriculum in almost 20 years at the college where this study was conducted. Over time, the program had grown from one class to four classes with half of the outcomes being repeated in 


\section{REDESIGN OF A DEVELOPMENTAL MATHEMATICS PROGRAM}

more than one course. Departmental policies and practices continually increased the number of roadblocks to student success. For example, if a student did not show to take the final exam, they were prohibited from receiving a passing grade. In these pass/fail classes, if a student had accumulated enough points to pass the class even by getting a zero on the final exam, they were still required to pass the final with a $50 \%$ or higher. However, the opposite was not true. If a student demonstrated competency on the final exam with an $80 \%$ or higher, they were not given a "pass" if they did not accumulate enough points to garner a passing grade. The student would be required to repeat the class. If the purpose of the class was to remediate deficiencies and the student demonstrated competency, why would the policy prohibit the student from moving forward? Students should have multiple exit opportunities, not just the accumulation of points.

This was the policy for all developmental math classes. All of the courses were pass/fail and the final exam was weighted as $20 \%$ of the final grade. Therefore, if a student was passing the class with an $88 \%$ or better, they could receive a zero on the final and still pass the class. As a reward, the student should have been exempt from taking the final. Instead they were penalized and received no credit for the course if they received less than a $50 \%$ on the comprehensive final exam. They had to retake the entire course.

One way to reduce the time spent in remediation is to target outcomes to prepare students for the subsequent college level course. Remediation is to provide equality of opportunity and the goal is to prepare for college-level success, not the passing of a remedial course (Bahr, 2008).

College algebra is part of the preparation for calculus. Most students that place into developmental math do not need to be prepared to take calculus. However, college algebra is a degree requirement for many students. If a student has passed Algebra 2 in high school, we must assume that they demonstrated competency to graduate. The problem, as stated earlier is that 


\section{REDESIGN OF A DEVELOPMENTAL MATHEMATICS PROGRAM}

students did not have the competencies but did receive a passing grade. In community colleges, as in the one that was the focus of this study, students are getting certificates and associates degree to prepare them for industry, not a calculus-based liberal arts curriculum. Many students need a liberal arts mathematics course that does not require higher-level concepts such as rational exponents, equations and expressions for example. Therefore, all students should not be required to remediate to the college algebra level.

These outcomes did not support the success of students in the liberal studies mathematics course required graduation, however all students regardless of major were required to remediate to the college algebra level. These policies and practices were eliminating hundreds of students from getting certificates and associate degrees every year. A drastic change was needed.

Computer-mediated Learning. Using computer-based software programs has been touted as the panacea to accomplish the goal of reducing outcomes, accelerating completion and targeting remediation. The Epper and Baker (2009) study concluded that the Ivy Technical Community College program incorporated self-paced computer-based modular courses and showed promising signs of success. However, there remained a need for complete transformations of course design instead of an "add-on" course design. Add-ons include requiring students to complete a set amount of homework/lab time, assigning online homework, or using the computer to administer quizzes or tests. Although these may be computer-based course requirements, they must be part of a larger program reform. Doing homework online vs. paper-pencil bookwork is still doing homework. It will not alone increase the success of students in a developmental mathematics course. Instead, Epper and Baker (2009) recommended a “multi-faceted holistic approach supporting interactive learning, multiple learning modalities, alternative delivery of instruction, learning centers, technology and student support services". At 


\section{REDESIGN OF A DEVELOPMENTAL MATHEMATICS PROGRAM}

the community college where this study was conducted, there was an online homework component, however it was optional. Students were not required to do any of the homework as part of their grade. The dean believed the cost for online placed an unnecessary financial burden on the students. There was no lab time allotted to the students during or outside of class. Because it was not required, very few students purchased the online access that included multimedia videos and PowerPoints.

There are multiple reports confirming Epper and Baker's (2009) conclusions. Mulvey (2008) concluded that active pedagogy with hands-on learning activities is generally more successful in the developmental classroom than lecture-based instruction. Students actively working on mathematics problems and getting immediate feedback from the computer and the instructor will keep students continuously engaged. In the National Mathematics Advisory Panel Foundations for Success report (2008), the panel "agrees broadly that the delivery system in mathematics education - the system that translates mathematical knowledge into value and ability for the next generation is broken and must be fixed" (p. 13). In developmental mathematics, we teach the same way it was taught in K-12, only faster. Although the National Mathematics Advisory Panel does not support the exclusive use of teacher-centered or studentcentered (computer instruction) learning, they agreed that instructional software has shown positive effects and should include group work, diagnostic and individualized problems with teacher guidance.

Hably and McClanahan (2004) addressed the issue of student retention in community colleges and found that the greatest contribution in 2-year public colleges fell into three categories: academic advising, learning support centers and mandated course placement testing. As stated earlier, the use of mathematics learning centers/labs can contribute to the success and 


\section{REDESIGN OF A DEVELOPMENTAL MATHEMATICS PROGRAM}

retention of the community college student. The learning centers are staffed with tutors and computers where students can work on computer-mediated mathematics courses and have access to immediate assistance.

In contrast, Zhu and Polianskaia (2007) concluded that computer-mediated instruction for developmental mathematics cannot substitute for traditional classroom instruction. However, his results may have been biased. In Texas, every high school graduating student was required to take the THEA skills pre-test. Students that tested into developmental mathematics were tracked if they enrolled in a Texas higher education institution. After 10 years, the results showed that lecture classes had better completion rates in 7 out of the 10 years. Zhu and Polianskaia also found that the level of difficulty and grading tendencies varied from institution to institution. A grade of $\mathrm{C}$ or better was considered passing for the lecture classes and in six of the years, lecture students maintained higher passing rates in the developmental classes when compared to the computer-mediated students.

However, the percentage of students who passed the Texas Higher Education Assessment (THEA) post-test was slightly higher for computer-mediated classes from 2002 to 2009 (Zhu \& Polianskaia, 2007). Course grades are normally tied to multiple assessments and requirements, including homework, quizzes, tests and more. However, a standardized test evaluates acquired skills and knowledge. It appears that more learning occurred with the computer-mediated platform than the traditional lecture yet more students in the lecture classes received passing grades. However, one cannot ignore the fact that the completion rates are lower for the computer-mediated students.

Trenholm (2006) conducted a causal-comparative quasi-experimental study on two of his classes focused on the efficacy of instruction related to two distinct developmental 


\section{REDESIGN OF A DEVELOPMENTAL MATHEMATICS PROGRAM}

mathematics courses in a community college setting. There were 164 students in the study. He raised an important point when he stated, "The method of implementation remains as important, if not more so, than the technology itself' (p. 75). He found that using technology is not the panacea. There are infinitely many ways to design a computer-mediated course. Figuring out how to implement it so that it enhances the learning experience is the challenge.

An advantage to the computer-mediated instruction is that students can pace themselves. If a student needs more time to grasp graphing yet understands the concept of solving equations, the student can adjust their pace to be successful. Colleges consistently offer tutoring, supplemental instruction and learning centers for students to get extra help. However, very few colleges provide opportunities for the motivated student to accelerate. It is just as important to provide the motivated student a faster path to completion. Students cannot afford to spend three to four semesters remediating prior to taking their college-level mathematics course and sometimes their major required courses. This is a deterrent to enrolling in college. However, if a student is given the opportunity to complete their remediation in one or two semesters, there is a monetary reward and incentive to attend college. Zachary (2008), Panitz (2007), Epper and Baker (2009) and the Dana Center report all advocate for providing opportunities for acceleration and reducing the gaps between courses. Although it appears everyone has an answer on how to fix developmental mathematics remediation, there is a lack of consensus.

\section{Program Review}

In 2005, Golfin, Jordan, Hall and Ruffin conducted a literature review that concluded no reliable studies existed that showed what was and was not working in developmental mathematics education. They recommended that community colleges collect and analyze data on pass rates, persistence of developmental students in college level courses and graduation rates 


\section{REDESIGN OF A DEVELOPMENTAL MATHEMATICS PROGRAM}

and ultimately be used to inform pedagogical structure. Without this information, institutions will never be able to help students advance toward earning a degree.

Collins (2010) concurred and found that there was a lack of quality research on success of developmental mathematics programs and what works. He discovered that most sound statistical research focuses on one intervention implemented in a controlled setting and it does not account for the multiple variables that influence success. However, the lack of rigorous studies should not preclude institutions from continually trying to improve instruction (Collins, 2010 \& Asera, 2011). Institutions need to use what they do know and what shows promising results.

One of the major reasons for the lack of research is that community colleges focus on teaching, not research. There is a lack of time to assess practices and a drive to get students enrolled. Community colleges have rolling enrollments and the time available to revise and revamp is limited. Safran and Visher (2012) conducted case studies on three community colleges and found that the developmental course sequence had not changed in ten years and placement cut scores were never validated. Funding full time faculty to evaluate their curriculum, placement policies, and institutional practices is critical to transforming the developmental mathematics program and student success. However, there is a growing interest in helping community colleges better remediate mathematics. The Lumina Foundation provided $\$ 100$ million by funding the Achieving the Dream initiative along with other big supporters including the United States Department of Education Institute of Education Sciences and the Bill and Melinda Gates Foundation Bailey (2009). Unfortunately, many community colleges must wait for the results of these studies and all the while students continue to fail every day. There is an alternative. 


\section{Summary}

With the increased use of online software programs, there is a plethora of data to analyze. Therefore, even without the support of a major grant, colleges can use institutional and data from online programs to assess engagement, successes, curricular holes, placement, policies and program effectiveness. Every institution can take the following steps to transform their developmental mathematics program

1. Commit to improving student outcomes

2. Identify and prioritize problems

3. Engage stakeholders in developing strategies for addressing priorities

4. Implement, evaluate and improve; and

5. Institutionalize effective policies and practices (Zachary, 2008, p. 6).

Using the design and developmental research methodology, I followed a similar approach to transform the developmental mathematics program at a small rural community college to answer the following research questions:

1. How did a small rural community college transform the developmental mathematics program from a three-course, lecture-based format to a one-course, computer-mediated design?

2. What were the effects of the resulting computer-mediated program on the student's success in the course, the program, their college-level mathematics course and graduation or transfer rate?

The design and developmental research methodology will reveal the transformation of the developmental mathematics program. 


\section{REDESIGN OF A DEVELOPMENTAL MATHEMATICS PROGRAM}

\section{Chapter 3: Methodology}

The following section will outline several aspects of the methodology. To start, I will define the design and developmental research methodology, discuss the participants and describe what I will use as my unit of analysis. The setting of the study is one of the most important aspects of the research. Therefore, I describe the setting prior to any changes to the program and describe in depth how each developmental mathematics course fits into the developmental mathematics program.

A description of the model that was used to redesign the program, the Emporium Model follows. The goal of redesigning the structure of the developmental mathematics program was to move it toward the Emporium Model. Results from colleges that employed the Emporium Model can be found in Appendix E.

Lastly, my data sources and the collection procedures used during each phase of the research cycle; needs assessment, design and development, and initiated program changes are presented. The reader will have a map to redesigning a developmental mathematics program.

\section{Design and Developmental Research}

Developmental research seeks to create knowledge grounded in data systematically derived from practice (Richey \& Klein, 2005). It is a way to establish new procedures, techniques, and tools based upon a methodical analysis of specific cases. The purpose of this research was to improve the developmental mathematics program at a small rural community college by developing new procedures and tools for increasing student success. There were five iterations of the test course that included curricular and policy changes made over three years. I focused on one course, and it served to illuminate the effects of the changes made to the developmental mathematics program. 


\section{REDESIGN OF A DEVELOPMENTAL MATHEMATICS PROGRAM}

There are two categories of development research, Type 1 and Type 2. Type 1

developmental studies focus upon a given instructional product, program, process, or tool. They reflect an interest in identifying either general development principles or situation-specific recommendations. Type 2 studies focus upon a given design, development, or evaluation model or process (Richey \& Klein, 2005 p. 26). I will use Type 1 study that will focus upon the design and development process of transforming a lecture-based developmental mathematics course to a self-paced, computer-mediated developmental mathematics program. The results will be a summary of the process of transforming the developmental mathematics course, pre-algebra, which transformed it into a coherent curricular reform for the entire developmental program. It will include an analysis of the success of the transformation by determining the students' developmental mathematics pass rates in comparison to students that were enrolled in one of the traditional lecture-based courses. Table 1 summarizes the common research method employed for Type 2 (adapted from Richey \& Klein, 2005, p. 31).

Table 1. Two Types of Developmental Research

Type $1 \quad$ Type 2

Emphasis
Study of specific product or Study of design, development, program design, development, or evaluation processes, tools or and/or evaluation projects models

Lessons learned from developing specific products and analyzing the conditions that facilitate their use Context specific conclusions
New design, development, and evaluation procedures and/or models, and conditions that facilitate their use

Generalized conclusions

Richey and Klein (2004) p. 1103

The design and development research approach includes a "focus on measurable goals and outcomes derived through an initial analysis phase, the selection of content and strategies 


\section{REDESIGN OF A DEVELOPMENTAL MATHEMATICS PROGRAM}

that match these goals, a process of routinely evaluating the products prior to finalizing the project, and the assessment of the learning and performance outcomes" (Richey \& Klein, 2007, p. 2). In this chapter, I will describe the design and development of the goal that led to the implementation of a transformational change to the developmental mathematics program using a course analysis, A description of how it led to the developmental mathematics program design changes and an assessment of the redesigned program. I will use this structure as my methodology, with one modification. I did the course analysis first, and then chronicled the design and development changes to the program and courses. Lastly, for the validation phase, I will present the results and the evaluation of the course and program changes that occurred. First, I begin with a description of the participants, each case and then the setting. I will follow that with an overview of the developmental mathematics program that was the focus of this study. Next, I will describe the emporium model for developmental mathematics programs. It is the model that I followed to redesign the program. Lastly, I will discuss my data sources and the collection procedures used.

\section{Participants}

The community college where the study was completed shared a campus with a four-year university. Students in the community college and university were intermingled in classes. Students were unable to determine which college their classmates were enrolled. However, there was a designation on the instructor's roster for which college the student was enrolled. Of the 173 students that were members of the study, 55\% were two-year community college students and the remaining were four-year university students. Eighty-five percent were freshman, 11\% were sophomores, $2 \%$ were juniors and $2 \%$ were seniors. First-time freshman accounted for 55\% of the students, $9 \%$ were re-admits, and $10 \%$ were transfer students. The remaining $26 \%$ were 


\section{REDESIGN OF A DEVELOPMENTAL MATHEMATICS PROGRAM}

internal transfers and first-time freshman-other. These were students that had transferred between the university and the community college.

The community college has approximately 3,000-degree seeking students and the university has approximately 4,500. According to the 2011-2012 institutional report, approximately $10.5 \%$ of the community college students were awarded a degree or certificate. Sixty percent of the students are female and 40\% male, $92 \%$ are West Virginia residents, and $56 \%$ are from three surrounding counties. Eighty-five percent are white/non-Hispanic and 8.5\% are African-American. Sixty-six percent are less than 24 years of age. The Carnegie classification is Associate, Public-Rural.

Twenty-two percent of the participants were associate undeclared majors, and $10 \%$ were bachelor undeclared. Fourteen percent were pre-nursing, $8 \%$ were pre-veterinary tech and 7\% were pre-education majors. The remaining 38\% included 30 different majors. Student majors with the largest populations are summarized in Table 2 . They are separated by 2 -year community college and 4-year university major degree sought.

Table 2. Community College Sample Population Student Majors

\begin{tabular}{lclc}
\hline Community College Major & Percentage & \multicolumn{2}{l}{ University College Major } \\
\hline Associate Undeclared & $22 \%$ & Bachelor Undeclared & $10 \%$ \\
Pre-Veterinary Tech & $9 \%$ & Pre-Education & $7 \%$ \\
Pre-Nursing & $7 \%$ & Pre-Nursing & $8 \%$ \\
Other & $19 \%$ & Other & $19 \%$
\end{tabular}

*Note: Rounding error leads to total greater than 100\%

Every student is required to take the ACT COMPASS placement exam if his or her mathematics ACT/SAT is below a 19/460 respectively, have no test scores, or have scores that 


\section{REDESIGN OF A DEVELOPMENTAL MATHEMATICS PROGRAM}

are more than 4 years old. Table 3 summarizes the entry-level mathematics courses and placement score requirements.

Table 3. Entry-level Mathematics Course Placement Requirements

\begin{tabular}{lcc}
\hline \multicolumn{1}{c}{ Course } & ACT or SAT math score & COMPASS Algebra score \\
\hline General Math & $<19$ or $<460$ & $0-16$ \\
Elementary Algebra & $<19$ or $<460$ & $17-25$ \\
Liberal Arts Math & $19+$ or $460+$ & $>36$ \\
Intermediate Algebra & $19 / 20$ or $460-499$ & $36-48$ \\
College Algebra & $21+$ or $500+$ & $49+$ \\
\hline
\end{tabular}

All participants for this study placed into the Pre-Algebra level or had passed the General Math level. These students were selected because they still had two to three more levels to pass (depending on their major) and were faced with at least one more year of developmental mathematics, provided they passed each level they faced. The goal of the redesign was to increase the developmental course work completion rate and reduce the time to completion with the hope that this will lead to an increase in the degree completion rate.

\section{Cases}

This study used each course delivery as the case to guide the developmental mathematics program changes. The unit of analysis is the developmental mathematics program. Each course offering (unit of observation) will be referred to as a case.

The transformation was led by the curricular and student needs in the developmental mathematics course to influence the design changes to the developmental mathematics program. 
REDESIGN OF A DEVELOPMENTAL MATHEMATICS PROGRAM

Data was collected over three consecutive semesters. Each case structure is summarized in Table 4.

Table 4. Case Structure

\begin{tabular}{lclc}
\hline Case & Number of students & Setting & Days of the week \\
\hline 1- Spring 2010 & 25 & Computer lab & MWF \\
2- Fall 2010 & 26 & Computer lab & MWF \\
3- Fall 2010 & 28 & Computer lab & TR \\
4- Spring 2011 & 23 & Computer lab & MWF \\
\hline
\end{tabular}

\section{Setting}

The first case was the semester in which changes to the course, curriculum and setting were made. It was a spring semester class, had twenty-five students, and met in a computer lab with a chalkboard, instructor computer, screen projector and a computer for each student. The class met three days a week on Monday, Wednesday and Fridays from 9:00-9:50am.

Two cases were offered in the subsequent fall semester, Case 2 and Case 3. Both cases had notes on the student schedule: Students may complete both pre-algebra and elementary algebra. This was to let students know that they could complete two courses in one semester. Case 2 had twenty-six students enrolled and met in a computer laptop lab. There was no faculty designated computer but had a rolling cart with a projector available to check out that could be connected to a laptop. There was one chalkboard that was on wheels and could be flipped to the other side. The class met three days a week on Monday, Wednesday and Fridays from 10:0010:50am. Case 3 was the second fall semester class offered, met in a computer classroom, and had twenty-eight students enrolled in it. The room had enough computers for every student and 


\section{REDESIGN OF A DEVELOPMENTAL MATHEMATICS PROGRAM}

an instructor computer was available with screen projection. There were four chalkboards across the front of the room. In the final data collection spring semester, two cases ran. They also had the note on the schedule for students to see: Students may complete both Math pre-algebra and elementary algebra.

Case 4 was on main campus and met in a computer lab with computers for every student, an instructor computer with screen projection, had 23 students enrolled, four whiteboards in the front and met from 9:30-10:45 on Tuesday and Thursdays. In all courses, students self enrolled and were not recruited.

Now, I will discuss the structure and parameters of the developmental program and the courses and the curriculum included in the program before any changes were enacted. Then I will present a deeper discussion of the target class, Pre-Algebra.

\section{Institutional Developmental Mathematics Program}

Each higher education institution in West Virginia can develop their own developmental mathematics program to remediate student deficiencies, provided it meets certain state guidelines. The most restrictive WV state law prohibits enrollment in any state two-year or four-year college-credit bearing mathematics course, which is designed to be applied toward a baccalaureate degree or an associate degree unless the minimum score of 19 on the math ACT or a 460 on the math SAT or a 36 on the COMPASS algebra test (Higher Education Policy Commission, 2010). Students that do not meet this standard must successfully complete a program(s) in developmental (pre-college level) mathematics in order to be placed in mathematics courses which count toward a baccalaureate, A.A., A.S., or A.A.S. degree (p. 2). This is a mandate from the West Virginia Higher Education Policy Commission titled Series 21 


\section{REDESIGN OF A DEVELOPMENTAL MATHEMATICS PROGRAM}

Freshman Assessment and Placement Standards. More standards exist for other nationally normed tests, but were not in use at this institution.

In summary, the minimum cut score for college-level mathematics is determined by the state. However, colleges are free to design the developmental curriculum with approval of the Higher Education Policy Commission Chancellor. At this institution, three levels of developmental mathematics were utilized for students to be permitted to take a liberal arts mathematics course that counted toward their degree or certificate. A fourth level was required, intermediate algebra, for students taking college algebra. The fourth course counted as a threecredit general education elective and not as a mathematics credit. The three levels of developmental included basic mathematics, pre-algebra, and elementary algebra. Each course was a three-hour, 16-week, no-credit course. Students had to take them sequentially beginning where they placed, continuing through Elementary Algebra or Intermediate Algebra (dependent on course required for degree) and were advised not to leave any gaps between semesters. Although this study focuses on the middle level, Pre-algebra, I will describe each level course requirement to enhance understanding.

The lowest level course was basic mathematics. There was no prerequisite for this class because it was the lowest developmental mathematics level, however students could not enroll in it unless they took the placement exam. This eliminated frivolous enrollments in the course. This class was CR-credit/NC-no credit. The students average was a weighted grade with tests $25 \%$, computer homework $25 \%$, quizzes $10 \%$, attendance $20 \%$ and a comprehensive departmental final $20 \%$. There was no penalty for missing six classes and if the student did not miss any classes, could earn an additional 20 bonus attendance points. Students were required to take the final exam and achieve an overall $78 \%$ average to receive credit for the class. The computer 


\section{REDESIGN OF A DEVELOPMENTAL MATHEMATICS PROGRAM}

homework was done with the Hawkes Learning System software. It was on a CD-ROM and did not require Internet access. The course had 19 outcomes beginning with understanding place value and progressing to solve one-step linear equations (Appendix A).

The next developmental mathematics course in the sequence is the course that is the focus of this dissertation, Pre-algebra. The prerequisites were completion of math 93 basic mathematics or placement into the class with a COMPASS score of 19 or better. This class was also CR-credit/NC-no credit, and used a weighted average with tests $45 \%$, internet-based homework $18 \%$, quizzes $9.5 \%$, attendance $9.5 \%$ and the departmental comprehensive final $18 \%$. This convoluted grade calculation was a challenge for the students, as they were already struggling with mathematical concepts.

Bonus points were available for doing assigned homework. The homework program was delivered in an Internet-based program, iLrn and was free with the book by the publisher Thompson-Brooks/Cole. This course had 44 outcomes and began with solving linear equations and concluded with graphing linear equations in two variables (Appendix B).

The highest level of developmental mathematics was Elementary Algebra. The prerequisite was successful completion of Pre-algebra or a COMPASS placement score of at least 26. This class had the same structure as Pre-algebra, had 31 outcomes that began with solving linear inequalities and concluded with using the quadratic formula to solve quadratic equations (Appendix C).

The three classes together constituted the developmental mathematics program and had a total of 84 outcomes. Several outcomes were repeated in each class. For example, solving linear equations was taught in basic math, pre-algebra and elementary algebra. If a student tested into the lowest level, the only course option was to pass three classes that were 16 weeks each over 


\section{REDESIGN OF A DEVELOPMENTAL MATHEMATICS PROGRAM}

three semesters. Students always had the ability to attempt to retest and attempt to place into a higher-level mathematics course. However, students were not permitted to test while enrolled in a course. Therefore, at the end of the semester, many students that did not pass the class would retake the placement test. I do not have figures as to how many students were able to test into a higher-level course, but I did track the students to see if they completed the developmental mathematics program and college-level course, which is where I will consider the student a "success" for completing their required college level mathematics course.

Realistically, students were faced with at least one and a half years of developmental mathematics. This was discouraging and a daunting task for students that tested into the lowest level. If the student had no stops or gaps, it would be at least two years before they could earn their college-level mathematics credit. If a student was working toward a two-year associate's degree and had mathematics as a prerequisite to major courses, they could end up spending three to four years getting a two-year degree. The course sequences described thus far were the only options available to students. This was cost prohibitive to many community college students.

All courses were taught in the 150-minute a week time frame, except one. There was one offering of an 8-week Saturday class. Students could complete pre-algebra and elementary algebra in one 16-week semester. Otherwise, all students had to enroll in a 16 -week lecture course. None of the sections were offered in a computer lab prior to the transformation. Table 5 summarizes the number and type of courses taught each semester. With an average enrollment of 23 students per section, this redesign would affect over 2,000 students a year. Next, I will discuss the instructional model that I followed to initiate the transformation of the developmental mathematics program. 


\section{Emporium Instructional Approach}

The Math Emporium model of teaching was developed at Virginia Tech in 1997 to increase student learning and decrease associated costs. The math emporium is a computerlearning center that serves over 8,000 students a semester. The lab is open 24 hours a day, seven days a week during the semester. Mathematics faculty, graduate students and upper level undergraduate students staff it. Students come to the center for assistance with online mathematics classes, take proctored tests, get help with group projects, study independently, and use the computers to access online videos, lectures and quizzes (Robinson \& Moore, 2006).

Table 5. Number and Type of Courses

\begin{tabular}{|c|c|c|}
\hline General Math & Pre-Algebra & Elementary Math \\
\hline
\end{tabular}

Spring 2009 7 18

18 43

Fall 2009

9

23

16 48

Spring 2010

8

16

17

41

Fall 2010

10

27

16

53

Spring 2011

9

20

21

50

The students at the school where this study was conducted do not have access to such a facility. Therefore, the model had to be modified to fit the school's facilities and resources. However, the foundational principles that supported this model could be maintained. The Emporium Model was developed with the following foundational principles:

Technology can be used to individualize a student's experience in a course, improving instruction. Allowing students to progress at their own pace, review material, and take practice quizzes as much as they like, while getting personal help only when desired, is a cost-effective way to improve the learning experience. 


\section{REDESIGN OF A DEVELOPMENTAL MATHEMATICS PROGRAM}

Active learning, as opposed to the traditional lecture model, improves outcomes. Faculty and other coaches provide just-in-time assistance using techniques designed to allow the students to discover answers themselves.

A course must clearly delineate expectations and provide comfortable and effective mechanisms to support learning. However, students gain other valuable real-world skills beyond course content, including self-discipline and organization, when entrusted with responsibility and authority to manage their own learning (Robinson \& Moore, 2006, p. 12)

To achieve these goals, all of my classes met in a computer lab with me as the only lead instructor. I used My Math Lab by Pearson as the computer program to deliver the content, assign homework and test student learning. To keep the course aligned with all the other prealgebra classes offered, the 16-week, 150-minute meeting pattern and comprehensive departmental final exam was maintained.

Lectures were rare and short. Students came to their scheduled class time, worked through the program watching lectures, PowerPoints, animations, and working problems. Students were assessed at the end of each chapter. The instructor role changed from lecturer to facilitator. Students were encouraged to spend time in the program outside of class and ask questions to get help from the instructor while in class. Although this idea is very simplistic, the details greatly influenced student behavior and success. Therefore, this dissertation will chronicle the design strategies and implementation decisions with respect to each case of the Emporium teaching model and analyze course, program and subsequent course pass rates to determine effectiveness of the redesign. 


\section{Data Sources and Collection Procedures}

This section describes all of the data sources and collection procedures that were used to document the model design and implementation decisions for the program for each case and the data sources that were used to evaluate the model. There are two parts to the process and they are intertwined. Changes were made to the program and to the course. The process was not linear and program changes led to course changes and vice versa. Much of the data were used for both program and course changes. I will present all of the sources and indicate which phase of the study in which it was used.

\section{Phase I- Needs assessment, Design and Development}

The developmental mathematics program was analyzed prior to any redesign changes. Various institutional documents were used during the evaluation of the design and development phase, including e-mails, grade books, syllabi, course catalog, course schedule and institutional data. Because the process overlapped, some of the documents were used for both of these phases.

The online course schedule was used to determine the number of sections offered, the room amenities for each, including chalkboard, white board, and instructor and student computer access. By enrollment trends, I determined the most popular class times, the amount of seat time and the number of weeks the classes met. I was able to determine whether an adjunct or full-time instructor taught a course. The purpose of this was to determine how many students, instructors, courses, and resources the redesign impacted for the developmental phase. Additionally, I was able to identify if the course resources were stagnant or fluctuated from semester to semester.

Next, all of the course syllabi were used to document each course's outcomes, structure, policies and pass criteria. The book, software and lab requirements were examined. This enabled 


\section{REDESIGN OF A DEVELOPMENTAL MATHEMATICS PROGRAM}

me to document policy and course changes before, during and after the redesign; hence during all three phases.

I used the following institutional data to do the program analysis, and subsequently the validation of the program: ACT/SAT/COMPASS placement scores, course pass/fail and withdraw rates, student success in subsequent course, college-level pass and whether a student graduated with a degree or certificate, had the GPA to transfer or was still enrolled. This data was used during the program analysis to help clarify where and when students were the least successful and determined the starting point for redesigning the program. The institutional catalog was used to clarify the progression of the developmental program, the prerequisites, and course credit hours. During the program validation phase, the catalog entries were used to help determine how to write the curriculum proposals and determine the impact on other courses that used the developmental mathematics courses as a prerequisite course.

I used student comments from my course evaluations to help understand the students' perspective. Their comments were considered when redesigning the program. Although these evaluations were from my courses only, I focused on the comments concerning course structure, teaching pedagogy and course pace. I will present and discuss some of the student comments.

The early results from a pilot course that ran as a summer bridge program. The results were encouraging and supported the validation phase. During this phase, a redesigned developmental program with course proposals was presented for approval to the faculty senate. I worked with other developmental mathematics instructors, the dean, the provost and the registrar to complete the redesign. Notes from meetings, emails and consequently the new catalog information will be used to document the completion of the redesign. 


\section{Data used for Phase II- Validation}

The MyMathLab (MML) online program by Pearson education was used before, during and after the program redesign. The data that were collected in the program was the most useful during the design and development stage to make adjustments to the course structure. This is where I was able to respond to course issues in the promptest manner. For example, if students were jumping around in the program homework, I was able to enable outcome prerequisites. This required students to master a concept before they could move on to the next. This kept the student on task and moving through the course sequentially, yet at their own pace. They could move through as quickly or sometimes as slowly as needed. I used MML data to: track student pace, adjust due dates, add prerequisites, pass/fail rates for outcomes and tests and time to completion.

As stated previously, the developmental course and program pass rates for students taking the lab classes versus the lecture classes, and time to completion will be used to assess the success of the redesign. Additionally, success in college-level mathematics courses will be analyzed.

I hypothesize that the students in the lab courses were more successful at passing their subsequent college level course vs. students in a lecture course and the lab classes helped to reduce the time to completion of the developmental mathematics program. This should be the result of the increased engagement with and demonstrated mastery of the content. Thirty-two institutions participated in Changing the Equation grant project. Participants tracked 86 developmental mathematics courses that underwent an Emporium Model redesign and found the $83 \%$ of the students in the redesigned courses showed significant improvements over their on their common final exam or final exam items versus students in non-redesign courses (Twigg, 


\section{REDESIGN OF A DEVELOPMENTAL MATHEMATICS PROGRAM}

2005). I do not anticipate my results to be this good due to the limited funding resources this institution faced and the inability to create and staff a learning lab. However, I do anticipate positive results.

Of the colleges and universities that were members of the Changing the Equation project, only $23 \%$ had higher developmental mathematics completion rates. Although this appears counter to the previous statement, one has to remember that the previous figure touts final exam averages and indicates that students better learned the content. Getting students to complete the developmental mathematics series is another struggle. The previous figure included only the students that completed the course and does not account for the dropout students that return to complete the course or program. At this institution, the dropout or stop-out rate averaged between $35 \%$ and $45 \%$ of the class enrollees. They attribute prior grade inflation, and the mastery-learning requirement in redesigned courses as two possible reasons for this low developmental mathematics completion rates.

Completing the developmental mathematics program has been and appears to always be a challenge for some students and avoidance is part of the students' culture. It is a common assumption that the better you are at a task, the more likely you will complete it. And the opposite is also true. All interested parties must understand that the population of students in developmental mathematics courses had previous struggles, or they would not be in a developmental class. Therefore, expecting success for all is irrational. However, we have a duty and responsibility to continually try to improve the developmental mathematics program toward increasing completion and college-level success. Admittance to a college or university comes with the responsibility to provide opportunities for success. 


\section{Research Limitations}

Institutional data and documents were used to redesign the course and program and to report the results of the redesign. Limitations with respect to the redesign and validation phase exist and are described below.

Design. Decisions with respect to the redesign used the documents created and used by the researcher to make design decisions. Personal bias and viewpoint must be considered when the researcher is integral to the research. Consideration must be given to the possibility that all aspects of the redesign were not reported and personal judgment was a contributing factor. Decisions were personal to the researcher's experience as the instructor.

Implementation of the changes began prior to the decision to do design and development research. Therefore, the timeline was recreated using historical emails, meeting notes, grade books and course syllabi. The accuracies are limited to the accuracy of the documentation used. Some of the changes that were implemented were completed before, during and after each course offering. Therefore, only the end result for each course offering was used as the basis for the documentation of the design change.

Evaluation. Multiple data sources were used to evaluate the success of the redesign. Data sources include institutional pass rates, course pass rates, college-level course pass rates, COMPASS placement scores, a survey, grade submissions and the course grade book. Using multiple data results increases the reliability of the results. 


\section{REDESIGN OF A DEVELOPMENTAL MATHEMATICS PROGRAM}

\section{Chapter 4: Findings}

In this chapter, I report on the design decisions that were used to transform the developmental mathematics program to the Emporium model. Then I evaluated the redesigned courses with the traditional courses by comparing course pass rates, developmental mathematics program pass rates, and college-level mathematics pass rates. Lastly, I examine whether the students in the redesigned courses graduated, were still enrolled or had the GPA to transfer to another institution.

The transformation included structural changes to the program that included the number

of courses, course curricular outcomes, course numbering, credit hours, classroom setting, course delivery, and instructor role. Classroom and common spaces were repurposed to include teaching labs and open labs for students to study and test. Four iterations of the course ran during the transformation and the course and program changes evolved over the three semesters. The redesign culminated with a faculty senate approved curricular change to the developmental mathematics program.

This chapter is divided into two parts. To answer the first research question, which is again listed below, I document the timeline of the design decisions and the implementation phase using the syllabus, emails, and historical documents. To answer the remainder of the research questions, I examined the student successes during the evolution of the courses.

1. How did a rural community college transform the developmental mathematics program from a three-course, lecture-based format to a one-course, outcomebased, computer-mediated design? 


\section{REDESIGN OF A DEVELOPMENTAL MATHEMATICS PROGRAM}

2. What were the effects of the resulting computer-mediated program on the student's success in the course, the program, their college-level mathematics course and graduation or transfer rate?

To enhance understanding, I begin with a presentation of the preliminary work done prior to changes in the program and describe how it operated prior to any changes.

\section{Pre-Redesign Analysis}

The purpose of the developmental mathematics program was to bring students' deficient mathematics skills up to the college level. This was meant to increase success in a college level mathematics course and decrease time to degree or certification. Students could not enroll in a college level mathematics course with a Math ACT/SAT score below 19/460 respectively. If a student was below this level, or needed mathematics course higher than their ACT/SAT placement, they could take the COMPASS placement exam. See Table 6 for the placement scores.

Table 6. Cut Scores for Math Placement

\begin{tabular}{ll}
\hline COMPASS Algebra Score & Course Placement \\
\hline $15-16$ & Basic Mathematics (Appendix A) \\
$17-25$ & Pre-algebra (Appendix B) \\
$25-35$ & Elementary Algebra (Appendix C) \\
ACT/SAT 19/460 or $36+$ & Intermediate Algebra (Appendix D) or Liberal \\
& Studies Mathematics Course \\
ACT/SAT $21 / 500$ or 49 & College Algebra \\
\hline
\end{tabular}

Therefore, if a student placed at the lowest level, they had to complete four courses prior to college algebra, which is two years of developmental mathematics for a regular full-time 


\section{REDESIGN OF A DEVELOPMENTAL MATHEMATICS PROGRAM}

student. The objectives for each course can be found in Appendix A, B, and C. The three courses cover 84 objectives. This dissertation does not cover intermediate algebra since the goal of the program is to remediate to the college level. Once students completed elementary algebra, they qualified for the general studies mathematics course, but not college algebra. Intermediate algebra was another layer that had to be completed prior to gaining entrance to college algebra and was not part of the redesign of the developmental mathematics program.

The course had an online textbook by Pearson and the e-book was in MyMathLab. The web-based program included videos, animations, and problem examples. Students had the ability to use a "help me solve this" tool. The tool was available in all homework and study plan problems, but not on tests and quizzes. Students were permitted to use a non-graphing calculator. The classes counted as three credit hours for financial aid purposes and had a credit (CR), nocredit (NC), and no-credit, not attending (NCX) grade mode that was added in the fall of 2010. The grade had no effect on GPA. Although the course counted toward credit hours earned vs. credit hours attempted for financial aid purposes, it took multiple semesters for the NC grade to impact their financial aid.

Therefore, many students did not drop the class if they were not passing or progressing. They simply stopped coming to class. I could not compare attendance rates for redesigned courses versus traditional courses due to the fact that faculty were not required to keep attendance records and attendance was not part of the student's grade calculation. However, I will report on the withdrawal rate. I cannot track the "stop out" rate due to the lack of data.

There was no lab requirement. An open lab was available during the day, but the department did not track how many students utilized it. It was not manned by a tutor and was not 


\section{REDESIGN OF A DEVELOPMENTAL MATHEMATICS PROGRAM}

exclusive to developmental mathematics students. Homework could be done from any computer on or off-campus, and did not require the student be in a lab.

A paper-based departmental final exam was used for all courses. To receive credit for the course, a comprehensive final exam grade of $50 \%$ or better was required for all courses in addition to an overall $75 \%$ pre-algebra and $78 \%$ elementary algebra average. If the student missed a test, the final exam counted as double. If the student missed two tests, the second missed test was a zero and could not be made up. The weighted grade was calculated with $10 \%$ from quizzes, $30 \%$ from tests, $40 \%$ for homework and $20 \%$ for the departmental final. Four percentage points were available as bonus points if the student had a homework average of $84 \%$ or better.

Table 7. Syllabus Summary Pre-redesign

Summary Pre-redesign

Required passing percentage $\quad 78 \%$

Outcomes

44

Minimum final exam score $50 \%$

Grade Calculation:

Tests $30 \%$

Online Homework $40 \%$

Quizzes and classwork $10 \%$

Final exam $20 \%$ 


\section{The Pre-Algebra Course}

The pre-algebra course is the focus of this dissertation. I chose this course because the majority of the students that placed into developmental mathematics placed into this course. I believed that initiating the restructuring with this course would permit a motivated student to complete all of the outcomes for the pre-algebra and the elementary algebra course in one semester, thus reducing their time to degree completion. Focusing on this course would have the largest impact on the program.

The pre-algebra course was revised over two years and in fact, subsequent revisions were made to the elementary algebra and basic mathematics course. Pass rates for these courses are not included in this study because the changes came at the end of the redesign.

Every semester, the pre-algebra course was altered in multiple ways, thus eliminating the possibility of an experimental study. In the first part of the results section, I will compare pass rates for the redesigned courses to those in a traditional lecture course, which were all courses that were not part of the redesign in addition to chronicling the redesign. 
Table 8. Data Points Related to Research Questions

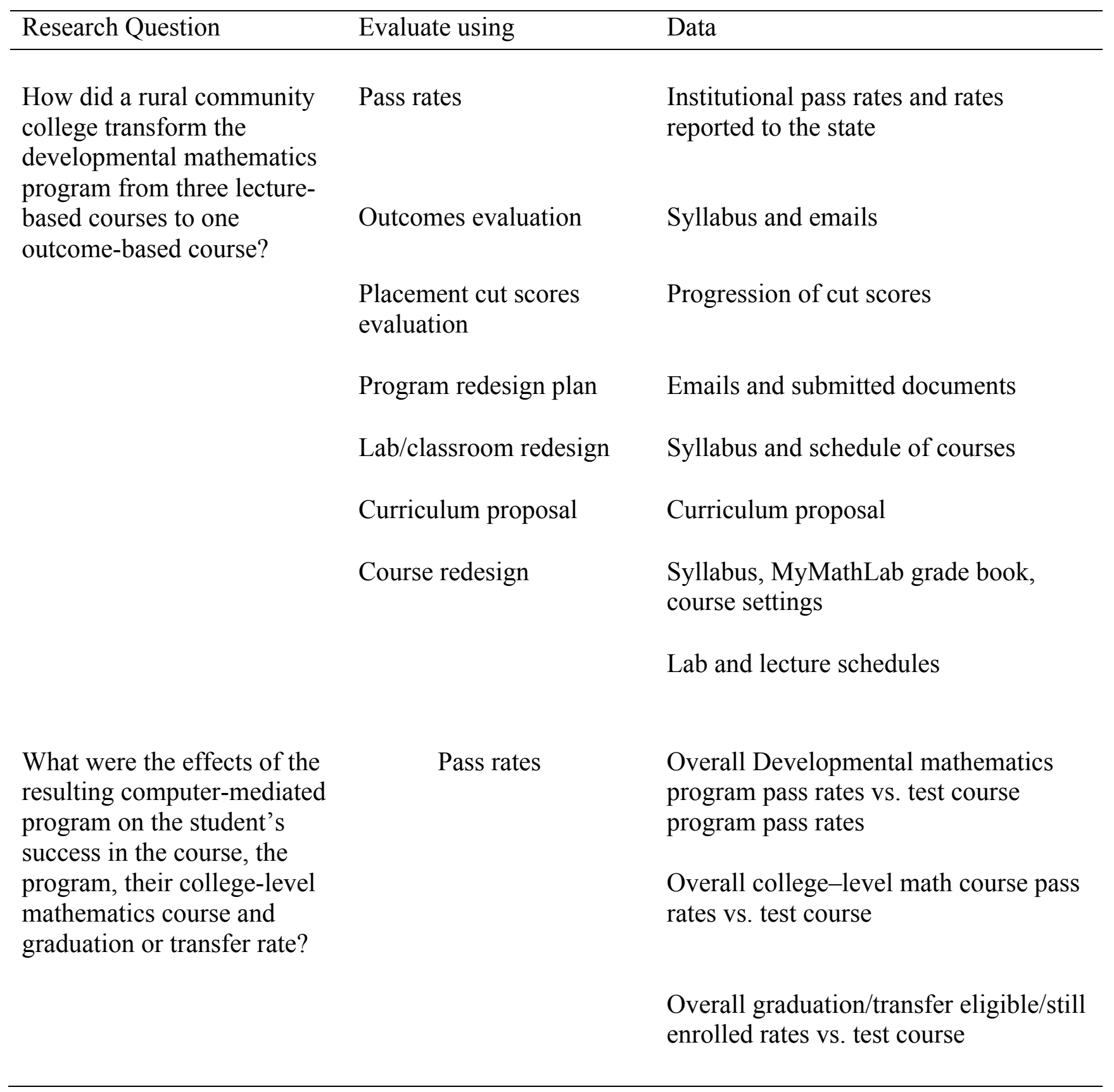

Data. Unfortunately, I am unable to parse out my results from the overall results for the institution. This will skew the data slightly, but is unavoidable due to the institutional data being comingled with my data. I do not have the pass rates for each course, nor the number of students 


\section{REDESIGN OF A DEVELOPMENTAL MATHEMATICS PROGRAM}

per course, making it impossible to separate out my data.

\section{Traditional courses}

All of the developmental mathematics courses were taught on a Monday, Wednesday, Friday or Tuesday, Thursday schedule that met for 150 minutes a week. The students were given a syllabus (Appendix $G$ ) on the first day that outlined how the course would be taught and the course expectations. In-class group work and lecture were meant to prepare students to independently complete the online homework. There were unannounced quizzes in class. Tests were announced one week in advance, and homework was to be completed at $80 \%$ or better, however they could move forward without hitting this benchmark.

There was a notes workbook that accompanied the text. Students were expected to bring the workbook to class and follow the lecture by filling in vocabulary words and doing problems in the workbook as we encountered them (Appendix H). Students were permitted to use a calculator with a fraction key, but not a graphing calculator.

Students were encouraged, but not required to keep a notebook with dated class notes, workbook pages completed in class, and worked homework problems. There was no requirement or point incentive to attend class or keep the notebook. This was a departmental syllabus and all on-campus classes for this course used the same syllabus.

There was a notes guide that instructors could use and students were required to purchase. Students met in a lecture room with no computers for the student and sometimes one for the instructor. Students would use the notebook pages to follow the lecture and would complete homework assignments outside of class on their own time. Many students did not complete the homework until the day before the test. Students were not regularly engaging in the content, and students were not required to do the homework prior to taking the test. Students could complete 


\section{REDESIGN OF A DEVELOPMENTAL MATHEMATICS PROGRAM}

the homework with a penalty until the last day of the term. It was obvious that students were more interested in gathering points than learning the content prior to the test from the pattern of homework completion. The homework was assigned to practice for the test, yet the students attempted it after the test.

If the student failed a test, they continued on in the course. There was no requirement to remediate or attend tutoring. The goal was to accumulate enough points to pass without having to demonstrate comprehension. Often times, students would request "extra credit" because they did not have the required passing score. Comprehension was not connected to passing. However, many of these students would become frustrated because it was too difficult to continue in the course without the necessary comprehension. The students usually stopped attending immediately after a test.

One apparent pattern that stood out was the lack of interest early in the semester for students that were repeating the course. They previously passed the first test, some two and three times. They were waiting to get to the content that caused them to stumble. Unfortunately, they would miss class and attempt to pick up again when the class caught up with them. This never worked. Continually starting over never gave the student more time he/she needed in the content that was difficult for them.

\section{Another Format}

In the summer of 2007, the program director for the West Virginia Department of Highways (WVDOH) contacted me and asked me if I could run an online professional development developmental mathematics course. He wanted the students to have the ability to complete the program in one semester. The WVDOH paid me a stipend to develop an online course and it ran in the fall of 2007. 


\section{REDESIGN OF A DEVELOPMENTAL MATHEMATICS PROGRAM}

The course was a compilation of the pre-algebra and elementary algebra course outcomes. The outcomes were sequenced to match the traditional on-campus lecture courses. Therefore, the students worked through all of the pre-algebra outcomes and then through all of the elementary algebra outcomes. At their own pace, the students used various learning aids, completed the homework assignments, took online tests and took a proctored final exam. There were many aids available to the students in the program (Appendix F.) The students could go to the multi-media library and search by chapter and section number for videos, animations, and power point lectures.

While doing the homework, the students could use a "help me solve this" link that guided them through the given problem. However, when the student returned to attempt the problem on his or her own, the computer generated a new problem. There was a link for "show me an example”. With this assistance, students would see a similar problem worked out, but not the exact problem they were assigned. When the students returned to complete the given problem, it did not change from the original.

There was also a direct link to "ask my instructor a question". This link would generate an email directly to me with the exact problem and a place for students to ask me a question. If a video or animation were available in the program for a particular problem, there would be a link to them as well. Lastly, there was a direct link to the e-textbook page of the problem explanation. This was beneficial in that students did not have to search the textbook for instruction (Figure 2). 


\subsection{Removing a Common Factor}

Objective: Factor polynomials whose terms contain a common factor.

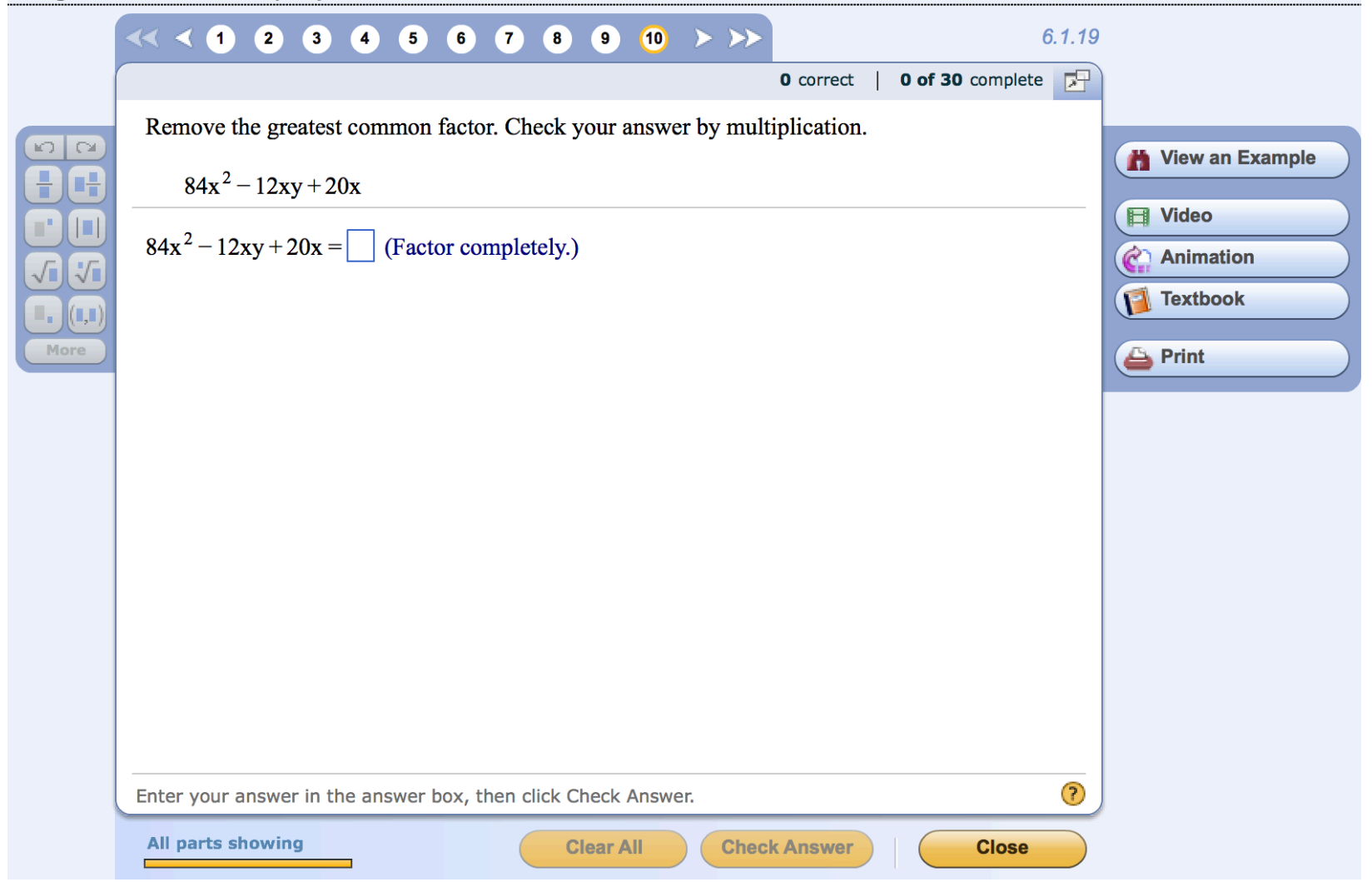

Figure 2. Online program question example

Due dates were set for students to complete only the pre-algebra outcomes in one semester. However, they were told they had the option to accelerate through all of the outcomes and complete both courses in one semester. Due dates were set for the first course outcomes only so as to not discourage students that could not keep up with the accelerated pace.

Additionally, students could click on any homework question and send it to me, the instructor, and ask a question. If more than an email response was necessitated, I would write out an explanation and scan it back to the students in an email.

Students rarely asked questions, so approximately once a week, I would review student progress and send suggestions via email when I would see students struggling. The majority of 


\section{REDESIGN OF A DEVELOPMENTAL MATHEMATICS PROGRAM}

the students were older adults and was very conscientious about keeping up with the class and getting help on their own.

Seven students successfully completed both courses in one semester, three students completed one course, four withdrew, and ten students continued to the end, but did not complete the course. This equates to a 50\% pass rate. However, the financial impact and timesaving that were afforded the seven students that completed two courses for the price of one was not reflected in the $50 \%$ pass rate.

One of the biggest struggles students had with the course was understanding the order of the outcomes. This was evident from the questions I received from the online students. They were always trying to go in the order of the textbook and believed they were locked out of the course when they tried to click on a section and received an error message that they did not meet the prerequisite. Although the outcomes were in the order in which they were supposed to complete them, the mixed order was confounding. All of the content had to be completed in a linear manner, as each outcome was a prerequisite for the next one. For example, solving equations had to be completed prior to solving systems of equations. The outcome was named as the corresponding book section number. For example, one outcome was named 2.5 or 3.1 in lieu of "solving systems" or "solving equations". This was confusing to the student, especially because the course did not follow the order of the textbook.

The on-campus course content jumped around and repeated outcomes too. This issue initiated a departmental discussion as to why we repeat outcomes and teach the content in a different order than most books prescribe. Most textbooks order linear expressions and equations prior to quadratic, exponential and logarithmic expressions and equations. The discussion resulted in the discovery that the reason for the mixed order was that we were following the 


\section{REDESIGN OF A DEVELOPMENTAL MATHEMATICS PROGRAM}

syllabus that had been in place from the previous textbook. It was never updated to reflect the new textbook. The reasoning behind repeating the same outcomes in two different classes was that students tended to forget content from previous classes and we would always need to review. Although I agreed that underlying content needed to be reviewed occasionally to refresh students' memories, reviewed content should not be considered as a course outcome, but should be integrated with the appropriate outcome.

As a result of this discussion, I was able to do a minor course revision to eliminate repetitive content, and align the outcomes in a more logical manner. Content was rearranged to the following: basic math, linear, exponential, quadratic, and rational and radical expressions and equations. I continued to run the accelerated online developmental mathematics course each semester generating similar results.

Unfortunately, this format was not available on campus in a classroom setting. I believed the pass rates would be greater in a face-to-face setting versus an online platform, although the student demographics were considerably different. A face-to-face course would provide more instructor support and encourage motivated students to fast-track through their developmental coursework. In addition, if students could not complete the outcomes in one semester, they could continue the course in a subsequent semester without starting over. Once a student demonstrated mastery, they could continue to progress forward. I decided to propose a summer pilot course that would utilize the structure of the online course in a face-to-face setting. I submitted the proposal and requested a course development grant to support it. However, the dean would not permit the students to get course credit because the seat-time was significantly less than the regular full-term course. The students would take the placement exam at the end of the week to attempt to test out of developmental. 


\section{REDESIGN OF A DEVELOPMENTAL MATHEMATICS PROGRAM}

The proposal was accepted and with grant money, I ran a mini one-week summer bridge course for first-time freshman in the summer of 2009. Students were recruited at new student orientation. When students took the placement exam and tested into developmental mathematics, they were given an informational flyer about the bridge course.

Nineteen students enrolled in the program that ran for two weeks prior to the start of the fall 2009 semester. Two students were out-of-state and paid to stay in the dorm for the week. The course, materials, and meals were free for students. It ran for five hours a day for four days and for three hours on the fifth day with a one-hour break every day for lunch. Students were not eligible for course credit, but again were given the opportunity to re-test and place out of one or more of the developmental mathematics courses. Therefore, the students did not "pass" the course. They had to retake the COMPASS placement exam with the hope of moving onto the next level.

The class met in a computer lab and I was the instructor. Students took an algebra diagnostic test on the first day in MyMath Test by Pearson. The diagnostic test questions were selected to match the outcomes of the pre-algebra and elementary algebra courses. The program assigned an individual study plan for each student based on the results of the diagnostic test. Students worked through the study plan independently, with me circulating throughout the room monitoring student progress and answering questions. Once students completed the study plan, they would retake the diagnostic test. Again, the program would generate a study plan that targeted student deficiencies. Students worked all week on the study plan questions, retaking the diagnostic test after completing all assigned study plan questions. The students continued this cycle until the end of the week. At the end of the week, students retook the COMPASS placement test. 


\section{REDESIGN OF A DEVELOPMENTAL MATHEMATICS PROGRAM}

The results were encouraging. Of the 19 students that enrolled, 18 completed the program. Nine students tested completely out of developmental mathematics and into a collegelevel mathematics course. One student tested one level higher in developmental mathematics. The remaining students tested the same or lower. However, unknown at the time, when I went back and tracked the students four years later I found that 14 out of the 18 students had successfully completed their developmental mathematics sequence and passed a college-level mathematics course within 5 years. Although a very small sample, this equated to a $78 \%$ success rate. Over time, I continued to track students that were in the new developmental mathematics courses and will report on their success rates later in this paper.

I proposed running a summer bridge program in subsequent summers; however, the dean would not support any future summer bridge programs reasoning "we had collected much of this relevant information for our [2007 report]. Let's go back and look at that information and use it to strategize and talk about placement options, etc." Unfortunately, the summer bridge was more than a data collection initiative. Getting the college to change the status quo was more challenging than anticipated. The data from the 2007 report was three years old at that point and had never been used to make significant improvements to the developmental mathematics program.

\section{Phase I: Redesigning Developmental Mathematics}

In a college-generated report, $86.8 \%$ of the college's students placed into developmental mathematics. For students that placed in the lowest level class, the four-year graduation rate was $5.56 \%$. For students in the second and highest level, the rate was $13.9 \%$ and $24.1 \%$ respectively. As one can see in Table 9, these rates are extremely low. But even more daunting is the fact that 


\section{REDESIGN OF A DEVELOPMENTAL MATHEMATICS PROGRAM}

only $39.9 \%$ of the college's freshman developmental mathematics students were successfully passing a developmental mathematics course.

Table 9. Four-year Graduation Rate for Developmental Mathematics Students

\begin{tabular}{lc} 
Level & Rate \\
\hline Lowest: Basic math & $5.56 \%$ \\
Mid: Pre-algebra & $13.9 \%$ \\
Highest: Elementary algebra & $39.9 \%$
\end{tabular}

Source: 2013 HEPC report

National statistics are similar and indicate that developmental mathematics had become the brick wall, blocking student attempts to improve their life through education. To put this into perspective, if 1,000 students enrolled in the college and 868 enrolled in developmental mathematics, and then only 346 students were successful in their first math course. At most, only 378 earned a degree after four years. That leaves 623 students behind. The money, time and resources that are used on these 623 students were in vain.

Students had communicated that the developmental program was inhibiting their ability to move forward because the class went to quickly at times. Students could not focus on content for which they struggled. Students in developmental mathematics have varying backgrounds and needs. Students could have placed in developmental mathematics for many different reasons. Some students had forgotten content leaned many years ago and needed a refresher; some had never learned content and needed a heavy amount of instruction and time for understanding, yet some passed high school mathematics courses without demonstrating comprehension and needed to fill in gaps. Whatever their need, increasing student success in developmental mathematics to 


\section{REDESIGN OF A DEVELOPMENTAL MATHEMATICS PROGRAM}

increase their degree and certificate attainment rate by creating a student controlled, flexible environment was the goal of the transformational change that followed.

In the fall of 2009, the department received a developmental mathematics retention and success report for 2004 through 2008 from the state higher education policy commission. The Pre-algebra pass rates are presented in in Table 10 and the institutional developmental mathematics pass rates are in Table 11.

The steady decline in pass rates was a wake-up call for the department and the new motivation for transforming the on-campus pre-algebra and elementary algebra courses. My goal was to start with the pre-algebra course and incorporate the outcomes of the elementary algebra course to bring two classes into one. Eventually, the basic mathematics course, which was the lowest level, could also be incorporated into the new course, condensing three courses into one, giving students a seamless transition to college-level mathematics readiness.

Table 10. Pre-algebra Pass Rates: $2004-2008$

\begin{tabular}{lccc}
\hline Year & Fall & Spring & Average \\
\hline 2004 & $58 \%$ & & $58 \%$ \\
2005 & $54 \%$ & $52 \%$ & $53 \%$ \\
2006 & $57 \%$ & $45 \%$ & $51 \%$ \\
2007 & $50 \%$ & $44 \%$ & $47 \%$ \\
2008 & $47 \%$ & $43 \%$ & $45 \%$ \\
\hline
\end{tabular}

Table 11. Institutional Developmental Mathematics Pass Rates 2006 - 2010

$\begin{array}{lllll}2006 & 2007 & 2008 & 2009 & 2010\end{array}$


REDESIGN OF A DEVELOPMENTAL MATHEMATICS PROGRAM

\begin{tabular}{llllll}
\hline Program Pass Rates & $55.8 \%$ & $47.7 \%$ & $42.1 \%$ & $39.5 \%$ & $36.8 \%$
\end{tabular}

Spring 2010. In October 2009, I submitted a proposal to run an accelerated version of the pre-algebra and elementary algebra course for the spring of 2010, mimicking the curriculum of the online class and classroom setting of the summer bridge program. This class would have a seamless curriculum without repeating outcomes and would provide students with a computerbased, instructor-assisted outcome-based course. The pre-algebra course would run for eight weeks and then the elementary algebra course would run for the second eight weeks. It would give students the opportunity to complete up to two courses over one semester. However, to satisfy the seat-time requirement, the class had to be double time. With this format, time was not reduced for the students, but they would now have the opportunity to complete two courses in one semester. This new course format was proposed to begin in the spring 2010 semester.

The proposal was not accepted, but I did get approval to pilot one section of the outcomebased pre-algebra course for a full semester and I was able to convince the dean to give the students credit for the subsequent course if they could complete all outcomes for both courses in one semester. This would provide an incentive for the students to stay on task and possibly accelerate.

Students enrolled in this outcome-based, accelerated course without knowing that it was a pilot course. I told the students on the first day that the course format would be different from the other pre-algebra courses offered on campus. They had the opportunity to complete one or both of the required developmental courses. It was self-paced and there would not be any lectures. Students had the option to do move out of the course and into a traditional-lecture course. 


\section{REDESIGN OF A DEVELOPMENTAL MATHEMATICS PROGRAM}

Students would work in and out of class on each unit until they successfully passed each unit exam. The class was outcome based and they would have to demonstrate mastery before moving forward. If they did not complete the outcomes for the pre-algebra class, they would not receive credit for the course. If they completed all of the pre-algebra outcomes, they would receive credit. If they completed all of the outcomes for the pre-algebra and elementary algebra course, they would receive credit for the higher-level elementary algebra course. They could not receive credit for both courses because they only registered and paid for one, three credit-hour course. This was a constraint from the registrar and financial aid officer.

To gain approval from the dean to run the course, I had to add a basic mathematics review to the outcomes. I believe this may have been an attempt to undermine the success of the course by the dean. The dean was very resistant to change. However, I believed it was more important to offer the course than to argue semantics at that time. Therefore, there were outcomes for three courses in the pilot course and students had to pass a test on the basic mathematics outcomes at $78 \%$ or better prior to beginning the pre-algebra content even though these students had passed or placed above the basic mathematics content. Accordingly, this slowed many students down. They were a little frustrated in the beginning, but I assured them that it was a review and they should be able to progress quickly through the review outcomes. Six students never passed the basic mathematics outcomes test. Two of them never took the test. Of the six students that did not pass the basic mathematics test, four of them stopped attending class, one withdrew and one remained in the class until the end of the semester.

The course used only homework and tests, and no quizzes. The difference between homework, quizzes and tests is the amount of computer-based help available in the program. With homework assignments, there were multiple links available to help students. The instructor 


\section{REDESIGN OF A DEVELOPMENTAL MATHEMATICS PROGRAM}

could not turn off these aids in the homework. In tests and quizzes, all of these links were disabled.

Students were instructed to complete each homework assignment with a minimum of $78 \%$ and then take the test. Although the students did not have to get a $78 \%$ on the homework, they did have to get a $78 \%$ on each test. However, they had to have enough points to earn a $78 \%$ overall average and had to earn a $50 \%$ or better on the final exam. Most students were selfmotivated to get the $78 \%$ score on the homework and would do it multiple times until they were achieved a $78 \%$ on each test. All tests were taken during class. Students could not access them outside of class because I had them password protected. However, all homework could be done in or out of class.

Due dates were set to keep students on pace to complete the first course by the end of the semester. Students were encouraged to keep pace with that schedule. To keep students from getting discouraged, I would roll the due dates along with the latest due date. Students could fall behind and continue to work in the class. Students were told if they did not complete the class in one semester, they could register for it again and pick up where they left off. They would not have to start all over again.

Again, the results were encouraging and are presented in Table 12. Out of the 27 students enrolled in the course, three students were able to complete both developmental mathematics courses in one semester, 11 students received credit for one course, two students withdrew and 11 students received no credit. This equated to a $52 \%$ pass rate and an effective pass rate of $57 \%$ when accounting for the students that passed two courses in one semester. The available institutional data showed that the overall pass rate for all pre-algebra courses was $37 \%$. 
REDESIGN OF A DEVELOPMENTAL MATHEMATICS PROGRAM

The pass rate for the outcome-based course had a pass rate $15 \%$ higher than the average for all pre-algebra courses.

Table 12. Comparison of Pass Rates for Spring 2010

Redesigned Pre-algebra class All classes

\begin{tabular}{lcc}
\hline Pass Rate & $52 \%$ & $37 \%$ \\
& $\mathrm{n}=25$ & $\mathrm{n}=342$ \\
\hline Passed two courses & $11 \%$ & $\mathrm{~N} / \mathrm{A}^{*}$ \\
& $\mathrm{n}=3$ & \\
\hline
\end{tabular}

*This was not an option for the non-redesigned course.

To gather student opinions about the redesigned course, I conducted an interview with four of the students that successfully completed two courses in one semester. First, I asked the students to describe their mathematics experiences prior to coming to college. All four students indicated they had passed algebra I, algebra II and geometry in high school. At that time, these three courses satisfied the minimum required mathematics curriculum to graduate from high school. Three students offered explanations as to why they were in developmental mathematics. One student indicated she was sick in high school and never learned the content, another said she had "a bad high school experience" but would not elaborate, and the third explained that she always got C's in mathematics.

Second, I asked the students about their mathematics experiences since coming to college. Every student had a previous mathematics failure, and every excuse placed part of the blame on someone other than himself or herself. One student felt they would have been successful had they been permitted to use a calculator, one attributed the failure to text anxiety brought on by 


\section{REDESIGN OF A DEVELOPMENTAL MATHEMATICS PROGRAM}

her mother telling her she was stupid, and one blamed the course pace. The last student communicated that she was sick and was exhausted all the time. This kept her from passing.

When I asked the students whether they liked the computer-based course, they all agreed they liked it and indicated they had control of the pace and focus of the course. They also indicated that the class felt more personal than the lecture course. I was pleased that I had achieved a student-friendly environment in a computer-based course as most students associate a self-paced course as online and without instructor support. Lastly, I asked the students if they could change anything about how the developmental mathematics course was taught and all agreed they preferred the computer-based course to a lecture course. One student suggested having a few mini lectures to supplement the course. I had considered doing this and in fact gave a few mini lectures during the first course offering. However, the course was self-paced and each student progression differed so much early on in the course that it was difficult to decide what to lecture.

Although these interviews were conducted with only four students, it addresses the motivated students' needs. This population of students is often ignored and the students that struggle get most of the attention and resources in supplemental instruction and tutoring. These students were serious about their college studies and wanted to move forward faster than the lecture class was allowing them. These students have a significant chance for college success and we needed to provide the platform to foster it.

Fall 2010. During the spring 2010 semester, I saw that students were enthusiastic about the format and were experiencing success. Therefore I began to petition for more classes using this format for the fall 2010 semester. A review of email exchanges with the dean and coordinator revealed that there was resistance. In particular, I was denied access to a computer 


\section{REDESIGN OF A DEVELOPMENTAL MATHEMATICS PROGRAM}

lab for the classes. Therefore, I appealed to the academic provost to help me find any available labs on campus that I could use. The provost was able to find me two labs in two different buildings on the other side of campus. This was a challenge for me to get to all of my classes. Now they would be spread across campus in four different buildings. One lab was in the same building as the departmental offices, however the dean would not permit any faculty to use it. It was to remain open to students for drop-in use.

I suspected the lab was not being utilized as intended and requested a room usage report. Since students had to enter in their student ID, name, and password to use computers on campus, this information was readily available. As suspected, the room was rarely used. Although I was not given permission to use the lab for classes, the dean was directed to work with the developmental mathematics faculty to find ways to better utilize it. The faculty agreed to have all developmental mathematics courses meet at least one day a week in the lab for the upcoming fall semester. Although it did not solve my lab issues, this was a positive step towards getting away from the daily lecture and getting students to engage in the content. I took what rooms were available and taught my two redesigned classes by traveling across campus.

In the fall of 2010, I taught two sections of the restructured pre-algebra course. Both courses were taught in a computer lab. One course had a note on the published schedule of courses, "Students may complete both [pre-algebra] \& [elementary algebra]". The premise was that this note would incentivize the motivated student to register for the course with the opportunity to eliminate a developmental mathematics level. Hopefully, the results would show that the overall pass rate would be greater than for this class. The other accelerated course did not have a note on it. Both classes were in a lab, although one was a laptop lab. There was no chalkboard in the laptop lab, but I was able to acquire moveable boards for the rooms. In the 


\section{REDESIGN OF A DEVELOPMENTAL MATHEMATICS PROGRAM}

laptop lab, students were at tables of four. This turned out to be an added benefit. Students enjoyed helping each other and working together.

The major structure of the course remained the same with a few changes. Homework was no longer a part of the student's grade. The students were relying too heavily on the "help me solve this" and "show me an example" link to do the homework problems, giving them an inflated grade without truly understanding the content. Although homework was not used to calculate their class average, the assignments were still available to the students. Their weighted grade was calculated using $70 \%$ for tests, $10 \%$ for study plan and $20 \%$ for the final exam. Students could choose to do the homework assignments and then the test, or they could skip the homework, test and then complete the study plan and retest if necessary. The learning aids were available in the study plan, but the program would not eliminate the question from their study plan until they were able to complete it on their own without the use of the aids.

Most students took a test, completed the assigned study plan and then retested. The students were not required to complete the study plan or homework prior to being permitted to retake the test, however the student had to pass the test at $78 \%$ in order to move forward. This ensured they had the average necessary to pass the class. They could retake the test as many times as necessary. Since I had to enable their test access, I was able to monitor how many times they took a test and could intervene if I saw them struggling. As with the previous semester offering, dates rolled as the class progressed to allow students to continue to make progress. Although the student may not have been able to pass the class, it was important to keep the student moving forward within the content.

In both classes, on the first day, students were told they could receive credit for either pre-algebra or elementary algebra based upon completion of the outcomes for each course. 


\section{REDESIGN OF A DEVELOPMENTAL MATHEMATICS PROGRAM}

Unfortunately, there was no relationship between having the note on the schedule and having a more motivated student. The pass rates were better for the students in the class where there was no note on the schedule, $66 \%$ versus $61 \%$. Although the pass rate was lower for the one class, this pass rate was significantly higher than the overall pre-algebra mathematics pass rate for the college, which was $44 \%$.

Table 13. Overall Pass Rates for Students in Redesigned Courses vs. All Courses Fall 2010

Redesigned Pre-algebra class $\quad$ All other classes

\begin{tabular}{lll}
\hline Pass Rate & $60 \%$ & $44 \%$ \\
& $\mathrm{n}=55$ & $\mathrm{n}=626$ \\
\hline Passed two courses & $7 \%$ & N/A* \\
& $\mathrm{n}=4$ &
\end{tabular}

*This was not an option for the non-redesigned course.

\section{Further Redesign Research}

During this semester, I was accepted as a participant in the National Center for PostSecondary Research sponsored conference titled "Developmental Education: What Policies and Practices Work for Students?" It was limited to 100 participants so that we would have access to the country's leading developmental education experts. Presenters included Thomas Bailey and Hunter Boylan, renowned developmental education experts, John Q. Easton, the director of the Institute of Education Sciences, and Martha Kanter, the Under Secretary of Education, whom gave the keynote. The goal of the conference was to present the latest high-quality research on developmental education, providing a solid basis for future practice, policy, and continued study (2010, NCPR). 


\section{REDESIGN OF A DEVELOPMENTAL MATHEMATICS PROGRAM}

The information was invaluable and confirmed that the redesign of the developmental mathematics program was on the right track. Among the conclusions that I drew from the conference was that administrative support was critical and lacking in my institution. To gain institutional support, I invited the college president, provost, dean and chair to a presentation on what I learned at the NCPR conference. All except the chair attended and were very receptive. I received permission from the president to continue expanding the accelerated and computermediated, outcome-based developmental mathematics program.

Spring 2011. In the spring of 2011, I continued developing the redesigned course. I taught one section on campus in a computer lab. This latest class changed very little from the previous semester. Over time, there were fewer drastic changes and more fine-tuning. One of the small but significant changes was the elimination of all optional homework assignments. It was confusing to students because it was not used in their grade calculation. Students had to start each unit by taking a test. Now, after testing, students were required to complete the computer assigned study plan prior to being permitted to retake the test. Another change was the elimination of some of the study plan content.

The study plan was customized to include only required course outcomes. This reduced the amount of time students spent in the study plan. For example, factoring a difference of two cubes was not one of the outcomes for the course and factoring two cubes was not tested. However, the study plan would automatically assign problems that had difference of two cubes because it assigned all types of factoring problems. Therefore, I edited the available problems and selected questions that matched the outcomes. Students could still access these problems if they wanted, but they were not included in the computer-generated study plan. 


\section{REDESIGN OF A DEVELOPMENTAL MATHEMATICS PROGRAM}

The second change was the elimination of due dates. This was a difficult decision. Deciding between self-paced and required deadlines would influence student behavior. If students could not meet that deadline, they would stop coming to class albeit I would roll the dates. If we did not impose deadlines, students may not keep the pace necessary to complete the course in one semester. We did not want students to stop coming because any progress they made would be carried over into the next semester. Yet we wanted students to complete the course in one semester. If they did not finish in one semester, students would not be required to start over again. They would be permitted to continue where they previously left off. It was imperative that students continued to come to class and make significant progress through the end of the semester. The solution was to provide a pacing guide to keep students on track yet give them the option of taking longer if necessitated. I continued to see success with the redesigned course. Table 14 displays the pass rates for this last class was $70 \%$ versus the $44 \%$ rate for all other on-campus classes.

Table 14. Overall Pass Rates for Students in Redesigned Courses vs. All Courses Spring 2011

$$
\text { Redesigned Pre-algebra class All classes }
$$

Pass Rate

\begin{tabular}{ccc} 
& $\mathrm{n}=27$ & $\mathrm{n}=230$ \\
\hline Passed two courses & $15 \%$ & $\mathrm{~N} / \mathrm{A}^{*}$ \\
& $\mathrm{n}=4$ & \\
& &
\end{tabular}

*This was not an option for the non-redesigned course.
The next step was to convince the dean and chair that this format should be expanded to all sections of developmental mathematics as soon as possible. 


\section{REDESIGN OF A DEVELOPMENTAL MATHEMATICS PROGRAM}

\section{The Open Pathway Project}

This community college was going through their initial accreditation process. The college was previously a division of a four-year institution and was mandated to separate into a freestanding community college by the West Virginia state legislature. The Higher Learning Commission (HLC) had an Open Pathway option for accreditation. The Open Pathway project is focused on quality assurance and institutional improvement. It is unique in that its improvement component is more open, giving institutions the independence to pursue improvement projects that are geared toward their current needs and aspirations. The accreditations team, which was comprised of member of the institution including the college president, the faculty senate president, faculty and an HLC representative, determined that redesigning the developmental mathematics program would be one of its major focuses.

The project goal was to modularize the instruction of the developmental skills mathematics, targeting instruction to students' individual areas instead of requiring students to complete the three-semester course sequence. This project will use best practices to allow student to complete their developmental mathematics requirements in a more timely fashion, thus increasing their ability to enroll in and complete college credit mathematics requirements sooner.

Labs. During this spring 2011 semester, I conducted a survey to determine student interest in a lab versus lecture class format and to gain student perceptions of the developmental mathematics program. The survey was delivered via Blackboard to all sections of developmental mathematics courses. There were 532 students enrolled in the pre-algebra and elementary algebra on-campus courses and 178 students responded to the survey, a 33\% rate of return. The survey questions are in Appendix $\mathrm{G}$ and the results are summarized below. 


\section{REDESIGN OF A DEVELOPMENTAL MATHEMATICS PROGRAM}

Survey Results. Although on-campus courses had an assigned lab time for faculty to get students involved in active learning in a lab at least three times a month, $42 \%$ of the respondents indicated that they had never met in the lab. The most interesting statistic of the survey was that $75 \%$ of students preferred a format other than lecture only. In the fall 2010 semester, there were 16 sections of pre-algebra on the main campus. Fourteen of them were lecture, two were the outcome-based accelerated courses, and two were online courses.

Due to the anonymity of the respondents, it was not possible to determine which faculty members were not meeting in the lab during their assigned times. However, it was imperative to get faculty buy-in and concluded that we needed to work on improving faculty and student lab use. Therefore, we gave our adjunct faculty a stipend to attend a professional development workshop on how to transition to an outcome-based course from a lecture-based one. This workshop was required for all developmental mathematics instructors and had to be completed prior to receiving their contract to teach.

More than $54 \%$ of the respondents had previously taken a developmental course prior to the one currently enrolled and received an NC-no credit grade. This figure is high albeit consistent with our institutional data. As a result of the survey, we considered an alternate grade, such as PR for progress and we would need to define progress for grading purposes. However, the course would need to be modularized to track students and see if in fact they were making progress. Additionally, $70 \%$ of the respondents had previously passed a developmental mathematics course. This indicated that an excessively high percentage of the students needed more than one level of developmental mathematics. Redesigning the course into modules would give students the opportunity to minimize the number of courses they had to take. The survey revealed that we had a student population that was struggling to find success in the 


\section{REDESIGN OF A DEVELOPMENTAL MATHEMATICS PROGRAM}

developmental mathematics program, confirming the dismal statistics that would be published in two years. Chart 1 shows the developmental mathematics path rates through 2011.

\section{Modularization}

The next step for the Pathway Project was to develop the modules for the program and eliminate the three-course structure. The modularization of the pre-algebra course and the incorporation of the elementary algebra course had effectively modularized two of the three courses. The last step was to bring the basic mathematics course outcomes into this redesigned course. The projected timeline to have all three courses modularized was by the spring of 2012 .

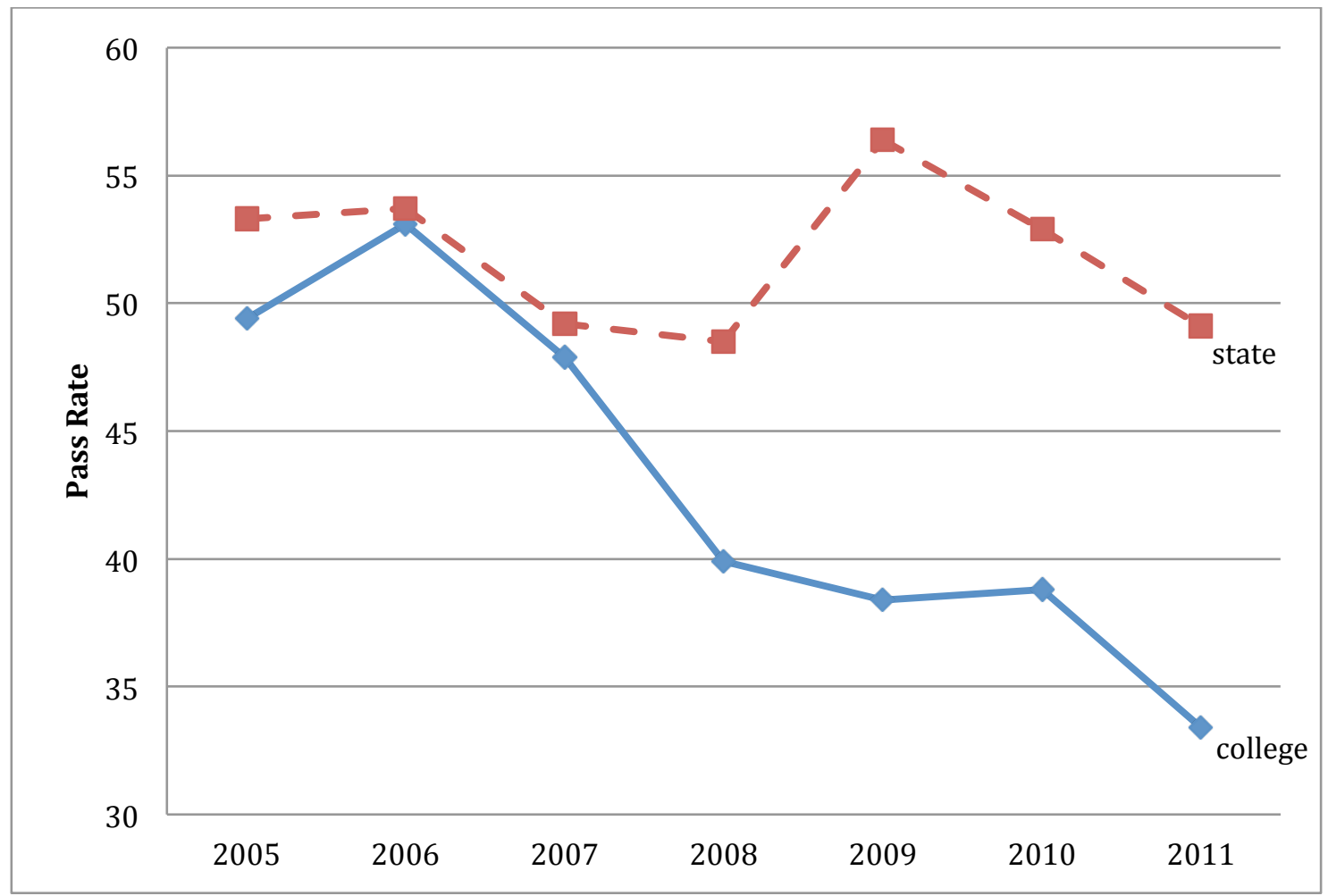

Figure 3. Developmental Mathematics Pass Rates: College vs State

Curriculum Proposal. To modularize, we had to determine how we could get all developmental courses into a lab. Although the premise behind modularization was computer- 


\section{REDESIGN OF A DEVELOPMENTAL MATHEMATICS PROGRAM}

based, the administration wanted us to explore whether or not we would continue to offer a traditional lecture course, online or hybrid. We were charged with determining the semantics of meeting patterns, lab space and faculty assignments. The departmental faculty came together and decided we would need to roll out the redesigned courses and then assess whether more formats would be necessary. A mathematics lab had to be established and we needed time to get faculty trained. With the help of the provost and money from the college president, a dedicated mathematics lab was created for the fall 2011 students. We would continue to assign each class lab time to complement the lectures and give students the opportunity to interact with the content. The redesigned lab classes that were being used for my redesigned courses would be used for the lab classes and offerings would be expanded.

Two full-time and one part-time faculty members embraced the redesigned model and with pressure from all, we were able to offer the redesigned courses. Unknowing at the time, these faculty were able to perpetuate the redesigned model after my departure from the institution. Programs and reformations should never be tied to a single entity so that they do not die with the departure of one individual.

We needed to develop the common assessment tool and the final exam needed to reflect the new structure. The final exam would have to be loaded into the online program and available to students at any time during the semester. Students would be able to complete the program at any point in the semester. We needed to work with the registrar to change three, three-credit courses into nine, one-credit courses and decide when students would take a comprehensive exam. To begin the college-level transformation, a curriculum proposal was presented to and approved by faculty senate in May of 2011 (Appendix I). This proposal eliminated repeated and 


\section{REDESIGN OF A DEVELOPMENTAL MATHEMATICS PROGRAM}

realigned the content. However, students had already scheduled for summer and fall. We had to defer the changes to the fall of 2012.

As of fall 2012, students would no longer sit in a 16-week long course for three credit hours. Students would continue to earn a grade of credit (CR), no-credit (NC) or no-credit-failing (NCX) for each of the nine courses. The PR grade for "progress" would not be necessary dur to the nine individual courses. Students would have rolling enrollment and were told to register for a minimum of three-credit hours per semester. If they completed those three modules (three credit hours), they could enroll in one to six more hours as necessitated. Each module was a credit hour covering one outcome. Those outcomes were:

1. Basic mathematics

2. Signed numbers and order of operations

3. Solving linear equations and inequalities

4. Graphing linear equations and inequalities

5. Solving system of linear equations

6. Operations with exponents and polynomials

7. Factoring and applications

8. Rational expressions and applications

9. Roots, radicals and solving quadratic equations

Each module was given a course number. Course 1 was a prerequisite for course 2, course 2 for course 3, etc. This change was instituted for the fall of 2012. Courses 1-9 would meet in the same room, at the same time. In other words, students from every level were mixed into one class. 


\section{REDESIGN OF A DEVELOPMENTAL MATHEMATICS PROGRAM}

In the discussions section, I will answer research questions 3 , 4, and 5 by addressing the pass rates, successes, and issues that followed. Now I will continue with Phase II of the results. This section will present the transformational change from the student's success in the developmental mathematics program and college-level class.

\section{Phase II- Results}

This section will answer the second research question. To revisit, the second research question is:

What were the effects of the resulting computer-mediated program on the student's success in the course, the program, their college-level mathematics course and graduation or transfer rate?

The pass rates for the redesigned course, program, college-level mathematics course and graduation or transfer GPA show significant signs of success.

\section{Pre-Algebra course pass rates}

In the previous section, I reported course pass rates for each iteration and compared them to the overall pass rates in the pre-algebra course. Now, I will present a summary of the course pass rates here for evaluation and comparison purposes. Table 15 shows the pass rates for the students in the pre-algebra redesigned courses from the spring 2010 term through the spring 2011 term. Students could earn a CR for credit, NC for no credit, NCX for no credit and not attending (beginning in fall 2010) or a $\mathrm{W}$ for withdrew. The pass rates increased over time during the development of the redesigned course. Although the population is not large enough to generalize 
results to the population, the results have possible proximal similarity to the main-campus student population.

Table 15. Redesigned Pre-Algebra Course Student Pass Rates Spring 2010-Spring 2011

\begin{tabular}{lccccc}
\hline & CR & NC & NCX & W & Pass rate \\
\hline Spring 2010 & 12 & 11 & - & 2 & $52 \%$ \\
Fall 2010 & 33 & 5 & 11 & 6 & $60 \%$ \\
Spring 2011 & 19 & 4 & 3 & 1 & $70 \%$ \\
\hline
\end{tabular}

The significant increase in the last iteration was most likely due to the elimination of the homework requirement. The course truly became outcomes-based and $70 \%$ of the student's grade was derived from the tests. If the student did not pass the test, they were told to complete the study plan. If they did not and requested to retest, I would encourage them to do the study plan first. If they did not, and did not pass a second time, I required them to complete the study plan before I would give them permission to test for the third time. All of the questions were algorithmically generated and were pooled. For example, when solving a linear equation, the student could have three possible answers: a number, no solution or all real numbers. The first test may give the student one of each, for the second test the student may see only two out of three possibilities with one answer repeated and so on. This reduced the test learning curve.

The overall pass rates for the institution for four years prior to the initiation of the redesign are in the Table 18. It is typical that spring pass rates are lower than fall pass rates due to fewer students and more students enrolled that are DFW repeating from fall. The yearly pass rate for the pre-algebra course declined every year by an average of $3 \%$. 


\section{REDESIGN OF A DEVELOPMENTAL MATHEMATICS PROGRAM}

Referring to Table 15 and Table 16, one can see that the pass rates for the redesigned courses are significantly higher than the institutional pre-algebra pass rates. The students in the redesigned courses were held to a higher standard than the lecture courses. These students had to demonstrate understanding for every outcome and pass the same comprehensive final exam as the lecture students. But the true test will be if the students from the redesigned courses successfully completed the developmental program, passed their college-level mathematics course and ultimately graduated or transferred.

Table 16. Institutional Pre-Algebra Course Pass Rates Fall 2004-Fall 2008 Prior to Redesign

\begin{tabular}{llccc}
\hline Year & Fall & Spring & Yearly Average & \% Change \\
\hline 2004 & - & $58 \%$ & $58 \%$ & \\
2005 & $52 \%$ & $54 \%$ & $53 \%$ & $-5 \%$ \\
2006 & $45 \%$ & $57 \%$ & $51 \%$ & $-2 \%$ \\
2007 & $44 \%$ & $50 \%$ & $47 \%$ & $-4 \%$ \\
2008 & $43 \%$ & $47 \%$ & $45 \%$ & $-2 \%$ \\
2009 & $48 \%$ & $37 \%$ & $43 \%$ & $-2 \%$ \\
\hline Average & $46 \%$ & $51 \%$ & & $-3 \%$ \\
\hline
\end{tabular}

Figures reported prior to the redesign showed that the four-year graduation rate for students that placed into the pre-algebra course was $13.85 \%$. For students that placed lower, in basic mathematics, the rate was 5.56\%. Next, I will examine the flow-through success for the students in the redesigned courses and compare their success to the institutional rates. 


\section{REDESIGN OF A DEVELOPMENTAL MATHEMATICS PROGRAM}

Passing Developmental Program. For students that place into developmental mathematics, the road is long to the mathematics degree requirement. As we have seen, a student that tests into the lowest level had three classes to pass prior to the college level class. If the student needed college algebra, four classes were needed prior to the college level course. The purpose of the redesign was to give students a clearer and shorter path to completing their developmental mathematics, eliminating repeating the same content and gives the motivated student an option to complete their requirements in a faster, more timely manner.

As I have shown, the students in the redesigned courses had better pass rates than their counterparts in the lecture courses. However, reporting on these rates does not alone indicate success. The real success test is to examine if these students were able to successfully complete the developmental program and subsequently, their college-level mathematics course. So to continue to determine the success of the redesigned course, I will now examine student success in the developmental program.

When I started to review the developmental program pass rates, I decided to go back and first look at the cohort of students that were in the summer bridge pilot program. The results were improbable. This can be confirmed when I look back at the cohort of students that participated in the one-week, not for credit class that I ran in the summer of 2009. Of the 19 students that enrolled in and completed the week, ten of them tested out of the pre-algebra course, or $52.6 \%$. Nine of these students tested completely out of the developmental mathematics program at the end of the week. This was unanticipated considering the course was only one week long. Even more startling is that when I followed up and tracked the students that participated in the one-week summer bridge, 17 out of 19 , or $89.5 \%$ completed their developmental mathematics program. 
REDESIGN OF A DEVELOPMENTAL MATHEMATICS PROGRAM

Table 17. Summer Bridge Pilot Course Results

\begin{tabular}{lccc}
\hline & $\begin{array}{c}\text { Tested out of } \\
\text { pre-algebra }\end{array}$ & $\begin{array}{c}\text { Tested out of } \\
\text { developmental program }\end{array}$ & $\begin{array}{c}\text { Passed through the } \\
\text { developmental program }\end{array}$ \\
\hline Percentage & $52.60 \%$ & $47.40 \%$ & $89.50 \%$ \\
Number & 10 & 9 & 17 \\
\hline$* \mathrm{n}=19$ & & &
\end{tabular}

Although the percentage of students that passed the course and were deemed "successful" is relatively low, it appears that it gave students the necessary foundation to make it entirely through the developmental program. The percentage of students passing the program is important because $49.1 \%$ of incoming freshman place into developmental mathematics and the retention for these students started to decline compared to the non-developmental student as seen in chart below.

This structure should be available to all first-time incoming students. It could have significant impacts on retention. The majority of first-time incoming freshman just recently completed high school and would benefit most as a refresher course. However, due to policies that dictate seat time for credit hours, one-week summer bridge programs do not meet the seat time criteria and cannot offer course credit, only the retesting option.

In the spring semester of 2010, I had one redesigned class with 27 students in it. Again, the pass rate was $52 \%$. Ninety-five percent of the students that passed the class were able to pass the developmental program. This equates to $48 \%$ of the roster of enrolled students. For the 13 students that did not pass, only two of them were able to eventually pass through the developmental program. Therefore, $56 \%$ of the original roster students eventually completed the developmental mathematics program. 


\section{REDESIGN OF A DEVELOPMENTAL MATHEMATICS PROGRAM}

In the fall of 2010, I ran two sections of the redesigned course. The pass rate for the two courses was $60 \%$ of the 55 students that took the course. Of the students that took and passed the class, $55 \%$ successfully completed the developmental program. Even more dismal is that of the 22 students that did not pass the redesigned course, only one student was able to eventually go on to pass the developmental program. Again, this reaffirms the importance of getting students through their first developmental course.

Lastly, for the spring of 2011 semester, $70 \%$ successfully passed through the redesigned course. As encouraging as this statistic is, only 13 of these students, or $68 \%$ of the passers were able to complete the developmental program. And the worst figure to date showed that not one student went on to pass through the developmental program that did not successfully pass the redesigned course. This data is summarized in Table 21.

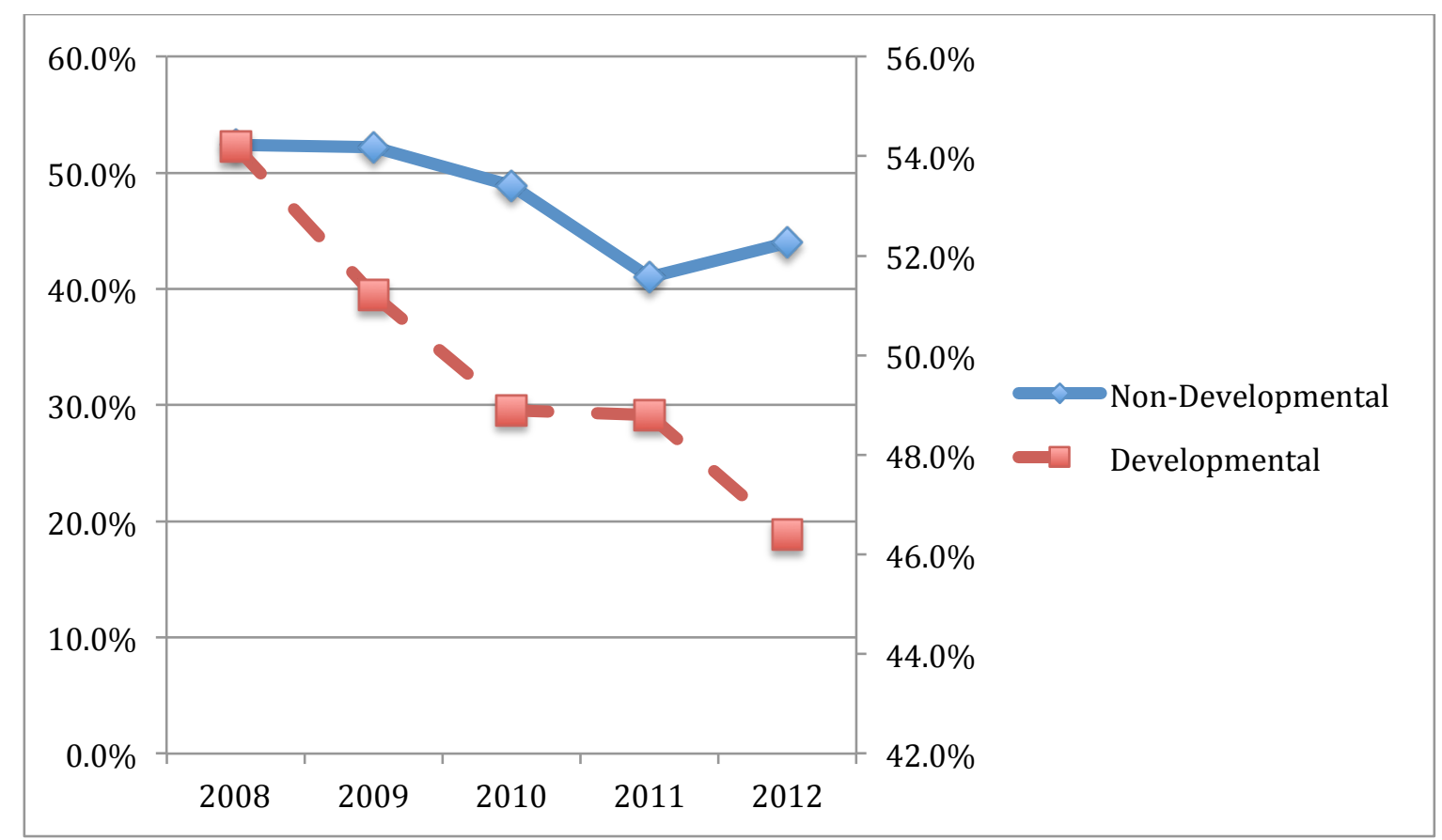

Figure 4. WVHEPC First-time, Full-time Freshman \% of Cohort Returning Following Fall 


\section{REDESIGN OF A DEVELOPMENTAL MATHEMATICS PROGRAM}

According to the Complete College America (CCA, 2012) data from 26 states, of the first-time entry students that enroll in developmental courses, $51.5 \%$ complete them, or in other words, completed the developmental program. The rate for the redesigned courses was $48 \%$, $35 \%$ and $48 \%$ for the three semesters, and was comparable to the national rate. For the spring 2011 term, the redesigned course pass rate rose to $70 \%$ and the pass rate for the developmental mathematics program for these students was $68 \%$ for the passers. Both rates are significantly higher than the state and college wide success rates, but comparable to the CCA rates. As with the fall 2010 statistics, it is disheartening to report that only one student was able to successfully pass through the developmental mathematics program if the student did not pass the redesigned course. This statistic brings a heightened sense of urgency to find a solution for the first-time developmental student to pass the developmental entry course.

Table 18. Summary of Redesigned Course Student Pass Rates

Summary of Redesign Course Students' Pass Rates

\begin{tabular}{lccccc}
\hline & $\begin{array}{c}\text { Course Pass } \\
\text { Rate }\end{array}$ & $\begin{array}{c}\text { Subsequent } \\
\text { Program Pass }\end{array}$ & $\begin{array}{c}\text { Failed or } \\
\text { Withdrew } \\
\text { Course }\end{array}$ & $\begin{array}{c}\text { Subsequent } \\
\text { Program Pass }\end{array}$ & $\begin{array}{c}\text { Overall } \\
\text { Program Pass }\end{array}$ \\
\hline Spring 2010 & $48 \%$ & $92 \%$ & $52 \%$ & $15 \%$ & $52 \%$ \\
$\mathrm{n}=25$ & $12 / 25$ & $11 / 12$ & $13 / 25$ & $2 / 13$ & $13 / 25$ \\
Fall 2010 & $61 \%$ & $55 \%$ & $39 \%$ & $5 \%$ & $35 \%$ \\
$\mathrm{n}=54$ & $33 / 54$ & $18 / 33$ & $21 / 54$ & $1 / 21$ & $19 / 54$ \\
Spring 2011 & $65 \%$ & $87 \%$ & $35 \%$ & $0 \%$ & $65 \%$ \\
$\mathrm{n}=23$ & $15 / 23$ & $13 / 15$ & $8 / 23$ & $0 / 8$ & $15 / 23$ \\
\hline Average & $58 \%$ & $78 \%$ & $42 \%$ & $7 \%$ & $51 \%$
\end{tabular}




\section{REDESIGN OF A DEVELOPMENTAL MATHEMATICS PROGRAM}

For the state in $2010-2011$, only $16.9 \%$ of students that enrolled in developmental courses complete their gateway course within two years, down from $20.5 \%$ in $2008-2009$ and $18.9 \%$ in 2009-2010. This has significance for the college, the student and the state. If we can help students get through their gateway developmental program and into their college-level course within the first two years, the student has a much better chance of completing a degree or certificate. Now, I will look at the college-level course success rate for the redesigned course students.

\section{College-Level Course Success}

When I ran the summer bridge course in 2009 , I did not evaluate the college-level success rate until I began to write this dissertation. I was astounded to find that 15 out of the 19 students passed their college-level mathematics course. This was $79 \%$ of the students that enrolled. Every student that enrolled in a college-level course passed it. The summer bridge course must be examined as a viable alternative for first-time incoming freshman. It appears that jump-starting the student into the developmental course is a successful pathway. If this option was available to all students, it may alter the face of developmental mathematics.

For the institution and the state, the success for the developmental students in their college-level course is in Table 22 . As one can see, these are very discouraging statistics. Outside of 2008 , the rate was steadily declining and never got above $21 \%$. In every year, the institutional rate was below the dismal state rate. Now I will look at the student results from redesigned course college-level course success as it compares to the overall institutional and state rate. Table 19. College-level Course Success from Developmental

\begin{tabular}{cccccc}
\hline Year & 2005 & 2006 & 2007 & 2008 & 2009 \\
\hline Institutional & $20.1 \%$ & $19.9 \%$ & $17.2 \%$ & $18.8 \%$ & $16 \%$
\end{tabular}


REDESIGN OF A DEVELOPMENTAL MATHEMATICS PROGRAM

State

$20.4 \%$

$21.6 \%$

$20.3 \%$

$20.5 \%$

$18.9 \%$

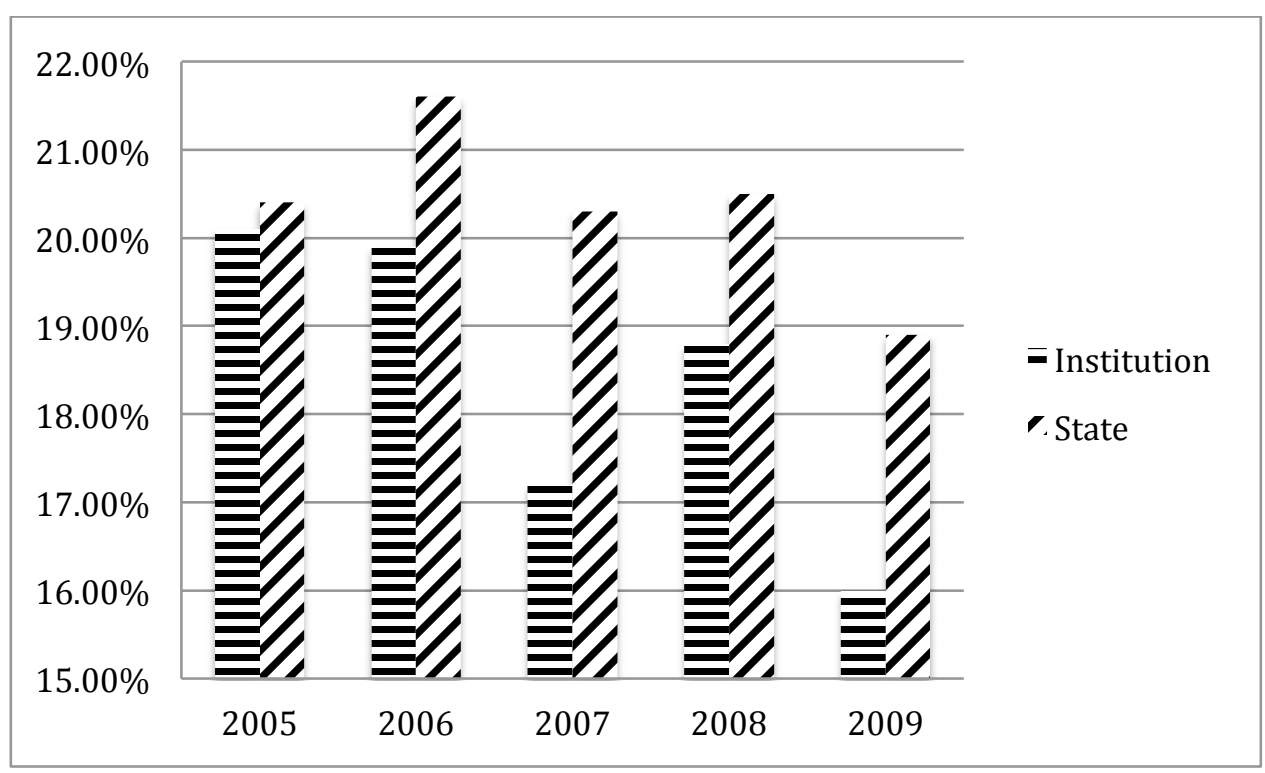

Figure 5. College-level Course Success from Developmental

\section{Institutional and State College-level Success}

The highest pass rate for the years 2008-2011 for college-level courses from developmental mathematics for the state was $15.9 \%$ and $14.1 \%$ for the institution. The lowest was $14.3 \%$ for the state and $8.4 \%$ for the institution. For the redesigned course students, Table 23 shows the college-level course pass rates were 54\%, 27\% (averaging 37\% for 2010) and 58\%. The redesign rates were significantly higher than the institutional and state rate. Out of the 106 students that enrolled in the redesigned courses, only four students that failed the course were able to move forward and eventually pass the college-level course (Figure 6). 
REDESIGN OF A DEVELOPMENTAL MATHEMATICS PROGRAM

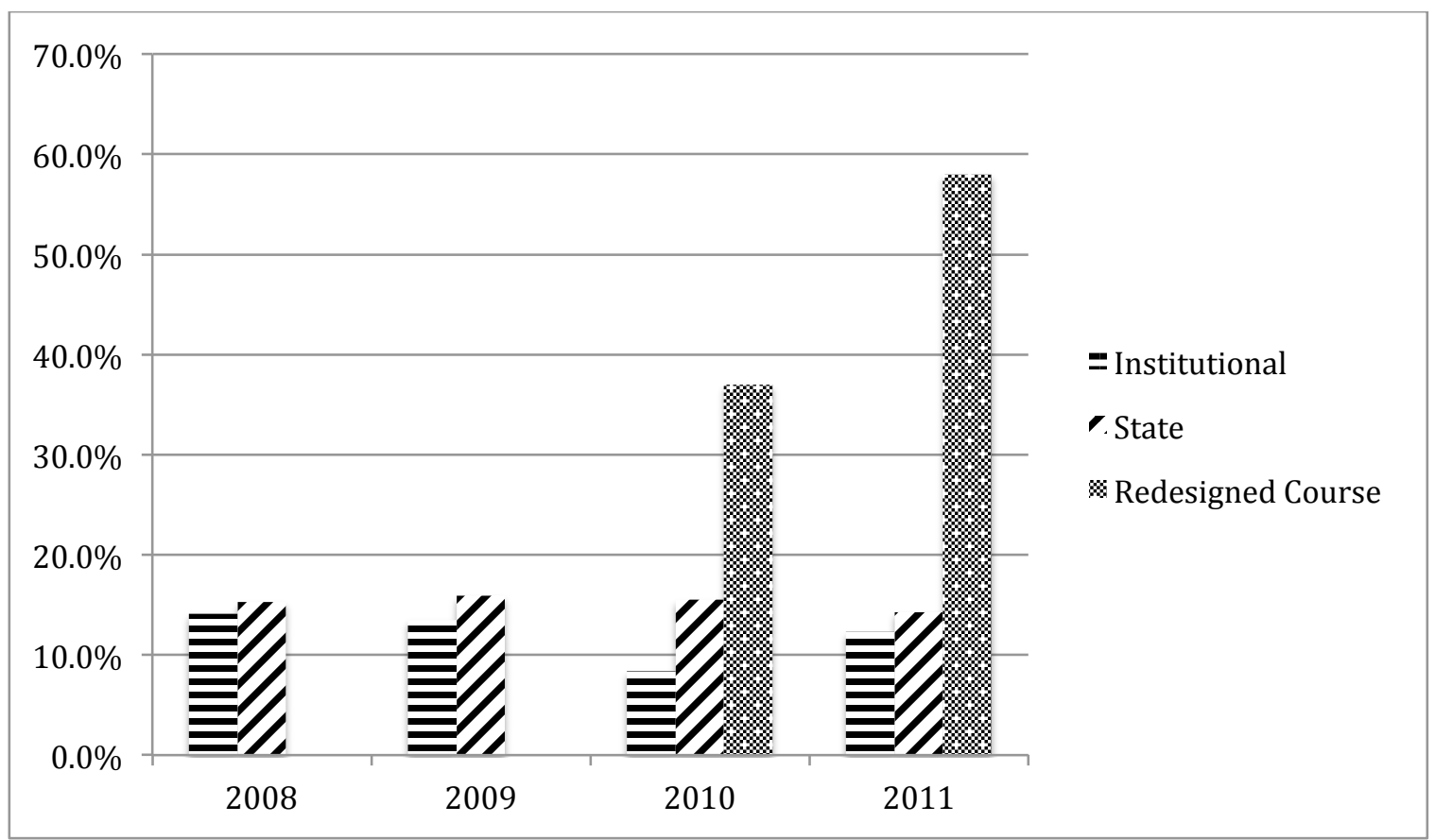

Figure 6. Pass Rates of College-level Course Through Developmental Program

Although the results for the redesigned course students was mixed, these college-level course pass rates showed much more promise than the reported institutional and state rate. It was very evident from the results that if the student failed the redesigned course, the chance of successfully getting to and passing the college-level class was a hurdle in which $91 \%$ of the students could not overcome. The bottom line is that students must experience success in their first developmental course.

One of the biggest hurdles to being successful in a mathematics class is for the student to be placed properly. If the course is too advanced, the student struggles to learn. If the placement is too low, the student becomes bored or misses class due to the fact that they believe the content is below their level and attending class is unnecessary. With the redesigned course, this should not be an issue. If the student is placed too low, they can move quickly to the level where they need the most help. Nobody should be misplaced since the course begins with basic mathematics 


\section{REDESIGN OF A DEVELOPMENTAL MATHEMATICS PROGRAM}

(which includes the four functions for whole numbers, integers, fractions and decimals). Lastly, I will examine the redesigned student's college success.

Table 20. College-level Pass Rates for Students in Redesigned Courses

\begin{tabular}{cccccc}
\hline & $\begin{array}{c}\text { Course } \\
\text { Pass Rate }\end{array}$ & $\begin{array}{c}\text { Subsequent } \\
\text { College- } \\
\text { level Pass }\end{array}$ & $\begin{array}{c}\text { Failed or } \\
\text { Withdrew } \\
\text { Course }\end{array}$ & $\begin{array}{c}\text { Subsequent } \\
\text { College-level } \\
\text { Pass }\end{array}$ & $\begin{array}{c}\text { Overall } \\
\text { College- } \\
\text { level Pass }\end{array}$ \\
\hline Spring 2010 & $48 \%$ & $83 \%$ & $52 \%$ & $8 \%$ & $44 \%$ \\
$\mathrm{n}=25$ & $12 / 25$ & $10 / 12$ & $13 / 25$ & $1 / 13$ & $11 / 25$ \\
\hline Fall 2010 & $61 \%$ & $33 \%$ & $39 \%$ & $10 \%$ & $24 \%$ \\
$\mathrm{n}=54$ & $33 / 54$ & $11 / 33$ & $21 / 54$ & $2 / 21$ & $13 / 54$ \\
\hline Spring 2011 & $65 \%$ & $27 \%$ & $35 \%$ & $13 \%$ & $22 \%$ \\
$\mathrm{n}=23$ & $15 / 23$ & $4 / 15$ & $8 / 23$ & $1 / 8$ & $5 / 23$ \\
\hline Average & $58 \%$ & $50 \%$ & $43 \%$ & $4 \%$ & $30 \%$ \\
\hline
\end{tabular}

\section{Degree or Transfer Success}

As previously stated, for students that placed in the lowest level class, the four-year graduation rate was $5.56 \%$. For students in the second and highest level, the rate was $13.9 \%$ and $24.1 \%$ respectively. In table 25 , I report the percentage of students that graduated, or had the GPA to transfer and stopped coming to the host institution. I do not have the ability to get the data to determine if students graduated or transferred to another institution. This rate should be equivalent or near equivalent since the institution includes these students in their graduation rate.

The course, program, college-level course pass rates and the graduation/transfer rates were much higher than the college or state rates. In my opinion, although they were higher, they were not good enough to claim success. As stated earlier, the road is long and difficult for the 
student that places into developmental mathematics. Next, I will present an analysis and synthesize my results for a clearer picture of the results.

Table 21. Graduation or GPA to Transfer Rates for Students in Redesigned Courses

\begin{tabular}{lccccc}
\hline & $\begin{array}{c}\text { Course } \\
\text { Pass Rate }\end{array}$ & $\begin{array}{c}\text { Subsequent } \\
\text { Graduate or } \\
\text { Transfer GPA }\end{array}$ & $\begin{array}{c}\text { Failed or } \\
\text { Withdrew } \\
\text { Course }\end{array}$ & $\begin{array}{c}\text { Subsequent } \\
\text { Graduate or } \\
\text { Transfer GPA }\end{array}$ & $\begin{array}{c}\text { Overall } \\
\text { Graduation/GPA } \\
\text { Rate }\end{array}$ \\
\hline Spring 2010 & $48 \%$ & $75 \%$ & $52 \%$ & $8 \%$ & $40 \%$ \\
$\mathrm{n}=25$ & $12 / 25$ & $9 / 12$ & $13 / 25$ & $1 / 13$ & $10 / 25$ \\
Fall 2010 & $61 \%$ & $52 \%$ & $39 \%$ & $14 \%$ & $37 \%$ \\
$\mathrm{n}=54$ & $33 / 54$ & $17 / 33$ & $21 / 54$ & $3 / 21$ & $20 / 54$ \\
Spring 2011 & $65 \%$ & $27 \%$ & $35 \%$ & $11 \%$ & $35 \%$ \\
$\mathrm{n}$ & $15 / 23$ & $5 / 15$ & $8 / 23$ & $3 / 8$ & $37 \%$ \\
\hline Average & $57 \%$ & $61 \%$ & $42 \%$ & $11 \%$ & 32 \\
\hline
\end{tabular}




\section{Chapter 5: Analysis and Synthesis}

\section{Introduction}

I presented my findings in two parts. The first part was to answer the question as to how to transform a developmental program into one that engages students and increases student success. As a reminder, the first research question was how did a rural community college transform the developmental mathematics program from a three-course, lecture-based format to a one-course, outcome-based, computer-mediated design? The conclusions form the connection between those answers and the problem driving the research and constitute the contribution of the study to the body of knowledge (Ellis \& Levy, 2010).

I will begin with a discussion about the developmental mathematics program transformation and lessons learned from the transformation and integrate the analysis of the results as they pertain to the remaining research questions and the results of the transformation.

\section{Key components to transformation}

Several factors are critical to implementing a change. Although I did not fully have the key components, I worked with what I did have. The program still struggles due to the fact that several of these components are partially missing. Safran and Visher (2010) recommended funding full time faculty to evaluate their curriculum, placement policies, and institutional practices, as they are critical to transforming the developmental mathematics program and increasing student success. The heavy reliance on adjunct faculty, the lack of funding and continual policy changes at the state level are factors that continue to hinder the college's ability to get a solid program established. However, a solid foundation was established and the college will need to build on that with the resources available to them. 


\section{REDESIGN OF A DEVELOPMENTAL MATHEMATICS PROGRAM}

Administrative support. Developmental mathematics is foundational to most college majors. It is the pathway to success and degree completion. Every program that requires a mathematics course must be vested in the success of the program. Many times, it is the mathematics that keeps students from progressing toward a program of study. Therefore, every chair, dean, provost and president should be cognizant of the issues that keep students from progressing in a developmental mathematics program. If the administrators that oversee the developmental mathematics program are unwilling to make significant transformational changes when success is eluding their students, an administrative change is warranted. Although the faculty may be willing to change, it will not be successful without administrative support.

Support was absent in this case. When I reviewed the email exchanges, I realized that the resistance to change was greater than I remembered. After I left the institution, I discovered that the department was given $\$ 30,000$ to build a computer lab to propagate the transformation. Unfortunately, the dean returned the money and it was reallocated to another program. The departmental faculty was told the lab was not funded. Therefore one must be willing to look higher up for support. I was able to get the attention of the provost and president and made a case for significant changes. This is an unpopular pathway and suggests garnering the support of the chair and dean. Sadly politics and personalities inhibited progress at this institution. Every institution will face opposition, but must find ways to overcome it. One must be willing to suffer political consequences to help students reap the rewards. Ironically, the president suggested that the dean retire when the transformational change passed through faculty senate.

Resources. Support comes in many forms. I needed funding to repurpose rooms and transform them into labs. I had to rearrange schedules so I could use the labs during open times. The registrar met with me several times to work out the details as to how to get the students the 


\section{REDESIGN OF A DEVELOPMENTAL MATHEMATICS PROGRAM}

proper credits on their transcripts. I had to consult with the administrators in financial aid had to ensure students' financial aid would not be affected. The number of people involved in each of these activities made it difficult to respond to changes in a timely manner. One person can impede the process. Although I had some unwilling participants and financial support struggles, I was willing to explore various avenues. Persistence, flexibility and the willingness to change were key factors to the implementation of significant changes.

Program structure. The college began with the three 3-credit hour courses with 84 outcomes and moved to the nine 1-credit hour courses. We streamlined the outcomes into nine broad outcomes. The rationale was that students could move through as many or as few as they were able to handle per semester and there were fewer hurdles to overcome. We knew we needed to give students some control over their pace and this was the solution.

The first semester that the new structure ran, students were told to register for a minimum of three credit hours per semester. However, this created a great deal of confusion for students and advisors. They were unsure what happened if the student completed all nine one-credit courses in one semester. Students needed prerequisite overrides and co-requisites were too complicated to enforce. If a student completed two courses and wanted to enroll in three, four and five, it would entail different prerequisites than a student starting from the beginning that needed to register for courses one, two and three. Therefore, most students needed overrides. Because each course was a prerequisite for the previous one, students could not enroll in more than one course a semester without the override.

After two semesters of struggling with making the square course fit into the round administrative hole, the college moved to one, three-credit hour course where students could earn NC (no credit), CR (credit), PR (making progress) or NCX (no credit failing). Students continue 


\section{REDESIGN OF A DEVELOPMENTAL MATHEMATICS PROGRAM}

in the course and continually enroll in the developmental course until they complete it. They need a CR to move to their college-level course. There are concerns with this system too, such as how do advisors know how much progress a student is making, but they have been unable to come up with a system that addresses all of the issues.

Faculty buy-in. Getting faculty to completely change how they teach and repurposing their role in the classroom was one of the biggest challenges after the program was implemented. It is more difficult to visit each student during every class, check and record their progress and address individual needs. They believed their role would be administrative as opposed to teacher. However, the exact opposite is true. In the redesigned courses, students felt they had a higher, more meaningful level of interaction with me, the instructor. Faculty were told they were required to meet in the lab once or twice a week. Many of them ignored the lab component and continued to lecture in the lab. They had no model to envision how this format could positively impact students and give students the necessary personal attention. The faculty needed to understand that their level of interaction with the student would increase, not decrease. However, how to do this eluded me.

\section{Curriculum components}

In addition to the administrative and faculty support, there were key course and program structural components that increased the chances for student success. They include program and course structure, room amenities, and

Program structure. Students needed to enter and leave the program without penalty. Once a student demonstrated competency of an outcome, they should not have to repeat that outcome. This was the biggest barrier to student success with the program prior to the redesign. Students were trapped in an endless cycle of repeating the same outcomes without moving 


\section{REDESIGN OF A DEVELOPMENTAL MATHEMATICS PROGRAM}

forward. This was the first major change to the program. The faculty and the students were much more receptive to the module structure. Students expressed relief that if they did not finish in one semester, they did not have to start over again. It gave everyone a clearer picture of what content they had learned and what content remained.

Course Structure. The course structure is one of the most important aspects of the redesign. As I saw with my redesign, it was a delicate balancing act between encouraging and discouraging completion. If the students found the amount of work insurmountable, they would drop or stop out. If they did not have enough practice, they struggled to learn the content. I found that the most successful structure was to give them an opportunity to determine their own level of remediation using the computer-mediated model. However, Trenholm (2006) found that using technology is not the panacea. There are infinitely many ways to design a computer-mediated course. Figuring out how to implement it so that it enhances the learning experience is the challenge. I was able to find a combination of strategies that increased student success, but unfortunately did not work well enough for every student to be successful.

Having the students take a test prior to any work initiated the program developed personalized study plan that included the depth necessary for success. Every time a student tested, the study plan would adjust and reassign missed outcomes. This gave the students remediation targeted to their needs, reducing repetition and increasing practice where necessitated. The data showed that this was the most significant aspect of the course structure. This held students accountable for their personal need. In-class proctored testing assured that the study plan was accurately responding to the student deficiencies. An added benefit was students were able to review missed concepts for the final exam, although they had passed the test with a $78 \%$ or better. 


\section{REDESIGN OF A DEVELOPMENTAL MATHEMATICS PROGRAM}

Until the student demonstrated $100 \%$ mastery, the study plan would continue to reassign missed outcomes.

Room amenities that enhance learning. A computer lab is critical to the success of the redesign. In fact, all classes should have every meeting in a lab classroom. When I first ran the course, I attempted to give small mini-lectures weekly. However, the students quickly separated themselves from each other because they individualized the pace. It was a waste of time for students to sit through a lecture when they had already mastered the content or had not progressed to the level of the lecture. Continuously giving students the opportunity to engage in the content is critical was critical to their success.

Finding funds to build the labs can be the biggest challenge. However, if you are able to acquire college and administrative support, it should be an institutional priority. Again, it affects every campus program and is the underpinning of student retention and success.

Instructors need to speak with every student, every day. Charting their progress and identifying struggling students was critical. The students in the class with tables of four were the most successful. The collaborative atmosphere gave the students an added level of support. Peer pressure to attend and peer support became another piece to the success puzzle.

Students needed to feel supported. Faculty and administrators must remember that this is a remediation program. The purpose of the program is to bring the student skills to the college level and prepare them for the next mathematical level. Remediation is to provide equality of opportunity and the goal is to prepare for college-level success, not the passing of a remedial course (Bahr, 2008). The students had communicated that they felt they were locked into a path that they could not escape. The redesigned courses gave the students a path that they controlled. 


\section{Recommendations for future implementation}

I have continued working in developmental mathematics since the redesign and continue to explore more strategies for success. I am making these suggestions based on observations and experiences in my modularized developmental mathematics program.

Test review. One of the most promising practices I have seen and used is to do a test review with each student. When students test, they are required to raise their hand and submit their test work prior to hitting the submit button. The student can then review their test without the paper in front of them. This insures that they do not change any answers on the test. During the next class meeting, the instructor reviews the test with the student to explain their errors and give them credit for typing errors.

The students learn from their mistakes and the one-on-one time with the instructor to ask questions is invaluable. I do not give the student the opportunity to refuse to review. It keeps me, the instructor, in touch with common student errors and gives me the chance to explain to students how to avoid them.

Increase contact time. Although students were able to work outside of class, most do not. Consequently, they lose traction and momentum in a class that meets only two or three days a week. The gap from Thursday to Tuesday is especially long and whether it was a lecture or redesigned course, two days a week over sixteen weeks is not a sufficient for success. The developmental student must stay focused and on task throughout the semester. There are too many gaps in the Tuesday, Thursday or Monday, Wednesday, Friday structure to promote student success.

Ideally, students would meet for class at least 50 minutes a day, five days a week. Unfortunately, this is unpopular with students and faculty. At my current institution, we struck a 


\section{REDESIGN OF A DEVELOPMENTAL MATHEMATICS PROGRAM}

balance of four days a week, Monday through Thursday, 50 minutes a day. Students can test on Fridays, but there is no class. This structure engages the student every weekday.

Lock out. One of the strategies that I started using two semesters ago was to lock students out of all assignments and tests if they miss more than two consecutive days or a total of four days a semester. They must return to class to get unlocked. Although this appears to be counterintuitive to promoting student progress, it has actually dramatically reduced student absences and increased success. Because the class is computer-mediated and self-paced, the students tend to treat it as an online class before they get acquainted with the unique design of the class. I have found that this process makes students very cognizant of the number of absences they have accumulated and are much more conscientious about attending class.

\section{Summary}

The literature review suggested that small incremental changes were not enough to propagate significant increases in student success. However, a plethora of small changes added to the significant transformational change that the literature recommended. The changes initiated with an online class, progressed to a pilot summer bridge course that led to redesigned courses. It culminated with structural changes to the developmental mathematics program and continues to evolve every semester. Enacting a transformational change takes time, commitments from stakeholders and many resources. There will be supporters and detractors, but the mission to provide opportunity for all to succeed is larger than the special interests of a few.

\section{Significance of the Research for Developmental Mathematics Programs}

The art of teaching and learning mathematics is a well-known challenge. I hear people proudly proclaim that they cannot do mathematics, yet they would shudder to admit that they could not read. It is widely acceptable to be mathematics deficient. Just as one cannot learn to 


\section{REDESIGN OF A DEVELOPMENTAL MATHEMATICS PROGRAM}

shoot a basketball by watching an instructor shoot, most people cannot learn mathematics by watching an instructor do it. Mathematics is a skill that is developed by practicing it. Students that end up in developmental mathematics courses are the ones that never fully understood it and did not practice the skill well enough to become proficient. They are the ones for which lecture was not conducive to their learning. Active learning is the key to build mathematical skills.

Bahr (2008) found that remediation has the capacity to fully resolve the economic disadvantage of mathematics skill deficiencies. Unfortunately, he also found that 75.4 percent of remedial mathematics students do not remediate successfully. The challenges for colleges are getting the student to engage in the content, designing a program that encourages and not discourages, and getting the student through to their college-level course quickly and effectively providing the skills for success at the college level.

This dissertation chronicled the difficulties faced and achievements realized by a small rural community college. Every college and university faces the same challenge with different parameters. This research has implications for administrators seeking to revise their programs to increase success and retention and faculty faced with changing roles. Although there is a plethora of suggestions for improving a mathematics remediation program, a holistic look at the redesign process was absent. The decision to remediate was a result of poor institutional pass rates and the suggestion that we were doing it all wrong based on the current literature at that time. Faculty and administrators should anticipate some of the challenges that I faced to redesign the developmental program.

The most disappointing result of the transformational change was there were still a significant number of students that did not achieve success. And the most profound result was how small the chance for success was for the student that failed that first course. This is a wake- 


\section{REDESIGN OF A DEVELOPMENTAL MATHEMATICS PROGRAM}

up call to all developmental educators. They must focus on helping the student achieve success in their first developmental math course. Getting this student to pass could have the greatest impact on an institution's first year student retention rate. This is the most vulnerable population and the least able to afford to not pass.

The computer-mediated modular program design gave the instructor and student a very high level of contact. The college must capitalize on this high level of contact to connect with the student and develop a trusting, supportive relationship. Additionally, this modularized design fermented relationships among classmates that added another level of support. This positive outcome was unanticipated and welcomed.

\section{Lessons Learned}

Designing a one-size-fits-all developmental program is not possible. Each institution faces unique challenges that cannot be addressed with a prescription for success. Redesigning a failing program into a successful one entails having someone lead the charge to coerce and gather support. The time commitment was unforeseen. Community college faculty already face a five to six course load per semester. Finding time to meet with constituents to solve problems and analyze results can undermine the desire and the possibility of a transformational change. I suggest one or two course releases to focus on the change and give the leader time to make informed decisions.

The key constituents involved in the process were the college president, provost, registrar, dean, chair, faculty and facilities and planning personnel. Coordinating and meeting with all can be difficult to arrange, especially adjunct faculty. It is suggested that the leader of the redesign have data to support requests and decisions, several options to consider, and the willingness to 


\section{REDESIGN OF A DEVELOPMENTAL MATHEMATICS PROGRAM}

compromise. Everyone's time is limited and being unprepared can undermine and delay the process.

In the end, there were many rewards. For the first time, I truly appreciated my students and the struggles that they faced. I found that the one-on-one contact with the students made the class more enjoyable for my students and me. I believe that this alone could significantly increase student success. I did not foresee this consequence and interestingly, this was not addressed in the literature.

It is critically important to make continuous minor adjustments to the course structure. Finding the correct balance, setting due dates, pre-requisite assignments, and testing requirements is not a one-time process. It may be necessary to adjust these settings for each class, program or college, depending on the parameters and available institutional resources. No two colleges have the same course structure, and most likely will require different settings to match.

Transformational changes are challenging, but with proper leadership, goals and collegial support, they can be accomplished. It was not a one-and-done process. Continuous assessment of student results and adjustments to the program was imperative to finding the best formula for success. This blueprint is not exclusive to developmental mathematics, but is transferable to all college programs.

\section{Research Limitations}

This dissertation utilized a Type 1 design and development research method. Because this type of research is context specific, there are situational conditions and conclusions that may not be generalizable (Richey, Klein \& Nelson, 2004). The conclusions were based on situational decisions and must be considered when attempting to generalize to a wider audience or larger 


\section{REDESIGN OF A DEVELOPMENTAL MATHEMATICS PROGRAM}

institution. The student and faculty population were from a rural community college and are homogenous. Limitations with respect to the data, analysis, and validity are outlined below.

Data management. Although I used the same data sources for each course offering, the offerings ended prior to the decision to use the data for this dissertation. Therefore, I could not use all of the course data that would have provided a clearer picture of the redesign. For future research, I would keep a detailed journal of the issues and decisions based on these issues.

Future re-designers will want to keep detailed records of issues that arose during redesign and document direct responses to those issues. I used MyMath Lab to offer the courses, so there was enough documentation data to recreate the changes between course offerings.

Data analysis. Care was taken to use only the data that were consistent across cases. This provided the consistency necessary to make comparisons for the changes to each course offering. Although data was not detailed enough to provide all of the necessary information, emails were analyzed from the students that sent questions so I could determine issues that they faced. These emails were student initiated and not consistent from course to course. However, they were used to fill in missing information. One of the hindrances to design and developmental research methodology is the changing environment for which the data is derived. I did face this issue and used historical documents to fill in voids that existed.

Validity. Researcher bias was a limitation that would most affect the reported results because I was the instructor of record for each course offering. To reduce this bias for students that passed the course, they were followed into their college-level course to determine success. Additionally, if the student did not achieve success in the redesigned course, the student was followed to see if they were able to pass another instructor's course, the developmental program and the college-level course. I was not the instructor for any of the students' college-level course. 


\section{REDESIGN OF A DEVELOPMENTAL MATHEMATICS PROGRAM}

Although I could not determine if the students in the redesigned courses transferred to another institution, I was able to determine if the student received a degree or certificate or had the GPA eligible to transfer. I considered all of these as successes.

\section{Suggestions for Further Research}

The small number of course offerings that were redesigned limited the amount of data that could be collected. However, it did allow for consistency and control of the changes that were made. The redesign culminated with a curriculum proposal to streamline the courses into nine, one-credit hour courses. Since that time, the structure has been altered again. It is now one three-credit hour course. Students continue to enroll in the course until they receive a passing grade. Students can get a NC, CR or NCX, which indicates students are not making adequate progress. The students continue in the course where they left off. This model appears to be working form the registrar's perspective. However, I am unaware of any follow-up analysis of student achievement in the course, program and subsequent college-level course.

However, the latest developmental mathematics program pass rates that were reported to the HEPC show that there was a significant increase in the overall institutional developmental mathematics pass rate from 2011 to 2012 from $33.4 \%$ to $48.6 \%$. This was a $15.2 \%$ increase. This is the latest year for which results were reported and is encouraging. I will take it as an indicator that the redesign is working and look forward to the trend continuing in a positive direction.

The college must revisit and analyze pass rates in the courses, program and subsequent college-level course to determine not if, but what changes should be made. The process did not end with the redesign and curriculum proposal but was only the beginning. Unfortunately, if the college does not learn that results must be continuously analyzed, they will revert back to the time when pass rates were falling and nobody knew why. The dean or chair must keep 


\section{REDESIGN OF A DEVELOPMENTAL MATHEMATICS PROGRAM}

departmental records of changes in policy and course structure and an analysis of each success or failure. This would reduce repeating unsuccessful strategies.

Lastly, for students that are in danger of not passing, investigate strategies to retain and support them. As the results showed, the chances that these students acquire a degree or certificate are extremely low. It would be helpful to develop a profile of these at-risk students and target them with more strategies in an attempt to reduce the costs associated with failure. Failures are bad for the student, the college and the community. As stated in the very beginning, as a person's educational level increases, so does their income potential. Higher education math educators have a responsibility to make every effort to bring understanding to all students that wish to increase their educational and income potential level, or at the minimum, commit to finding out how to accomplish it. 


\section{REDESIGN OF A DEVELOPMENTAL MATHEMATICS PROGRAM}

\section{References}

ACT. (2008). ACT's college readiness system: Meeting the challenge of a changing world. Retrieved from http://www.act.org/research/policymakers/pdf/crs.pdf

American Federation of Teachers (2010). A national survey of part-time/adjunct faculty. American Academic, 2, 3-4.

Asera, R. (2011). Developments: Reflections on developmental mathematics - Building new pathways. Journal of Developmental Education, 34(3), 28-31

Attewell, P., Lavin, D., Domina, T. \& Levey, T. (2006). New evidence on college remediation. The Journal of Higher Education, 77, 886-924.

Bahr, P. (2008). Does mathematics remediation work? A comparative analysis of academic attainment among community college students. Research in Higher Education, 49(5), 420-450.

Bailey, T. (2009). Challenge and opportunity: Rethinking the role and function of developmental education in community college. New Directions for Community Colleges, 2009: 11-30. doi: $10.1002 /$ cc. 352

Bailey, T., \& Cho, S. (2010). Developmental education in community colleges. Community College Research Center at Columbia University. http://dx.doi.org/10.7916/D8JS9NHX

Bettinger, E.P., \& Long, B.T. (2005). Addressing the needs of under-prepared students in higher education: Does college remediation work? (Working Paper No. 11325). Retrieved from National Bureau of Economic Research website: http://www.nber.org/papers/w11325.pdf?new_window=1

Boylan, H. R. (2011). Improving success in developmental mathematics: An interview with Paul Nolting. Journal of Developmental Education, 34(3), 20-27. 


\section{REDESIGN OF A DEVELOPMENTAL MATHEMATICS PROGRAM}

Calcagno, J.C. \& Long, B.T. (2008). The impact of postsecondary remediation using a regression discontinuity approach: Addressing endogenous sorting and noncompliance (July 2008). National Bureau of Economic Research Working Paper No. W14194. Available at SSRN: http://ssrn.com/abstract=1179864

Complete College America. (2012). Remediation: Higher education's bridge to nowhere. Retrieved from http://completecollege.org/docs/CCA-Remediation-final.pdf

Charles A. Dana Center. (2012, December). Core principles for transforming remedial education: A joint statement. Retrieved from http://www.jff.org/publications/core-principles-transformingremedial-education-joint-statement

Collins, M. L. (2010). Bridging the evidence gap in developmental education. Journal of Developmental Education, 34(1), 2-8, 25. Retrieved from http://iws.collin.edu/dweasenforth/Calderwood/JDE\%2034-1.pdf

Complete College America (2014). Game changer state data: West Virginia. Indianapolis, IN. Retrieved from http://completecollege.org/state-data-loader/?state=West $\% 20$ Virginia

Community College Research Center. (2014) Our research. Retrieved from http://ccrc.tc.columbia.edu/our-research.html

Education Sector. (2013). Higher education accountability report: West Virginia report card. Washington, DC. Retrieved from http://www.educationsector.org/usr_doc/West_Virginia.pdf

Ellis, T. J., \& Levy, Y. (2010, June). A guide for novice researchers: Design and development research methods. In Proceedings of Informing Science \& IT Education Conference, InSITE.

Epper, R.M. \& Baker, E. D. (2009). Technology solutions for developmental math: An overview of current and emerging practices. 


\section{REDESIGN OF A DEVELOPMENTAL MATHEMATICS PROGRAM}

http://www.gatesfoundation.org/learning/Documents/technology-solutions-for-developmentalmath-jan-2009.pdf

Golfin, P., Jordan, W., Hull, D., \& Ruffin, M. (2005). Strengthening mathematics skills at the postsecondary level: Literature review and analysis. US Department of Education, (ERIC Document Reproduction Service No. ED494241)

Grigg, W., Donahue, P., \& Dion, G. (2007). The Nation's report card: 12th-grade reading and mathematics 2005 (NCES 2007-468). U.S. Department of Education, National Center for Education Statistics. Washington, D.C.: U.S. Government Printing Office

Habley, W. R., \& McClanahan, R. (2004). What works in student retention? Two-year public colleges. Iowa City, IA: ACT, Inc. (ERIC Document Reproduction Service No. ED515396)

Hord, S. M. (1997). Professional learning communities: Communities of continuous inquiry and improvement. Retrieved September 13, 2013, from http://www.sedl.org/change/issues/issues61.html (ERIC Document Reproduction Service No. ED410659)

Johnson, J. L. (2000). Teaching and learning mathematics: Using research to shift from the "yesterday" mind to the" tomorrow" mind. Office of Superintendent of Public Instruction. Retrieved from http://www.k12.wa.us/research/pubdocs/pdf/mathbook.pdf

Klein, B., \& Wright, L. M. (2009). Making prealgebra meaningful: It starts with faculty inquiry. New Directions For Community Colleges, (2009),67-77. doi: 10.1002/cc.356

McCabe, R. H., \& Day, P. R. (1998). Developmental Education: A Twenty-First Century Social and Economic Imperative. http://files.eric.ed.gov/fulltext/ED421176.pdf

Mulvey, M. (2008). Under-prepared students - A continuing challenge for higher education. Research \& Teaching in Developmental Education, 24(2). 


\section{REDESIGN OF A DEVELOPMENTAL MATHEMATICS PROGRAM}

National Center for Education Statistics (NCES). (2012) Educational attainment of persons 25+ by state: 2006-2008. www.nces.ed.gov

National Center for Academic Transformation (NCAT). (2005) Redesigning developmental math. http://www.thencat.org/Mathematics/CTE/CTE_Lessons.html

National Center for Academic Transformation (NCAT). (2005) Redesigning developmental math. http://www.thencat.org/PlanRes/R2R_PrinCR.htm

National Center for Postsecondary Research (NCPR). (2012) Welcome.

http://postsecondaryresearch.org/index.html?Id=Home\&Info=Welcome

National Mathematics Advisory Council. (2008). Foundations for Success: The Final Report of the National Mathematics Advisory Panel. Washington, D.C.: U.S. Department of Education. Retrieved September 8, 2014, from

http://www.ed.gov/about/bdscomm/list/mathpanel/report/final-report.pdf

Panitz, T. (2007). Sabbatical report. Retrieved from http://tpanitz.jimdo.com/retention-ideas-for-demath/

Pierpont Community and Technical College (PCTC). (2012). Retrieved July 30, 2014, from http://nces.ed.gov/collegenavigator/?id=443492\#admsns

Robinson, B. L., \& Moore, A. H. (2006). Chapter 42. Virginia Tech: Math Emporium. Retrieved February 2014, from Educause.edu: https://net.educause.edu/ir/library/pdf/P7102cs29.pdf

Richey, R. C., \& Klein, J. D. (2005). Developmental research methods: Creating knowledge from instructional design and development practice. Journal of Computing in Higher Education, 16(2), 23-38. doi: 10.1007/BF02961473 


\section{REDESIGN OF A DEVELOPMENTAL MATHEMATICS PROGRAM}

Richey, R. C., Klein, J. D., \& Nelson, W. A. (2004). Developmental research: Studies of instructional design and development. Handbook of research on educational communications and technology, 2, 1099-1130

MDRC, Inc. (2011). Turning the tide: Five years of achieving the dream in community colleges. Community College Research Center.

Safran, S., \& Visher, M. G. (2010). Case studies of three community colleges: The policy and practice of assessing and placing students in developmental education courses. National Center for Postsecondary Research. Retrieved July 18, 2013, from http://www.mdrc.org/sites/default/files/full_54.pdf

Trends in international mathematics and science study (TIMSS) - TIMSS 2011 results. (2011). TIMSS 2011 Results. Retrieved from http://nces.ed.gov/timss/results 11.asp

Trenholm, S. (2006). A study on the efficacy of computer-mediated developmental math instruction for traditional community college students. Research \& Teaching in Developmental Education, $22(2), 51$.

Twigg, C. A. (2008). Developmental courses: An oxymoron? NCAT Developmental Courses: An Oxymoron. Retrieved August 30, 2013, from http://www.thencat.org/NCATPlans/Dev\%20Courses\%20An\%20Oxymoron.htm

Twigg, C.A. (2005) Improving learning and reducing costs: Program outcomes from Changing the Equation. Retrieved August 2, 2014 from http://www.thencat.org/Mathematics/CTE/CTE_Lessons.html

Visher, M. G., Weiss, M. J., Weissman, E., Rudd, T., Wathington, H. D., Teres, J., \& Fong, K. (2012). The effects of learning communities for students in developmental education: A synthesis of findings from six community colleges. MDRC. 


\section{REDESIGN OF A DEVELOPMENTAL MATHEMATICS PROGRAM}

United States. Executive Office of the President. (2014). Increasing college opportunity for low-income students: Promising models and a call to action. Retrieved from https://www.whitehouse.gov/sites/default/files/docs/white_house_report_on_increasing_college_ opportunity_for_low-income_students.pdf

West Virginia Center on Budget \& Policy. (2011) Poverty remains high as effects of recession linger in West Virginia. http://www.wvpolicy.org/downloads/news_releases/NR092211.pdf

West Virginia Education Policy Commission. (2010) Series 21. Retrieved from Freshman Assessment and Placement Standards: https://www.wvhepc.org/resources/Series_21_(830-10).pdf

West Virginia Higher Education Policy Commission and Community and Technical College System. (2013). Report Card Retrieved from http://www.wvhepc.com/wp-content/uploads/2014/01/2013Report-card-LR.pdf

Zhu, Q., \& Polianskaia, G. (2007). A comparison of traditional lecture and computer-mediated instruction in developmental mathematics. Research \& Teaching in Developmental Education, 24(1), 63-82. Retrieved from ProQuest Education Journals. (Document ID: 1396747491).

Zachry, E. M., \& Schneider, E. (2008). Promising instructional reforms in developmental education. MDRC. Retrieved from http://www.mdrc.org/publication/promising-instructional-reformsdevelopmental-education 


\section{Appendix A: Teaching Objectives for Basic Mathematics}

1. Solve word problems using addition, subtraction, multiplication, and division of fractions;

2. Understand the meaning of decimals and solve word problems using addition, subtraction, multiplication, and division of decimals;

3. Connect fractions, decimals, and percents;

4. Perform estimations and rounding operations;

5. Apply order of operations to evaluate numerical expressions;

6. Understand the meaning of "variable" and apply it to evaluating basic algebraic expressions and solving very elementary equations;

7. Solve word problems by writing ratios and solving basic proportions;

8. Solve word problems using addition, subtraction, multiplication, and division of signed numbers;

9. Find the mean, median, and mode of a set of data; 


\section{Appendix B: Teaching Objectives for Pre-algebra}

(*designates a crucial goal).

1. *Apply order of operations

2. Use exponential notation

3. Evaluate algebraic expressions given values for the variables

4. Translate word statements to expressions and equations.

5. Distinguish between expressions and equations

6. *Add signed numbers

7. *Subtract signed numbers

8. *Multiply and divide signed numbers

9. Set up a ratio

10. Use algebraic properties

11. Simplify algebraic expressions

12. *Solve one-step equations

13. Solve equations using the distributive property.

14. *Solve multi-step equations

15. Solve linear equations with fractional coefficients

16. *Use the six steps for solving applied problems

17. Solve vertical, complementary, and supplementary angle problems

18. Use a formula to solve an applied problem

19. Solve literal equations

20. Solve applied proportions

21. Solve one step percent problems

22. Solve multi-step percent problems 
23. Graph linear inequalities with one variable

24. Solve addition inequalities with one variable

25. Solve multi-step inequalities with one variable

26. Graph inequalities using interval notation.

27. Use product and quotient rules for exponents

28. Use exponential power rule

29. Use zero exponent rule

30. Use negative exponents

31. Use rules of exponents to simplify expressions (multi-steps)

32. Use scientific notation rules

33. *Add polynomials

34. *Subtract polynomials

35. *Multiply binomials

36. Multiply polynomials

37. *Multiply conjugates

38. Multiply powers of binomials

39. Divide polynomials by monomials

40. State the ordered pair if a point has been plotted

41. Interpret graphs

42. *Plot ordered pairs

43. *Graph linear equations 


\section{Appendix C: Teaching Objectives for Elementary Algebra}

1. Factor common factors

2. Factor by grouping

3. Factor trinomials

4. Factor difference of two squares

5. Factor perfect square trinomials

6. Solve quadratic equations by factoring

7. Solve applied quadratic equations

8. Reduce rational expressions

9. Multiply and divide rational expressions

10. Find the least common denominator for rational expressions

11. Add or subtract rational expressions with like denominators or with monomial denominators

12. Solve rational equations in which the rational expressions have monomial denominators

13. Solve direct and indirect variation problems

14. Solve problems using proportionality

15. Graph data

16. Graph linear equations

17. Find the slope of a line

18. Find the equation of a line in slope-intercept form

19. Interpret graphs to find slope and/or the equation of a line

20. Use functional notations

21. Find the solution of a system of equations by graphing

22. Find the solution of a system of equations by using the substitution method 
23. Find the solution of a system of equations by using the addition method

24. Solve system-of-equations application problems

25. Use the Pythagorean Theorem

26. Use the radical product rule and the radical quotient rule

27. Add and subtract radical expressions

28. Simplify radical expressions

29. Solve radical equations

30. Use the square root property of equality to solve quadratic equations

31. Use the quadratic formula to solve quadratic equations 


\section{Appendix D: Learning Outcomes for Intermediate Algebra}

Students who finish Intermediate Algebra (even with a minimal mastery level of $60 \%$ ) will be able to:

1. Identify the important subsets of the real numbers (counting, integer, rational, and irrational) using roster form and set-builder notation.

2. Use roster form, set-builder notation, and Venn Diagrams to describe the union and intersection of sets

3. Use the rules of exponents (including zero, negative and rational exponents) to simplify expressions

4. Convert between scientific notation and standard notation

5. Use scientific notation in problem solving

6. Solve multi-step linear equations including those that contain fractions

7. Identify conditional equations, contradictions, and identities

8. Solve for a variable in an equation or a formula

9. Use formulas to do application problems

10. Solve word problems using a variable to represent one quantity and an algebraic expression (in terms of the variable) to represent a second and /or third quantity

11. Solve word problems that involve mixtures, percent, distance, and interest

12. Solve multi-step linear inequalities, graph the result, and give the result in interval notation.

13. Understand the geometric interpretation of absolute value

14. Solve equations of the form $|x|=a, a>0$

15. Solve inequalities of the form $|x|<a, a>0$

16. Solve inequalities of the form $|\mathrm{x}|>\mathrm{a}, \mathrm{a}>0$ 
17. Solve inequalities of the form $|\mathrm{x}|>$ a or $|\mathrm{x}|<\mathrm{a}, \mathrm{a}<0$

18. Solve inequalities of the form $|\mathrm{x}|>0$ or $|\mathrm{x}|<0$

19. Solve equations of the form $|\mathrm{x}|=|\mathrm{y}|$

20. Graph (with or without using a graphing calculator) linear equation in two variables, quadratic equations in two variables, and equations of absolute values.

21. Determine the slope of a line by using the slope formula and by putting the equation in slopeintercept form.

22. Identify standard form, slope-intercept form, and point-slope form of the equation of a line and be able to convert from one form to another

23. Understand the definition of function, function notation, and applications of functions

24. Understand the definition of the domain and the range of a function and be able to state the domain of polynomial functions and rational functions

25. Distinguish between a relation that is a function and a relation that is not a function and be able to use the vertical line test

26. Graph linear inequalities in two variables.

27. Solve systems of equations in two variables by graphing, by using the substitution method, by using the addition method, and by using determinants and Cramer's Rule

28. Tell if a system of linear equations in two variables is consistent, inconsistent, or dependent.

29. Add, subtract, multiply, and divide polynomials

30. Divide a polynomial by a binomial using synthetic division

31. Factor polynomials completely including trinomials and sum/difference of cubes

32. Solve quadratic equations by factoring, completing the square, square root property and the quadratic formula 
33. Use factoring to find the $\mathrm{x}$ - intercepts of quadratic functions

34. Recognize a complex number and find powers of $i$.

35. Add, subtract, multiply, and divide complex numbers

36. Add, subtract, multiply, and divide rational expressions

37. Simplify complex fractions

38. Solve rational equations and application problems involving rational equations including rate of work problems

39. Evaluate radical expressions having odd indices and radical expressions having even indices

40. Evaluate radical expressions using absolute value

41. Convert between radical expressions an exponential expressions

42. Simplify radical expressions

43. Add, subtract, multiply, and divide radical expressions.

44. Solve equations containing radicals 
REDESIGN OF A DEVELOPMENTAL MATHEMATICS PROGRAM

Appendix E :NCAT Pre-Post Redesign Pass Rates NCAT Pre-Post Redesign Pass Rates

\begin{tabular}{|c|c|c|c|c|}
\hline Institution & Course & Traditional & Redesign & Increase \\
\hline Bowling Green Technical College & PA & $60 \%$ & $65 \%$ & $5 \%$ \\
\hline Cleveland State Community College & EA & $50 \%$ & $69 \%$ & $19 \%$ \\
\hline Cochise College & EA & $54 \%$ & $71 \%$ & $17 \%$ \\
\hline Cossatot Community College & IA & $56 \%$ & $76 \%$ & $20 \%$ \\
\hline Guilford Technical Community College & IA & $55 \%$ & $56 \%$ & $1 \%$ \\
\hline Jackson State Community College & EA & $41 \%$ & $59 \%$ & $18 \%$ \\
\hline Leeward Community College & PA & $75 \%$ & $80 \%$ & $5 \%$ \\
\hline Lurleen B. Wallace Community College & EA & $53 \%$ & $65 \%$ & $12 \%$ \\
\hline Manchester Community College & PA & $61 \%$ & $66 \%$ & $5 \%$ \\
\hline Northwest-Shoals Community College & EA & $52 \%$ & $64 \%$ & $12 \%$ \\
\hline Oakton Community College & EA & $53 \%$ & $59 \%$ & $6 \%$ \\
\hline Pearl River Community College & $\mathrm{BA}$ & $38 \%$ & $51 \%$ & $13 \%$ \\
\hline Robeson Community College & IA & $48 \%$ & $65 \%$ & $17 \%$ \\
\hline Somerset Community College & PA & $57 \%$ & $81 \%$ & $24 \%$ \\
\hline Wayne State University & $\mathrm{BA}$ & $36 \%$ & $43 \%$ & $7 \%$ \\
\hline West Virginia University at Parkersburg & EA & $46 \%$ & $55 \%$ & $9 \%$ \\
\hline Average & & $52 \%$ & $64 \%$ & \\
\hline
\end{tabular}


REDESIGN OF A DEVELOPMENTAL MATHEMATICS PROGRAM

Appendix F: Example of Multimedia Aids 


\section{REDESIGN OF A DEVELOPMENTAL MATHEMATICS PROGRAM}

\section{Chapter 6. Factoring Polynomials}

Animation

(e. Chapter 6 Vocabulary Check Activity

6. Factor out a GCF before factoring a trinomial of the form $a x^{2}+b x+$

(e.) Factor perfect square trinomials

6. Factor trinomials of the form $a x^{2}+b x+c$

e. Factor polynomials completely

Multimedia Textbook

6.1 The Greatest Common Factor and Factoring by Grouping

1 6.2 Factoring Trinomials of the Form $x^{2}+b x+c$

E 6.3 Factoring Trinomials of the Form $x^{2}+b x+c$ and Perfect Square Trinomials

6.4 Factoring Trinomials of the Form $x^{2}+b x+c$ by Grouping

6.5 Factoring Binomials

6.6 Solving Quadratic Equations by Factoring

Chapter Test Prep Videos

197 Chapter 6: Chapter Test Prep Videos

Section Video Lectures

I] 6.1 The Greatest Common Factor and Factoring by Grouping

用 $6.1 \mathrm{Obj} 1$ Find the greatest common factor of a list of integers

目 $6.1 \mathrm{Obj} 2$ Find the greatest common factor of a list of terms

用 $6.1 \mathrm{obj} 3$ Factor out the greatest common factor from a polynomial

目 6.1 Obj 4 Factor a polynomial by grouping

用 6.1 Interactive Concept Check

目 6.2 Factoring Trinomials of the Form $\mathrm{x}^{2}+\mathrm{bx}+\mathrm{c}$

用 6.2 obj 1 Factor trinomials of the form $x^{2}+b x+c$

目 6.2 obj 2 Factor out the greatest common factor and then factor a trinomial of the form $\mathrm{x}^{\underline{2}}+\underline{b x}+\mathrm{c}$

用 6.2 Interactive Concept Check

目 6.3 Factoring Trinomials of the Form $a x^{2}+b x+c$ and Perfect Square Trinomials

用 6.3 obj 1 Factor trinomials of the form $a x^{2}+b x+c$, where $a$ ? 1

用 6.3 Obj 2 Factor out a GCF before factoring a trinomial of the form $a x^{2}+b x+c$

用 6.3 Obj 3 Factor perfect square trinomials

围 6.3 Interactive Concept Check

国 $\underline{6.4 \text { Factoring Trinomials of the Form } \mathrm{ax}^{2}} \underline{\underline{2}}+\mathrm{bx}+\mathrm{c}$ by Grouping

用 6.4 Obj 1 Use the grouping method to factor trinomials of the form $a x^{2}+b x+c$

四 6.5 Factoring Binomials

用 $6.5 \mathrm{Obj} 1$ Factor the difference of two squares

国 $6.5 \mathrm{Obj} 2$ Factor the sum or difference of two cubes

用 6.5 Interactive Concept Check

回 Integrated Review - Choosing a Factoring Strategy

间 6.6 Solving Quadratic Equations by Factoring

四 6.6 Obj 1 Solve quadratic equations by factoring

目 6.6 obj 2 Solve equations with degree greater than 2 by factoring

国 6.6 Obj 3 Find the $x$-intercepts of the graph of a quadratic equation in two variables

间 6.6 Interactive Concept Check 


\section{Appendix $G$ : Pre-algebra Syllabus}

Syllabus: MATH-XXX - MATH-XXX-05 Fall 2009

CODE TO ENROLL IN MY MATH LAB Access code: angeline21377

Section Information: MATH-XXX-05 Fall 2009

Course Name MATH

Course Description Pre-Algebra

Method of Evaluation

Class Organization: A variety of teaching methods will be used including question and answer, lecture, and individual and group activities that will prepare you for your homework.

Method of Evaluation: This is a Credit/No Credit class. To receive "credit" for this course the student must obtain an average of at least $78 \%$ on the following:

$\begin{array}{lc}\text { Evaluations } & 30 \% \\ \text { My Math Lab Homework Grade } & 40 \% \\ \text { Quizzes / Class work } & 10 \% \\ \text { Comprehensive Departmental Final } & 20 \%\end{array}$

You will need $78 \%$ overall average AND at least a 50\% on the departmental final to earn credit for Math 0094.

For Math XX the following grading scale will apply for program. students that need a letter grade submitted for a 
The grading scale follows:

- $92 \%-100 \% \mathrm{~A}$

- $84 \%-91 \%$ B

$-78 \%-83 \% \mathrm{C}$

- $55 \%-77 \% \mathrm{D}$

- below $55 \%$

You must take the final exam and score a $50 \%$ or better to receive credit in the class.

All departmental finals will be given during final exam week according to the Registrar's official schedule.

Evaluations (Tests) Note: You must take the departmental finals and receive a minimum of 50\% to receive credit in the class.

I will give a minimum of 1 weeks' notice for an upcoming test. Tests must be taken as scheduled and on time. If an emergency occurs and you are unable to take a test, you should notify me immediately and before the next class meeting. YOU CANNOT MAKE UP A TEST! Your percentage score on the final exam will be substituted for the missing grade. (Note: I will only substitute the percentage grade from your final in for one missing grade. If you miss more than one exam, you will receive a ZERO for all but the first missed exam.)

All tests are tentative and subject to change at the instructor's discretion.

My Math Lab Homework 
- Practice is your key to success! Completing each and every practice set is vital to success in this course. Good and regular practice enables the learner to retain the information taught in class.

- You should expect to spend a minimum of two hours a day on your My Math Lab practice outside of each class. Each practice set should be completed with a minimum of $80 \%$ mastery.

- The My Math Lab homework problems will reflect material we are currently covering in class. You may rework sets as often as you wish during the time it is posted. I will accept the highest percentage earned and will determine your semester "Homework" grade. It is imperative that you attend class so you will be able to understand the lessons.

- Students are required bring the Beginning Algebra Workbook pages needed for the days class work to each class.

\section{Departmental Final}

- All departmental finals will be given during final exam week according to the Registrar's official schedule.

- Note: You must take the departmental finals and receive a minimum of $50 \%$ to receive credit in the class.

\section{Course Information Class Meets: TR 10:00-11:00 in XXXX.}

The following topics will receive attention in Math XXX Pre-Algebra: operations on positive and negative real their applications; operations on numbers; order of operations, solving elementary equations and polynomial and exponential expressions.

This course offers three hours of institutional credit only. Credit hours will not apply toward hours required for graduation. This course must be completed in the first 32 hours of work in a student's program of study. 


\section{$\underline{\text { Withdrawals }}$}

Please be aware that there is a fee attached if you withdraw from more than four courses in the Community College or more than eight classes in the University.

\section{Instructor Information}

Office Phone: $\mathrm{xxx}-\mathrm{xxxx}$

Email: MaryBeth.Angeline@XXX.edu

Office Hours: MWF 11:00-12:00 TR 2:00-3:00

Office Location: $200 \mathrm{XXXXX}$

\section{Goals}

By the end of the semester you should have gained factual knowledge (terminology, classifications, methods, and trends), learned the fundamental principles, and learned to apply the course material on the following list of course goals. (*designates a crucial goal).

\section{See Error! Reference source not found.}

\section{Supplemental Instruction}

- Free tutoring is available! Go to Room 200 or 207 XXX Hall.

- This course is attached to SI, a Supplemental Instruction learning enhancement program. It is designed to organize and improve the ways in which students prepare for class outside of class. SI will provide you with a systematic and disciplined approach for processing the course material assigned.

- Through this program you will have an opportunity to work with an SI leader. This student has demonstrated proficiency in this course and has undergone SI training.

- SI sessions are open to all students in the course and are attended on a voluntary basis. However, students are encouraged to avail themselves of all SI sessions throughout the 
semester. Historically it has been shown that students who attend SI sessions are more successful. Please take advantage of this wonderful opportunity!

Here is the current schedule:

http://www.XXX.edu/academics/CTC_TutorialServices/SISchedule.asp

\section{$\underline{\text { Student Expectations }}$}

Students are expected to be:

- Present and attentive in class; aware of official university communication via email;

- Prepared for university life; prepared for class

- Participating in class and in extra- and co-curricular activities;

- Polite and respectful to everyone in our academic community.

XXXX Core Values:

- Scholarship

- Opportunity

- Achievement

- Responsibility

Expectations of Excellence: We value your educational experience. Please refer to the following link for our institutional expectations of excellence.

http://www.XXX.edu/academicaffairs/expectations.asp

\section{$\underline{\text { Pre-requisites }}$}

Students entering Math XXXX either earned credit in Math

XXXX or have a COMPASS Algebra score of at least 17. If you do meet the criteria, you must talk to me. Entering this class you should be able to 
1. Perform prime factorization

2. Add fractions

3. Subtract fractions

4. Multiply and divide fractions

5. Connect fractions, decimals, and percent.

6. Perform rounding operations

You will have an opportunity to review these skills at the beginning of the semester through My Math Lab

Textbook and My Math Lab Requirements

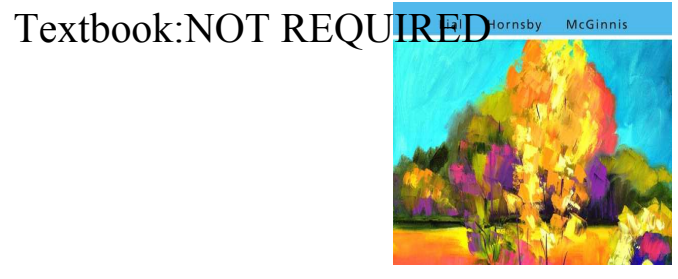

Beginning Algebra 10th edition. This book is available to students online through your My Math Lab code. This code and accompanying workbook may be purchased through the bookstore or online at: www.coursecompass.com

Instructor code: angeline21377

My Math Lab and class notebook requirements

- Each student should have a calculator with a fraction key.

- Students will be expected to use Adobe pdf files. If you do not have the Adobe Reader, click on the link below Free Adobe Reader Download 


\section{REDESIGN OF A DEVELOPMENTAL MATHEMATICS PROGRAM}

- Departmental policy requires each student to use My Math Lab. My Math Lab will permit you to work with real mathematics notation in real time, providing instant analysis and feedback. You will be given assignments on My Math Lab throughout the semester, which will help you build your skills in this course. This online homework will be $20 \%$ to $30 \%$ of your semester grade.

To develop good mathematics study skills keep your work organized in a notebook. Your notebook should contain:

1) Complete dated class notes including workbook pages

2) Homework record of online and in class assignments. You will use the notebook to evaluate your work and study skills, and it will guide you to a successful classroom and My Math Lab experience

Features in My Math Lab

You will have access to the following resources using My Math Lab:

- Online homework

- Online tutorials

- Free tech support 1-800-677-6337

- Live tutors 5 pm to 12 am EST Sunday-Thursday call 1-

$800-435-4084$ or $1-888-777-0463$

- Online quizzes and tests

- Announcements from your instructor

- Complete textbook online

\section{Classroom Policies}

You are in college. Please follow the rules of academic etiquette and expectations.

- Turn off cell phones and other electronic devices 


\section{REDESIGN OF A DEVELOPMENTAL MATHEMATICS PROGRAM}

- Do not arrive after me. If you are tardy, do not be disruptive when you do arrive. Repeated lateness will be addressed individually.

- Do not leave class unless it is an EMERGENCY!

- Treat you peers and professor with respect and consideration at all times.

- Always ask permission before leaving early.

- Avoid packing up noisily before class is dismissed

- Please abstain from personal conversations.

- Attend class, stay awake and focused.

Section Instructor: Mary Angeline

E-mail MaryBeth.Angeline@XXX.edu 
Name:

Date:

Instructor:

Section:

\section{Chapter 7 RATIONAL EXPRESSIONS AND APPLICATIONS}

\subsection{The Fundamental Property of Rational Expressions}

\section{Learning Objectives}

1 Find the numerical value of a rational expression.

2 Find the values of the variable for which a rational expression is undefined.

3 Write rational expressions in lowest terms.

4 Recognize equivalent forms of rational expressions.

\section{Key Terms}

Use the vocabulary terms listed below to complete each statement in exercises 1-3.

\section{rational expression lowest terms fundamental property of rational expressions}

1. A rational expressign the quotient of two polynomials with denominator not 0 . fundarnental property of

2. The rational expressions states that $\frac{P K}{Q K}=\frac{P}{Q}$ for $Q \neq 0$ and $K \neq 0$.

3. A rational expression is in Lowest terms if the greatest common factor of its numerator and denominator is 1.

\section{Objective 1 Find the numerical value of a rational expression.}

Find the numerical value of each expression when (a) $x=4$ and $(b) x=-3$.

$$
\begin{aligned}
& \text { (1.) } \frac{3 x^{2}-2 x}{2 x} \text { a) } \frac{3(4)^{2}-2(4)}{2(4)}=\frac{48-8}{8}=\frac{40}{8}=5 \text {. } \\
& \text { 2. } \frac{(-4-x)^{2}}{x+3} \frac{3(-3)^{2}-2(-3)}{2(-3)}=\frac{3(9)+6}{-6}=\frac{33}{6}=\frac{31 \cdot 1}{2}=11 / 2 \\
& \text { a) } 2(4)+5=\frac{8+5}{64-25}=\frac{13}{39}=\sqrt{3} \\
& \text { (3.) } \frac{2 x+5}{4 x^{2}-25}=\frac{2(4)+5}{4(4)^{2}-25}=\frac{84-25}{64}=39 \\
& \text { 4. } \frac{3 x^{2}}{3 x+2} \text { b) } \frac{2(-3)+5}{4(-3)^{2}-25}=\frac{-6+5}{36-25}=\frac{-1}{11} \\
& \text { (5) } \frac{-3 x}{x^{2}-x-12} \frac{-3(4)}{4^{2}-4-12}=\frac{-12}{16-4-12}=\frac{-12}{0} \text { undefire? } \\
& \frac{-3(-3)}{(-3)^{2}-(-3)-12}=\frac{9}{9+3-12}=
\end{aligned}
$$


Name:

Instructor:

6. $\frac{2 x^{2}-4}{x^{2}-2}$

7. $\frac{2 x-5}{2+x-x^{2}}$

8. $\frac{-2 x^{2}}{2 x^{2}-x+2}$

Date:

Section:

6.

7.

8.

Objective 2 Find the values of the variable for which a rational expression is undefined.

Find all values for which the following expressions are undefined.

(9.) $\frac{9}{4 x} \quad x \neq 0$

9.

10. $\frac{4 x^{2}}{x+7}$

$\begin{aligned} x+7 & =0 \\ x & =-7\end{aligned}$ therefor $x \neq-7$

10.

11. $\frac{x-4}{4 x^{2}-16 x}$

11.

12. $\frac{4 x+3}{x^{2}+x-1}$
13. $\frac{5 x}{x^{2}-25}$

14.) $\frac{z-3}{z^{2}+9}$

$(x+4)(x-3)=0$
$x \neq-4 x \neq 3$

12.

13.

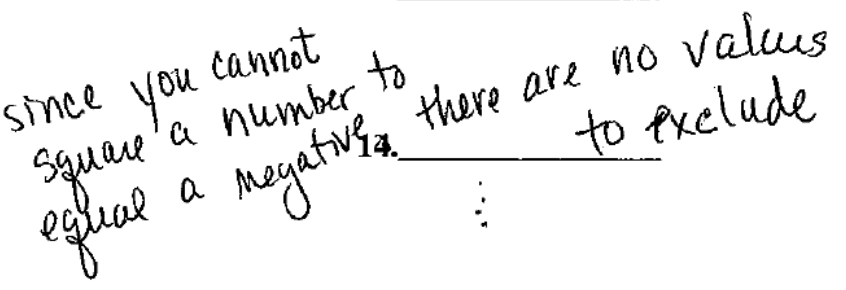

15.

15. $\frac{x+5}{x^{3}+9 x^{2}+18 x}$ 
Currently, my mathematics class(es) meet

\begin{tabular}{lcc} 
In a lab every class & $21.3 \%$ & 38 \\
In a traditional classroom for every class & $42.1 \%$ & 75 \\
In a traditional classroom and go to the lab at least twice a month & $30.3 \%$ & 54 \\
Totally online & $6.3 \%$ & 11 \\
\hline & $100 \%$ & 178
\end{tabular}

How many developmental mathematics courses [Basic math, pre-algebra, elementary algebra] have you successfully completed?

0

1

2

3 or more
$28.4 \% \quad 50$

$44.9 \% \quad 79$

$25 \% \quad 44$

$1.7 \% \quad 3$

$100 \% \quad 176$

Is the course that requested your response to this survey your first developmental level mathematics course?

\begin{tabular}{lcc} 
Yes & $44.6 \%$ & 78 \\
No & $55.4 \%$ & 97 \\
& & \\
\hline & $100 \%$ & 175
\end{tabular}

If you answered "no" to the previous question, how many final course grades of NC-no credit or NCX- No credit/withdrew have you received in your prior developmental level mathematics courses? 
3 or more

I would prefer to take my developmental mathematics course for

A full 16 week format

An 8 week format

A 4 week format

Self-paced: time varies depending on how quickly or slowly you progress through course units
$51.7 \% \quad 90$

$16.1 \% \quad 28$

$3.4 \% \quad 6$

$28.7 \% \quad 50$

$99.9 \% \quad 174$

I would prefer to take my developmental mathematics course

Two days a week schedule: Monday and Wednesday

Two days a week schedule: Tuesday and Thursday

Three days a week: Monday, Wednesday, and Friday

Four days a week: Monday through Thursday

Only one day a week: Friday, Saturday or any evening

Totally online
$19.5 \% \quad 34$

$36.8 \% \quad 64$

$15.5 \% \quad 27$

$3.4 \% \quad 6$

$8.0 \% \quad 14$

$16.7 \% \quad 29$ 
I would prefer to take my developmental mathematics course as/in:

$\begin{array}{lr}\text { Traditional classroom meeting only } & 25.3 \% \quad 44\end{array}$

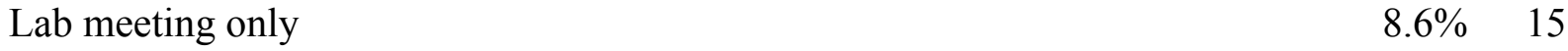

$\begin{array}{lll}\text { Online only } & 16.1 \% & 28\end{array}$

Hybrid: traditional classroom and lab meetings $\quad 33.3 \% \quad 58$

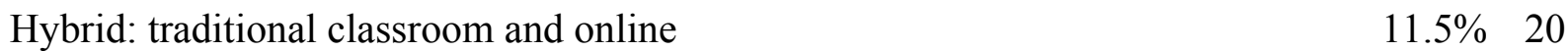

$\begin{array}{lr}\text { Hybrid: lab meeting and online } & 5.2 \% \quad 9\end{array}$

$100 \% \quad 174$

The description below that best fits me is:

I did well in math in high school and just need to review $\quad 26.9 \% \quad 46$

I did not do well in math in high school and need a lot of help to understand $\quad 17.0 \% \quad 29$

I have been away from math for so long, I need to relearn in $\quad 38.0 \% \quad 65$

I never had this math in school and am learning it for the first time $\quad 11.7 \% \quad 20$

$\begin{array}{ll}\text { None of the above- please describe below } & 6.4 \% \quad 11\end{array}$

- I didn’t do well in high school because I didn’t apply myself, but now I really am understanding and getting it.

- I did decent in mathematics but need a review.

- $\quad$ I did well in mathematics in HS, but have been away from it so long.

- $\quad$ I did ok in mathematics in high school and still need help with some parts in mathematics.

- I was good at mathematics in high school, but I didnt take any type of math class my freshman year of college so it had been awhile since I took a math class. 


\section{REDESIGN OF A DEVELOPMENTAL MATHEMATICS PROGRAM}

- $\quad$ i had math 1093 ti prepare for math95

- I have been in developmental Mathmatics(sic) classes since the fourth grade. I've always had a difficult time understanding math and the teachers in our county were terrible. The teacher I have right now has been a dream come true and I've learned more from her in two semesters than I've learned in my life.

- $\quad$ my college did not receive my act scores

- $\quad \mathrm{NO}$ on has been able to correlate and help material stick with me.

- I wasn't taught some of the equations that are on these tests and have to spend all of my time trying to learn them myself.

- I passed trig with an A in high school. The only reason I'm taking development math course is because I scored somewhat low on the compass test.

The description that best fits me is:

My class moves too quickly for me

My class moves too slowly for me

My class is moving at the correct pace

I would prefer to move at my own pace
$14.1 \% \quad 24$

$2.9 \% \quad 5$

$63.5 \% \quad 108$

$19.4 \% \quad 33$

$99.9 \% \quad 170$

The amount of time I spend working on mathematics is:

More than all of my other classes

$37.3 \% \quad 63$

About the same as my other classes

$46.7 \%$

79

Less than my other classes

$16.0 \%$

27 
I spend approximately

\begin{tabular}{lrc} 
Less than one hour per week on mathematics & $2.9 \%$ & 5 \\
1 to 2 hours per week & $30.6 \%$ & 52 \\
3 to 4 hours per week & $35.9 \%$ & 61 \\
5 to 6 hours per week & $18.2 \%$ & 31 \\
7 or more hours per week & $12.4 \%$ & 21 \\
\hline
\end{tabular}

Have you utilized the services of the Mathematics-Writing Tutoring Center?

\begin{tabular}{ccc} 
Yes & $20 \%$ & 34 \\
No & $80 \%$ & 136 \\
\hline & $100 \%$ & 170
\end{tabular}

If you answered "Yes" to the previous item, how often did you visit the Mathematics-Writing Tutoring Center during the current semester?

\begin{tabular}{lcc} 
Daily & $10.8 \%$ & 4 \\
Weekly & $37.8 \%$ & 14 \\
Every other week & $13.5 \%$ & 5 \\
Monthly & $5.4 \%$ & 2 \\
Less than monthly & $32.4 \%$ & 12 \\
\hline
\end{tabular}




\section{REDESIGN OF A DEVELOPMENTAL MATHEMATICS PROGRAM}

Please offer any suggestions that would help the [college] mathematics department be more responsible to your needs.

- more tutors available in the math and writing center

- I work full time and have a 6 year old child it is hard for me to do any extra class room time, like tutoring. I would rather it be on-line I also believe some of this mathematics is not going to be used and is a waste of time to learn. I have never used factoring or quantum problems in my 48 years of life. I think it is safe to say I will not use it in the future.

- Maybe a teacher that DOES NOT say on the first day and everyday that she does not like the textbook or the way she is supposed to teach it.

- My mathematics teacher has done nothing for me. In my opinion she is a horrible teacher and needs to take some time to explain things in class.

- I honestly do not feel that this Math is required for my course of study, as a nontraditional student. I have never used algebra in my life, yet I sit here 3 semesters later STILL trying to pass [Elementary algebra] to get into [Introductory concepts]...

- I feel that [Instructor] is one of the best math teachers i have ever had including my highschool years. she explains everything and goes at great pace through all the material. i liked her so much that $\mathrm{i}$ have her for my next semester class

- [Instructor] is the greatest! she really cares about her students and will go over any problem with you till you get it down correctly.

- Class was good and [instructor] was an excellent teacher. Personally I have has $30+$ years out of a classroom. Would highly recommend the 8 week course for the non-traditional student. 


\section{REDESIGN OF A DEVELOPMENTAL MATHEMATICS PROGRAM}

- I just think that meeting for two days a week for an hour and fifteen minutes is not enough time to allow the students in these classes to grasp and understand all the material. I think we need a lot more time.

- I do not feel that some of this math is needed by certain students. I am 48 yrs old and have never used factoring or algebra in my day to day life.

- I think that [Basic Math] and [Pre-algebra] would do well online as long as the teacher doesn't overload the student with EXTRA assignments. I really enjoyed the math lab online.

- The classes should be better geared to the non-traditional student who has been out of school more than 10 years.

- I'm not very good in math at all and I take full responsibility for that outcome. My math teacher is though and answers all question. Not everyone does well in math and can't get it no matter who the teacher is.

- My math lab is awful. change it.

- mathlab is difficult to work with sometimes. I think that if you ask it for help the question should count and you shouldn't have to do it over every time

- shouldn't assume we can pick it up a short amount of time I haven't been in school in seven years need a little review

- Don't move to fast for the older folks (students) There should be a class for older students at a pace they can follow

- Self Paced Classes that are offered in my hometown

- Probably more access to computer labs during class time. This semester we have only used the lab once, whereas last semester we used it a couple times a month 


\section{REDESIGN OF A DEVELOPMENTAL MATHEMATICS PROGRAM}

- I think [instructor] does an excellent job of teaching. She is understanding and helpful and a really great teacher.

- I have no problems with the way the class is being ran.

- My teacher doesn't slow down, even when you have a question. He'll give you a very brief answer that never fully explains it and then moves on the next problem while more than half the class is still on the last one. I know I'm not the only one that feels this way about [instructor].

- No suggestions [Instructor] is an excellent teacher. I wish I had her in high school then I wouldn't be having the problems that I would be having in Math. She makes sure we understand it and is very fair. She is very kind and understanding. I wish I could have her in my other math classes!

- Make sure teachers asigned are concerned to the needs of all their students

- Have at least one class a month in the lab to get caught up on homework

- Keep using mylabsplus \& start using the new methods of teaching like [instructor] uses; it is so much easier to understand. Remember, "if you cant' explain it in simple terms, then you don't understand it good enough." (Albert Einstein)

- Taking [intermediate algebra] in the lab has made me learn at a pace that suits me and has made learning math less stressful. I have more time to learn and retain the info and that is very helpful. I only wish that I could take the next level math in a lab setting as well.

- Get rid of math lab!!!

- I think that [Pre-algebra] requires its students to cover too much material in a very short period of time. You are tested on material that you went over in class the day before. For non-traditional students like myself its very frustrating to have to repeat this extremely 


\section{REDESIGN OF A DEVELOPMENTAL MATHEMATICS PROGRAM}

expensive class multiple times when it is not even counted as a credit to graduate. That is the most frustrating of all!!!!!!!!

- I feel more demonstrations of math problems would greatly improve this class.

- I would like to see the math courses be a little slower so I don't feel so rushed to learn things. I would also like to be able to have more individual time with the instructor and them to take more time with me to help me learn the material. I am not at all good with math and need alot of help and dont feel I have gotten it yet with these math courses.

- I feel that a lot of people, is doing horrible in math many people dont understand $t$. and its holding lots of people back in compeleting and moving on with there degree, and iam speaking for myself personaly, math is a daily life thing that everybody has to know regarles, but if a students needs to graduate and they cant pass this math and repeating the same math over and over, stead of the school trying to make there money, they should pass he/she. Especially if it's the same math they cant pass, and they shoud only have students take there math profession math. Not these [Basic math, Pre-algebra, Elementary algebra] yes i understand we have to know these in order to get to college math or health related math, but its quite trieding and i see why people drop out of school, the school wants so much from a student, and some students have learning disabilities, and people dont get a tutor isnt going to help 100 of then time, when it comes down to it if you dont know it you dont know it? Math is my worsy subject, hopefull one day i will be a good at math and be able to teach it, because iam struggling big time, and i see a professional tutor everyday.

- Would be nice to have math classes that were available more toward the end of the day. The middle of day kills me, with working also, but I understand that you are all working as well. 


\section{REDESIGN OF A DEVELOPMENTAL MATHEMATICS PROGRAM}

- I've enjoyed my math class with [Instructor]. She's an excellent teacher and would love to take [Pre-algebra] with her. She knows how to take the fear out of math!

- My MAth teacher was amazing! Best one I have ever had, From middle school through college! By far the best, she actually helped me out alot.

- I think all math classes should be either in a class room or in a lab every class and it should not be self paced. When you are self paced every person is in a different chapter. It is easier if the teacher teaches something and everyone is on the same page. I have noticed from experience when i took [Elementary algebra] self paced my teacher was going every where from one kid to another and could never get her attention. In my [Elementary math] that I am in now he teaches a lesson for one week we do practice together and everyone is on the same page my grades have been really good and its all because we all practice together along without teacher.

- I really enjoy the class. I have never done well in math, but [Instructor] is a great teacher and I am happy to learn more than I ever have.

- as I stated that I have never had thistype of math because I have been out of school for so long, the math lab does the problems different than in class so I get confused and I freeze up on test it's like I don't have enough time to take the test and then I end up hurring and messing up on a test so I feel if I took it on line I could work at my own pace and not feel rushed, but [Instructor] is an awesome teatcher because this is my second time taking her.

- I honestly think that a group for those who are having a hard time learning or comprehending math. Almost like a "math for dummies" club that has sectors for each portion with tutors. I would participate in the tutoring program if there were more people also seeking that help. I know its not a bad thing to seek help but I feel less-than when I do. 


\section{REDESIGN OF A DEVELOPMENTAL MATHEMATICS PROGRAM}

- Revamp the online math lab to accept all correct answers. Not just the answers that it wants. Sometimes they are up to 4 ways to answer a question, with the math lab it is very frustrating to have the correct answer, just not in the format or the answer that the system wants and you have to continuously try to figure out how it wants the answer.

- I think [Institution] Math department meets every college students needs. I know it has help me a lot with understanding math more.

- $\quad$ KEEP UP THE GOOD WORK THINK U GUYS ARE DOING WHAT YOU CAN FOR US THANKX ANDREA

- Remember that not all students have access to internet at home. It will help to give enough class time to get it completed.

- $\quad$ Stop using My math lab plus and return to the traditional way of using a text book and doing work in class. First of all, the internet thing is expensive, and it come with a book that you never use and can never get the money back for.

- I like the online practices/homework because it let me now what I did wrong and how to solve the problem step by step. I also like the video component for each chapter. I learn better in this way, viewing and practicing. I think the remedial math can be totally online. But I like that I can talk to a teacher face to face, if there was any other problem.

- I think that a classroom teaching would be better for students to learn. Most students do not ask for help.

- let students know that they are entering a math lab online class 


\section{REDESIGN OF A DEVELOPMENTAL MATHEMATICS PROGRAM}

\section{Appendix J: Curriculum Proposal}

\begin{tabular}{|c|c|c|}
\hline $\begin{array}{l}\text { Proposal Number (assigned by } \\
\text { Curriculum Committee) }\end{array}$ & \multicolumn{2}{|c|}{ [Click here to enter text.] } \\
\hline School/Department/Program & \multicolumn{2}{|c|}{ XXXXXXX/Mathematics/Developmental } \\
\hline Preparer/Contact Person & \multicolumn{2}{|c|}{ Mary Beth Angeline/XXXXXXXX } \\
\hline \multicolumn{3}{|l|}{ Telephone } \\
\hline \multicolumn{3}{|l|}{ Proposal Reviewers } \\
\hline & \multicolumn{2}{|c|}{ [Click here to enter text.] } \\
\hline Date Originally Submitted & \multicolumn{2}{|l|}{$4 / 28 / 2011$} \\
\hline $\begin{array}{l}\text { Revision Date (Indicate date and } \\
\text { label it Revision } \# 1, \# 2 \text {, etc.) }\end{array}$ & $\begin{array}{l}\text { [Click here to } \\
\text { enter a date. }\end{array}$ & $\begin{array}{l}\text { Click here to } \\
\text { enter text. }\end{array}$ \\
\hline Implementation Date Requested & \multicolumn{2}{|l|}{ Fall 2011} \\
\hline
\end{tabular}

\begin{tabular}{|l|l|}
\hline PROPOSAL. Write a brief abstract, not exceeding 100 words, which describes the \\
overall content of the proposal. \\
This proposal seeks to re-order the student learning outcomes of [Pre-Algebra] Math \\
and [Elementary-Algebra] Math 1 No student learning outcomes of either course \\
eliminated, thereby streamlining both courses in the continuing effort to allow students to \\
proceed through their developmental skills math requirements in a more timely fashion. \\
This proposal would bring our courses into alignment with our course materials. This \\
proposal will only affect the internal instructional design of the course and will NOT change
\end{tabular}




\section{REDESIGN OF A DEVELOPMENTAL MATHEMATICS PROGRAM}

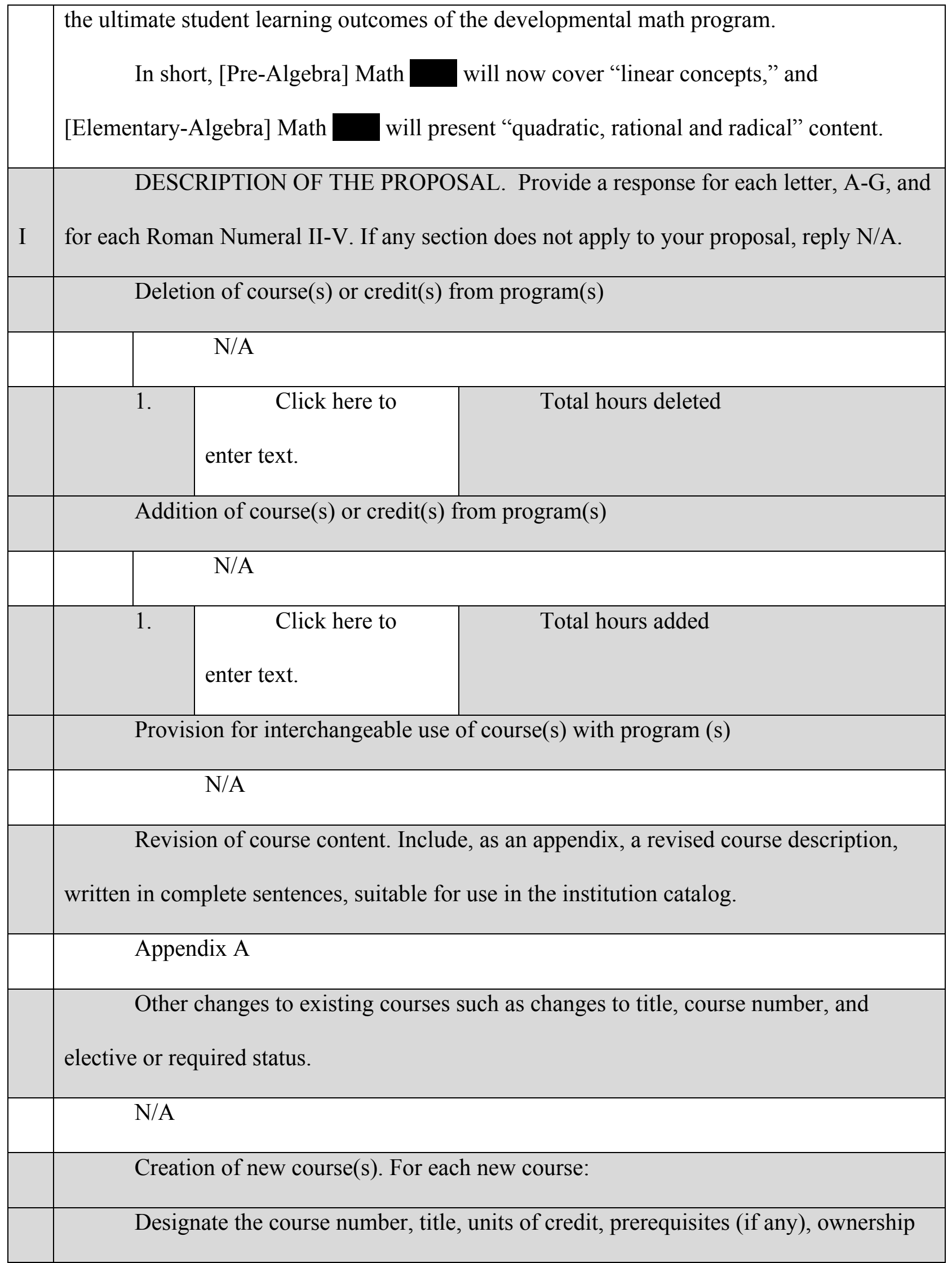




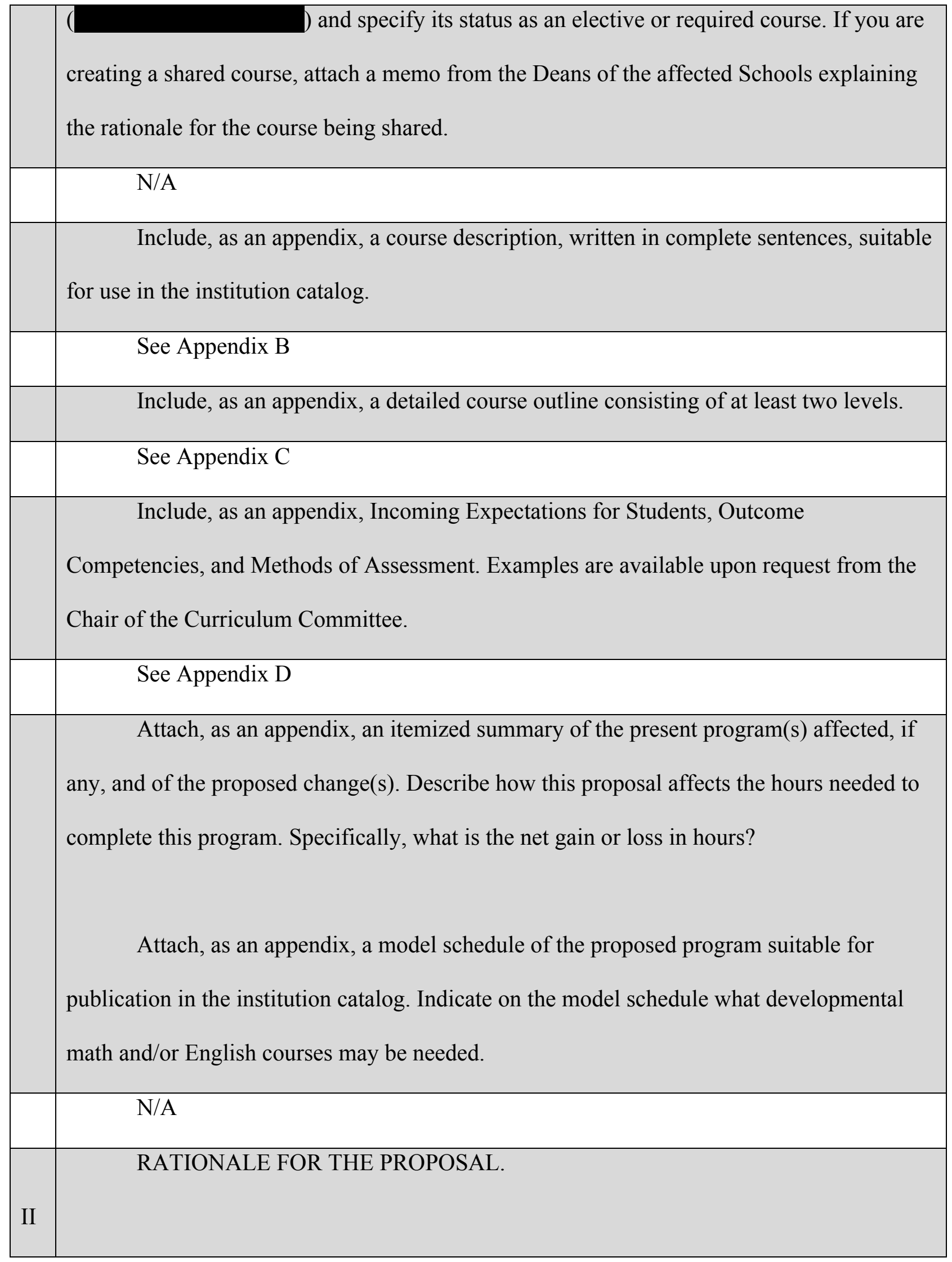




\section{REDESIGN OF A DEVELOPMENTAL MATHEMATICS PROGRAM}

\begin{tabular}{|c|c|}
\hline & $\begin{array}{l}\text { Quantitative Assessment: Indicate the types of assessment data, i.e., surveys, } \\
\text { interviews, capstone courses, projects, licensure exams, nationally-normed tests, locally } \\
\text { developed measurements, accreditation reports, etc. collected and analyzed to determine } \\
\text { that curricular changes were warranted. Quantitative data is preferred. }\end{array}$ \\
\hline & $\begin{array}{l}\text { Our current developmental pass rates are } 40.3 \%, 44.2 \% \text { and } 44 \% \text { for Math [Basic } \\
\text { Math] } \square \text {, [Pre-Algebra] } \square \text { and [Elementary-Algebra] } \square \text {, respectively. This proposal will } \\
\text { align our content with all nationally recognized developmental math programs that are } \\
\text { currently using "best practices," as published by the National Center of Academic } \\
\text { Transformations (http://www.thencat.org/R2R/R2RArchives/R2R_Full_Project.htm) }\end{array}$ \\
\hline & $\begin{array}{l}\text { Qualitative Assessment: Based upon the assessment data above, indicate why a } \\
\text { curricular change is justified. Indicate the expected results of the change. Be sure to include } \\
\text { an estimate of the increased cost, or reduction in cost of implementation. FOR EXAMPLE: } \\
\text { Will new faculty, facilities, equipment, or library materials be required? }\end{array}$ \\
\hline & $\begin{array}{l}\text { Streamlining the content of these courses will align our course outcomes according } \\
\text { to the sequence that has been recommended by NCAT. This streamlining of content will } \\
\text { allow instructors to cover all content more in-depth, integrating the necessary review of } \\
\text { material as opposed to addressing such material separately in repeated, separate outcomes. }\end{array}$ \\
\hline V & $\begin{array}{l}\text { School Notification. Should this proposal affect any course or program in another } \\
\text { school ( }) \text { a memo must be sent to the Dean of each school impacted and } \\
\text { a copy of the memo(s) must be included, as an appendix, with this proposal. Dean's } \\
\text { signatures must be obtained verifying their notification. } \\
\text { If a new or existing course is seeking general studies designation, a memo of }\end{array}$ \\
\hline
\end{tabular}


REDESIGN OF A DEVELOPMENTAL MATHEMATICS PROGRAM

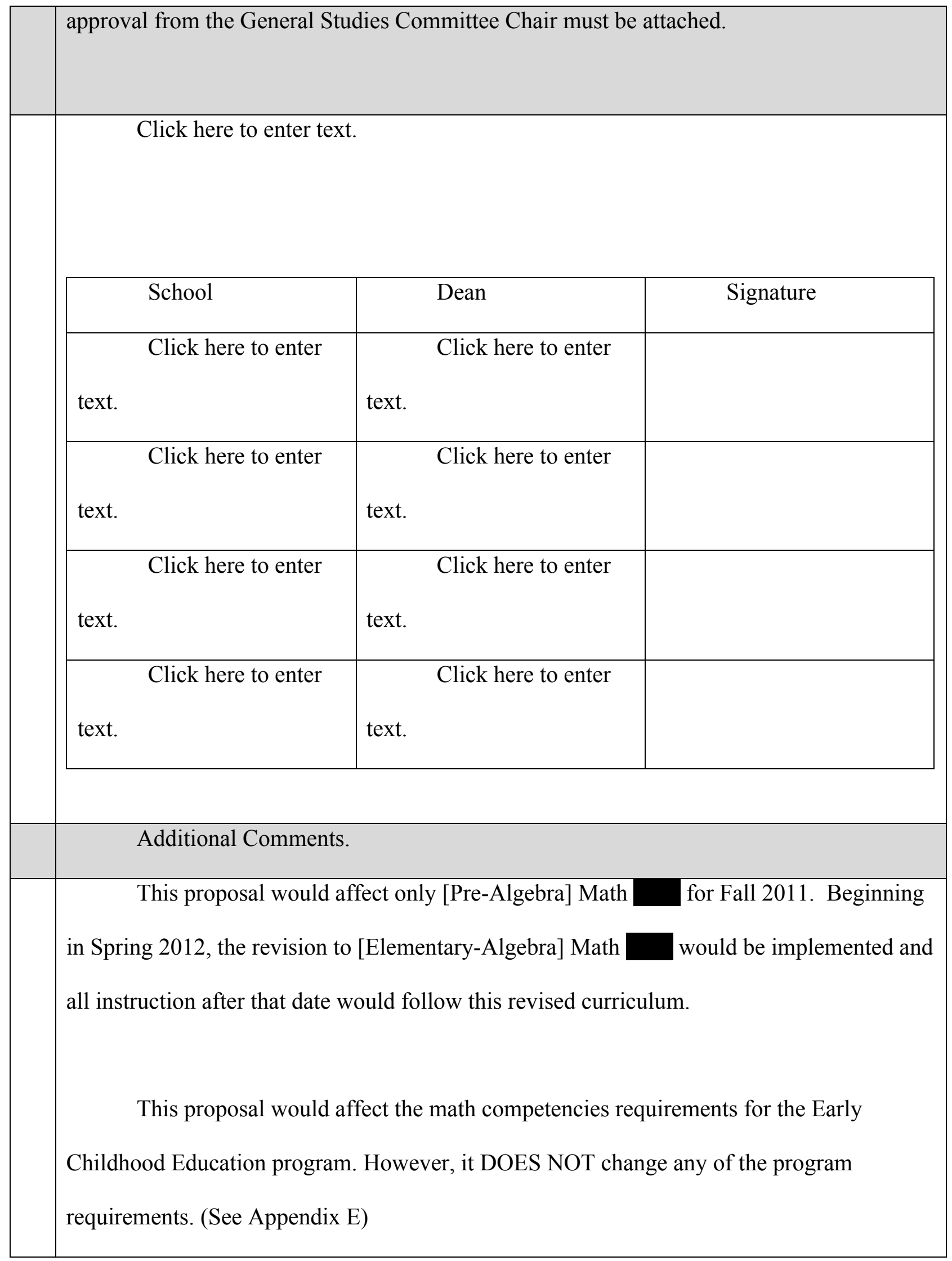


[Pre-Algebra] Math $\square$ Outcomes (highlighted would be moved to [Elementary Algebra] Math $\square$

Apply order of operations guidelines

Use exponential notation

Evaluate algebraic expressions given

value for the variables

Translate word statements to expressions and equations.

Distinguish between expressions and equations

Define real number system

terminology

Add signed numbers

Subtract signed numbers

Multiply and divide signed numbers

Set up a ratio

Use algebraic properties

Simplify algebraic expressions

Solve one-step equations
Solve equations using the distributive property.

Solve multi-step equations

Solve fractional equations

Solve general applied problems using the six steps for solving applied problems

Solve vertical, complementary, and supplementary angle problems

Solve applied number problems

Use a formula to solve an applied problem

Solve literal equations

Solve applied proportions

Solve one-step percent problems

Solve multi-step percent problems

Graph linear inequalities

Solve addition inequalities 
REDESIGN OF A DEVELOPMENTAL MATHEMATICS PROGRAM

Solve multi-step inequalities

Use product and quotient rules for

exponents

Use exponential power rule

Use zero exponent rule

Use negative exponents

Use rules of exponents to simplify

expressions (multi-steps)

Use scientific notation rules

Add polynomials

Subtract polynomials

Multiply binomials

Multiply polynomials

Multiply conjugates

Multiply powers of binomials

Divide polynomials

State the ordered pair if a point has

been plotted

Interpret graphs

Plot ordered pairs

Graph linear equations 
[Elementary Algebra] Math $\square$ Outcomes (highlighted will be moved to [Pre-Algebra] Math $\square$

Factor common factors

Factor by grouping

Factor trinomials

Factor difference of two squares

Factor perfect square trinomials

Solve quadratic equations by factoring

Solve applied quadratic equations

Reduce rational expressions

Multiply and divide rational expressions

Find the least common denominator for rational expressions

Add or subtract rational expressions with like denominators or with monomial denominators

Solve rational equations in which the rational expressions have monomial denominators

Solve direct and indirect variation problems

Solve problems using proportionality

Graph data

Graph linear equations

Find the slope of a line

Find the equation of a line in slope-intercept form

Interpret graphs to find slope and/or the equation of a line

Find the solution of a system of equations by graphing 
Find the solution of a system of equations by using the substitution method

Find the solution of a system of equations by using the addition method

Solve system-of-equations application problems

Use the Pythagorean Theorem

Use the radical product rule and the radical quotient rule

Add and subtract radical expressions

Simplify radical expressions

Solve radical equations

Use the square root property of equality to solve quadratic equations

Use the quadratic formula to solve quadratic equations

Revised List of Outcomes for [Pre-Algebra] Math

Unit I- Signed numbers and order of operations

Apply order of operations guidelines

Use exponential notation

Evaluate algebraic expressions given value for the variables

Translate word statements to expressions and equations.

Distinguish between expressions and equations

Define real number system terminology

Add and subtract signed numbers

Multiply and divide signed numbers

Use algebraic properties to simplify algebraic expressions

Unit II- Solving linear equations and inequalities

Solve one-step equations 
Solve equations using the distributive property.

Solve multi-step equations

Solve fractional equations

Solve general applied problems using the six steps for solving applied problems

Solve vertical, complementary, and supplementary angle problems

Use a formula to solve an applied problem

Solve literal equations

Setup and solve a proportion

Solve applied proportions

Solve one-step percent problems

Solve multi-step percent problems

Graph linear inequalities

Solve multi-step inequalities

Unit III- Graphing linear equations and inequalities

State the ordered pair if a point has been plotted

Interpret graphs

Graph data

Graph linear equations

Find the slope of a line

Find the equation of a line in slope-intercept form and graph

Interpret graphs to find slope and/or the equation of a line

Introduce the concept of functions

Unit V- Solving systems of linear equations

Solve a system of equations by graphing 
Solve a system of equations by using the substitution method

Solve a system of equations by using the addition method

Create and solve system-of-equations application problems

Revised List of Course Outcomes [Elementary Algebra] Math

Unit I- Operations with Exponents and Polynomials

Use product and quotient rules for exponents

Use exponential power rule

Use zero exponent rule

Use negative exponents

Use rules of exponents to simplify expressions (multi-steps)

Use scientific notation rules

Add and subtract polynomials

Multiply polynomials

Multiply conjugates

Multiply powers of binomials

Divide polynomials by monomials

Unit II- Factoring and Applications

Factor common factors

Factor by grouping

Factor trinomials

Factor difference of two squares

Factor perfect square trinomials

Solve quadratic equations by factoring

Solve applied quadratic equations 
Unit III- Rational Expressions and Applications

Simplify rational expressions

Determine where a rational expression is undefined

Multiply and divide rational expressions

Find the least common denominator for rational expressions

Solve rational equations in which the rational expressions have monomial denominators

Solve direct and indirect variation problems

Solve problems using proportionality

Unit IV- Roots and Radicals

Use the Pythagorean Theorem

Use the radical product rule and the radical quotient rule

Add and subtract radical expressions

Simplify radical expressions

Solve radical equations

Interpret the graph of a radical function

Unit V- Solving Quadratic Equations

Use the square root property of equality to solve quadratic equations

Use the quadratic formula to solve quadratic equations

Determine the most effective method to solve a quadratic equation

Interpret the graph of a quadratic function

Math $\square$ Course Descriptions

Current:

MATH Pre-Algebra 3 hrs. 
$\mathrm{T}$ he following topics will receive attention in this course: operations on positive and negative real numbers; order of operations; solving elementary equations and their applications; operations on polynomial and exponential expressions. Students will need computer access to use the online homework system required in the class. Prerequisite: Math or a COMPASS score of $17^{*}$. This course offers institutional credit only. Credit hours will not apply toward hours required for graduation. This course must be completed in the first 32 hours of work in a student's program of study. *Students with ACT below 19 or SAT below 460 must take COMPASS exam.

\section{Proposed: MATH $\square$ Pre-Algebra 3 hrs.}

The course topics include signed numbers and order of operations, solving linear equations and inequalities, graphing linear equations and inequalities and systems of linear equations. All topics will include applications. Students are required to have internet access for the required online course component. Prerequisite: Math $\square$ or a COMPASS Algebra score of 17*. This course offers institutional credit only. Credit hours will not apply toward hours required for graduation. This course must be completed in the first 32 hours of work in a student's program of study. *Students with ACT below 19 or SAT below 460 must take COMPASS exam. Math $\square$ Course Descriptions

Current: MATH D-C\&TC Elementary Algebra 3 hrs.

The following topics will receive attention in this course: order of operations; operations on exponential, polynomial, and rational expressions; solving linear, simultaneous, and quadratic 
equations in the set of real numbers and their applications; graphing equations and forms of equations of a line; operations on roots and radicals. Students will need computer access to use the online homework system required in the class. Prerequisite: Math $\square$ or Compass score of 26 or more*. Students enrolling in this course should be able to manipulate fractions and positive and negative integers and to solve elementary equations. This course offers institutional credit only. Credit hours will not apply toward hours required for graduation. This course must be completed in the first 32 hours of work in a student's program of study. *Students with ACT below 19 or SAT below 460 must take COMPASS exam

Proposed: MATH _ C\&TC Elementary Algebra 3 hrs.

$\mathrm{T}$ he following topics will receive attention in this course: factoring, operations on exponential, polynomial, and rational expressions, solving quadratic equations in the set of real numbers and their applications; and operations on roots and radicals.

Students are required to have internet access for the required online course component. Prerequisite: Math $\square$ or COMPASS Algebra score of 26 or more*. Students enrolling in this course should be able to graph and solve linear equations. This course offers institutional credit only. Credit hours will not apply toward hours required for graduation. This course must be completed in the first 32 hours of work in a student's program of study. *Students with ACT below 19 or SAT below 460 must take COMPASS exam. 
Course Outline for Math

Unit I- Signed numbers and order of operations

Apply order of operations guidelines

Use exponential notation

Evaluate algebraic expressions given value for the variables

Translate word statements to expressions and equations.

Distinguish between expressions and equations

Define real number system terminology

Add and subtract signed numbers

Multiply and divide signed numbers

Use algebraic properties to simplify algebraic expressions

Unit II- Solving linear equations and inequalities

Solve one-step equations

Solve equations using the distributive property.

Solve multi-step equations

Solve fractional equations

Solve general applied problems using the six steps for solving applied problems

Solve vertical, complementary, and supplementary angle problems

Use a formula to solve an applied problem

Solve literal equations

Setup and solve a proportion

Solve applied proportions

Solve one-step percent problems

Solve multi-step percent problems 
Graph linear inequalities

Solve multi-step inequalities

Unit III- Graphing linear equations and inequalities

State the ordered pair if a point has been plotted

Interpret graphs

Graph data

Graph linear equations

Find the slope of a line

Find the equation of a line in slope-intercept form and graph

Interpret graphs to find slope and/or the equation of a line

Introduce the concept of functions

Unit V- Solving systems of linear equations

Solve a system of equations by graphing

Solve a system of equations by using the substitution method

Solve a system of equations by using the addition method

Create and solve system-of-equations application problems

Course Outline for Math

Unit I- Operations with Exponents and Polynomials

Use product and quotient rules for exponents

Use exponential power rule

Use zero exponent rule

Use negative exponents

Use rules of exponents to simplify expressions (multi-steps) 
Use scientific notation rules

Add and subtract polynomials

Multiply polynomials

Multiply conjugates

Multiply powers of binomials

Divide polynomials by monomials

Unit II- Factoring and Applications

Factor common factors

Factor by grouping

Factor trinomials

Factor difference of two squares

Factor perfect square trinomials

Solve quadratic equations by factoring

Solve applied quadratic equations

Unit III- Rational Expressions and Applications

Simplify rational expressions

Determine where a rational expression is undefined

Multiply and divide rational expressions

Find the least common denominator for rational expressions

Solve rational equations in which the rational expressions have monomial denominators

Solve direct and indirect variation problems

Solve problems using proportionality

Unit IV- Roots and Radicals

Use the Pythagorean Theorem 
Use the radical product rule and the radical quotient rule

Add and subtract radical expressions

Simplify radical expressions

Solve radical equations

Interpret the graph of a radical function

Unit V- Solving Quadratic Equations

Use the square root property of equality to solve quadratic equations

Use the quadratic formula to solve quadratic equations

Determine the most effective method to solve a quadratic equation

Interpret the graph of a quadratic function

Incoming Expectations

Because there is no change to the ultimate student learning outcomes of the course, the incoming expectations remain the same.

Outcome Competencies

See above for revised List of Outcomes for each course.

\section{Methods of Assessment}

There will be no changes in methods of assessment, as there are no changes in the student learning outcomes from the courses as they currently exist: only the question items on each final exam would change in that they would be re-ordered to reflect the "linear equations" and "quadratic, rational and radical" concepts of each course. 


\section{MEMO TO AFFECTED DEPARTMENTS/DIVISIONS}

MEMO

From:

To:

Sent: April 28, 2011

Subject: Proposed Changes to Math

The School of Math Faculty of

is proposing a realignment of the course outcomes for Math $\square$ (Pre-Algebra) and Math (Elementary Algebra). With this redesign, Math will cover signed numbers, order of operations, solving linear equations and inequalities, graphing linear equations and inequalities and systems of linear equations.

This change would affect the math competencies for the Early Childhood AAS degree. 
Appendix K: Data Points Related to Research Questions

\begin{tabular}{|c|c|c|}
\hline Research Question & Evaluate using & Data \\
\hline \multirow[t]{9}{*}{$\begin{array}{l}\text { How did a rural community } \\
\text { college transform the } \\
\text { developmental mathematics } \\
\text { program from three lecture- } \\
\text { based courses to one } \\
\text { outcome-based course? }\end{array}$} & Outcomes evaluation & $\begin{array}{l}\text { Institutional pass rates and rates } \\
\text { reported to the state }\end{array}$ \\
\hline & $\begin{array}{l}\text { Placement cut scores } \\
\text { evaluation }\end{array}$ & Progression of cut scores \\
\hline & Program redesign plan & Emails and submitted documents \\
\hline & $\mathrm{Lab} /$ classroom redesign & Syllabus and schedule of courses \\
\hline & Curriculum proposal & Curriculum proposal \\
\hline & Course redesign & Syllabus, MyMathLab grade book, \\
\hline & & course settings \\
\hline & & $\begin{array}{l}\text { Overall pass rates vs. test course } \\
\text { pass rates }\end{array}$ \\
\hline & & Lab and lecture schedules \\
\hline \multirow{3}{*}{$\begin{array}{l}\text { What were the effects of the } \\
\text { resulting computer-mediated } \\
\text { program on the student's } \\
\text { success in the course, the } \\
\text { program, their college-level } \\
\text { mathematics course and } \\
\text { graduation or transfer rate? }\end{array}$} & & $\begin{array}{l}\text { Overall Developmental } \\
\text { mathematics program pass rates vs. } \\
\text { test course program pass rates }\end{array}$ \\
\hline & & $\begin{array}{l}\text { Overall college-level mathematics } \\
\text { course pass rates vs. test course }\end{array}$ \\
\hline & & $\begin{array}{l}\text { Overall graduation/transfer } \\
\text { eligible/still enrolled rates vs. test } \\
\text { course }\end{array}$ \\
\hline
\end{tabular}

